\title{
Prediction of Shore Retreat and Nearshore Profile Adjustments to Rising Water Levels on the Great Lakes
}

Edward B. Hands

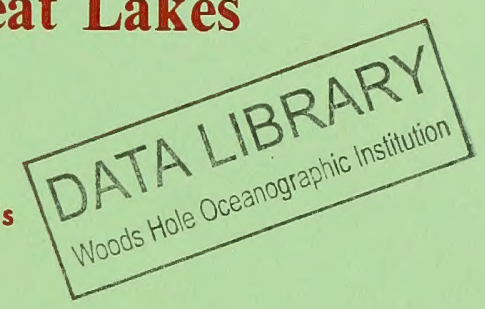

TECHNICAL PAPER NO. 80-7

OCTOBER 1980

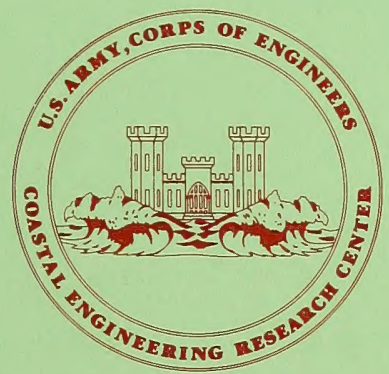

Approved for public release; distribution unlimited.

$G B$ 
Reprint or republication of any of this material sha11 give appropriate credit to the U.S. Army Coastal Engineering Research Center.

Limited free distribution within the United States of single copies of this publication has been made by this Center. Additional copies are available from:

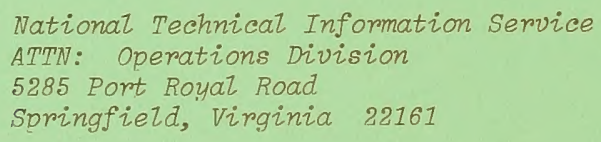

The findings in this report are not to be construed as an official Department of the Army position unless so designated by other authorized documents. 


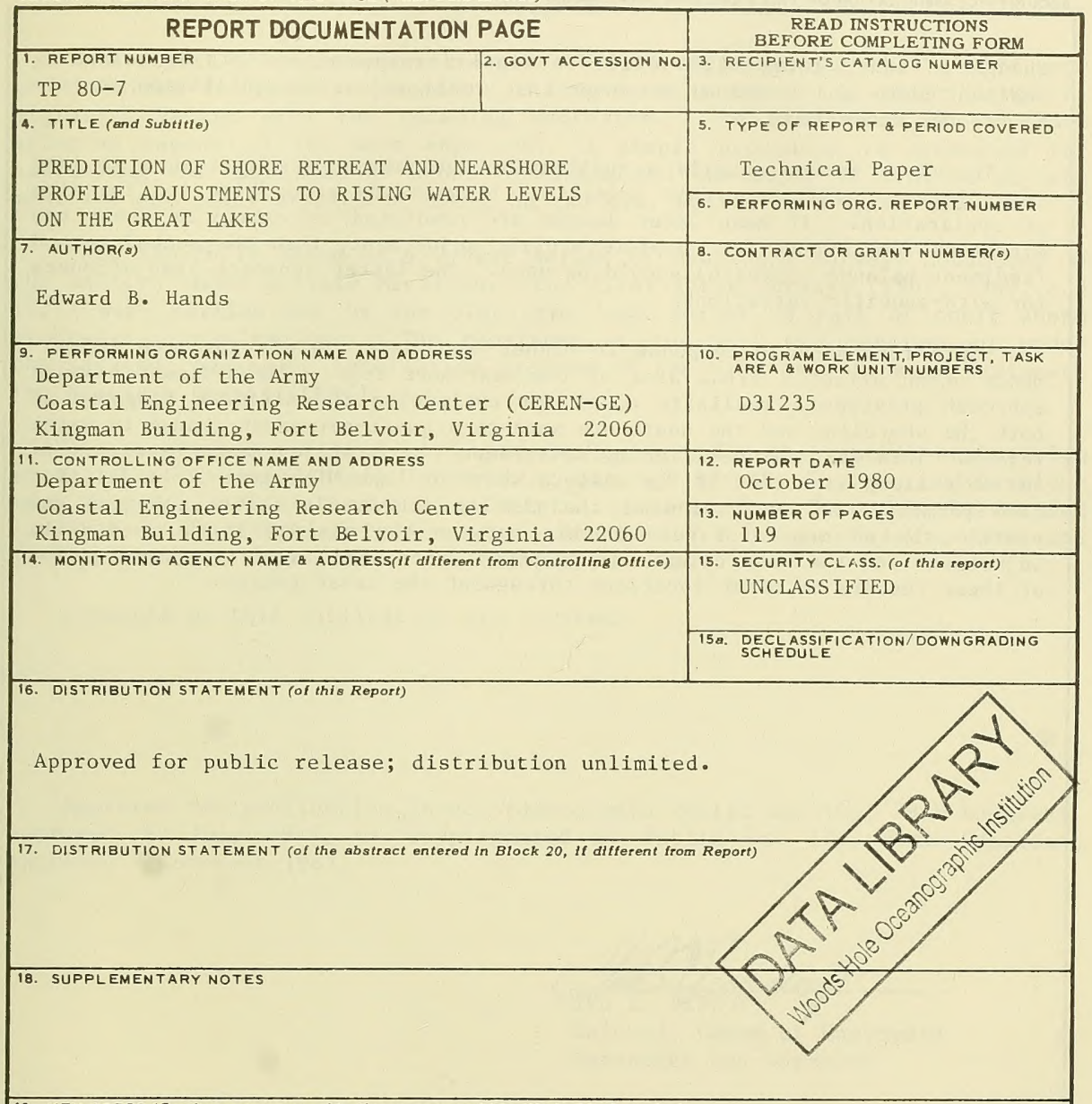

19. KEY WORDS (Continue on reverse side if necessary and identlfy by block number)

Beach profile adjustments

Great Lakes

Lake level changes
Lake Michigan

offshore bathymetry

20. ABSTRACT (Continue on reverse side if necesaary and identify by block number)

The effects of water level changes on shore recession are particularly important in the Great Lakes because annual mean lake levels often rise rapidly for periods of 5 to 10 years and then decline for a similar number of years. To a limited extent, man can anticipate and influence these fluctuations. Two methods of predicting the response of a beach to such fluctuations are (a) by measuring rates of shore change at certain locations during and after a recent rise in the water surface elevations, and assuming the next (continued) 
UNCLASSIFIED

SECURITY CLASSIFICATION OF THIS PAGE(Whan Data Entered)

change in water level will illicit a similar response, or (b) by balancing sediment gains and losses in a manner that would adjust an equilibrium profile to the new water level.

The first method entails a qualitative evaluation of differences in lake level behavior and geomorphic conditions between the study site and the site of application. If mean water levels are predicted to remain at their new elevation long enough for complete profile adjustment, then the second method (sediment balance approach) should be used. The latter approach also accounts for site-specific variations.

Shore recession in response to higher mean water levels involves adjustrents which affect a broad area of the nearshore zone. The sediment balance approach provides a realistic model for evaluating the ultimate response of both the shoreline and the nearshore zone to a quasi-permanent change in water' levels. This fact was verified by measurements of profile change between 1967 and 1976 along a section of the eastern shore of Lake Michigan. This data set also permitted an evaluation of the timelag between lake level changes and profile readjustment. A relationship between the maximum depth of profile adjustment and the wave climate is proposed which will facilitate application of these results to other locations throughout the Great lakes.

2

UNCLASP IF IED

SECURITY CLASSIFICATION OF THIS PAGE(Whon Data Entered) 
This report provides coastal engineers with documentation that a wide zone of nearshore bathymetry responds to long-term increases in water level by migrating inland with the receding shoreline. The dimensions of the zone affected depend on the wave exposure. A simple procedure is presented for estimating the magnitude of shore recession and the depth of profile adjustment for any sandy stretch of shore on the U.S. side of the Great Lakes.

This report is based on a 9-year series of nearshore surveys conducted on the eastern shore of Lake Michigan. The first three surveys (1967, 1969, and 1971) were carried out by the U.S. Army Lake Survey as part of their shore processes investigations. The remainder of the work was carried out under the sediment hydraulic interaction program of the U.S. Army Coastal Engineering Research Center (CERC).

The report was prepared by Edward B. Hands, under the general supervision of Dr. C.H. Everts, Chief, Engineering Geology Branch, Engineering Development Division, CERC. Reviews and helpful comments from Drs. C.H. Everts and R.D. Hobson of CERC, and P. Bruun, are deeply appreciated. Dr. W.L. Wood and J. Pope provided data used in the example problems.

Comments on this publication are invited.

Approved for publication in accordance with Public Law 166, 79th Congress, approved 31 July 1945, as supplemented by Public Law 172, 88th Congress, approved 7 November 1963.

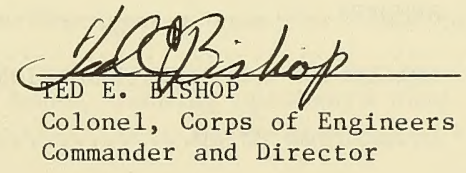


CONVERSION FACTORS, U.S. CUSTOMARY TO METRIC (SI) .......... 6

SYMBOLS AND DEFINITIONS.......................... 7

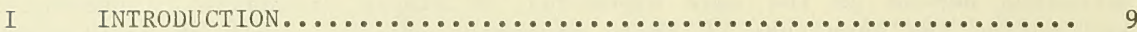

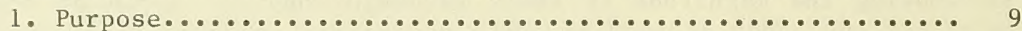

2. Background..................................... 9

II DATA COLLECTION. . . . . . . . . . . . . . . . . . . . . . . 10

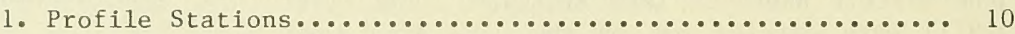

2. Survey Periods and Earlier Reporting................ 10

3. Profile Procedures............................. 10

III PROFILE CHANGES................................ 14

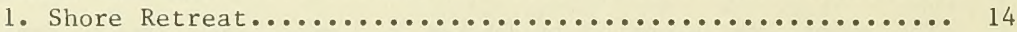

2. A Qualitative Description of Nearshore Adjustment........ 15

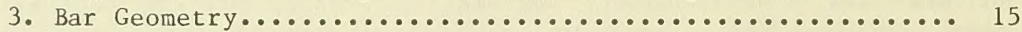

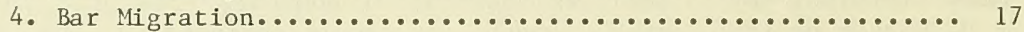

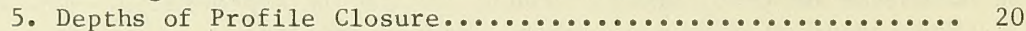

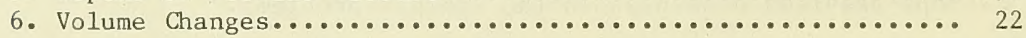

IV PREDICTION MODEL.................................. 24

1. Idealized Concept of the Sediment Balance Approach....... 25

2. Difficulties in Applying the Sediment Balance Approach.... 26

3. Suitability of Present Data for Testing the Sediment

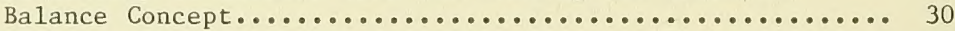

4. Application of the Sediment Balance Approach........... 32

5. Using Wave Climate to Estimate the Pinch-out Depth....... 39

6. Inferences from Profile Shape Alone.................. 41

V EXAMPLE PROBLEMS............................... 44

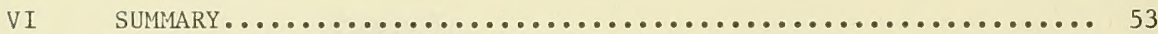

VII CONCLUSION AND RECOMMENDATIONS..................... 54

LITERATURE CITED................................ 56

APPENDIX

A SHORE AND NEARSHORE PROFILES IN THE AREA OF LITTLE SABLE POINT,

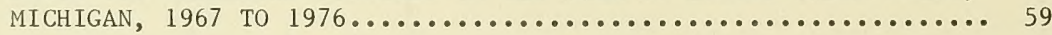

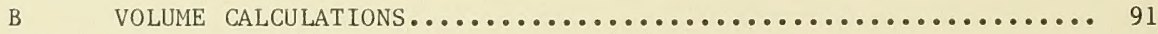

C VARIATIONS IN EXPOSURE TO STORM WAVES AT THE GREAT LAKES....... 111 TABLES

1 Volume change per unit width of shore....................... 24

2 Predicted and observed profile retreat in units................ 38

3 Cross-validation indicates the effect of estimating pinch-out

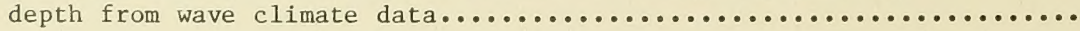


1 Location of the study area............................. 8

2 Comparison of annual mean water levels at ocean and Great Lakes sites........................................... 8

3 Profile stations in vicinity of Pentwater jetties............... 11

4 Station locations throughout the study area................. 12

5 Hydrograph showing change in lake levels between survey periods on Lake Michigan..................................... 13

6 Longshore continuity of bars in the Great Lakes................. 15

7 Beach and nearshore bathymetry in the vicinity of the Pentwater

Channel which transects the beach and barred areas.............. 16

8 Short-term changes in bathymetry versus long-term bar migration..... 17

9 Net results of 1 ong-term migration......................... 18

10 Envelope of bottom change, station $4(1967-75) \ldots \ldots \ldots \ldots \ldots \ldots \ldots$

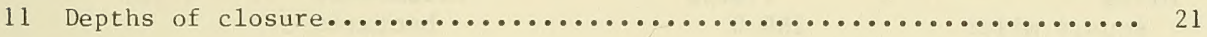

12 Schematic diagram of volume change calculations................ 23

13 Schematized view of profile adjustment as two rigid translations...... 25

14 Fathogran with field notations........................... 31

15 Direction of net longshore transport along the eastern shore....... 33

16 Pumped storage facility south of Ludington................... 34

17 Silver Lake dunes, looking from Lake Michigan across the dunes to

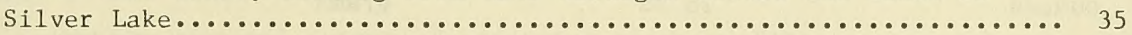

18 Shoreline scarps along Silver Lake dunes, looking northward over

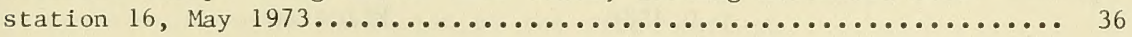

19 Longshore variation in net shore retreat from 1969 to $1976 \ldots \ldots \ldots . . . .37$

20 Calculated versus measured retreat....................... 38

. 21 Importance of offshore slope......................... 41

22 Diagram for determining if a suspected error weakens or strengthens arguments based on the sediment balance prediction............. 42

23 Limitations of analytical models with profiles everywhere concave up.. 43

24 Adjacent profiles from various subregions within the study area..... 45

25 A composite of all profiles as surveyed in $1975 \ldots \ldots \ldots \ldots \ldots \ldots \ldots \ldots$ 
U.S. customary units of measurement used in this report can be converted to metric (SI) units as follows:

\begin{tabular}{|c|c|c|}
\hline Mu1tip1y & by & To obtain \\
\hline $\begin{array}{l}\text { inches } \\
\text { square inches } \\
\text { cubic inches }\end{array}$ & $\begin{array}{l}25.4 \\
2.54 \\
6.452 \\
16.39\end{array}$ & $\begin{array}{l}\text { millimeters } \\
\text { centimeters } \\
\text { square centimeters } \\
\text { cubic centimeters }\end{array}$ \\
\hline $\begin{array}{l}\text { feet } \\
\text { square feet } \\
\text { cubic feet }\end{array}$ & $\begin{array}{l}30.48 \\
0.3048 \\
0.0929 \\
0.0283\end{array}$ & $\begin{array}{l}\text { centimeters } \\
\text { meters } \\
\text { square meters } \\
\text { cubic meters }\end{array}$ \\
\hline $\begin{array}{l}\text { yards } \\
\text { square yards } \\
\text { cubic yards }\end{array}$ & $\begin{array}{l}0.9144 \\
0.836 \\
0.7646\end{array}$ & $\begin{array}{l}\text { meters } \\
\text { square meters } \\
\text { cubic meters }\end{array}$ \\
\hline $\begin{array}{l}\text { miles } \\
\text { square miles }\end{array}$ & $\begin{array}{l}1.6093 \\
259.0\end{array}$ & $\begin{array}{r}\text { kilometers } \\
\text { hectares }\end{array}$ \\
\hline knots & 1.852 & kilometers per hour \\
\hline acres & 0.4047 & hectares \\
\hline foot-pounds & 1.3558 & newton meters \\
\hline millibars & $1.0197 \times 10^{-3}$ & kilograms per square centimeter \\
\hline cunces & 28.35 & grams \\
\hline pounds & $\begin{array}{r}453.6 \\
0.4536\end{array}$ & $\begin{array}{l}\text { grams } \\
\text { kilograms }\end{array}$ \\
\hline ton, long & 1.0160 & metric tons \\
\hline ton, short & 0.9072 & metric tons \\
\hline degrees (angle) & 0.01745 & radians \\
\hline Fahrenheit degrees & $5 / 9$ & Celsius degrees or Kelvins ${ }^{l}$ \\
\hline
\end{tabular}

${ }^{1}$ To obtain Celsius (C) temperature readings from Fahrenheit (F) readings, use formula: $\mathrm{C}=(5 / 9)(\mathrm{F}-32)$.

To obtain Kelvin (K) readings, use formula: $K=(5 / 9)(F-32)+273.15$. 


\section{SYMBOLS AND DEFINITIONS}

D average height of affected dunes

d depth of profile adjustment

$\hat{\mathrm{d}}$

estimate of d $\left(\hat{d}=2.1 h_{5}\right)$

$\mathrm{h}_{5} \quad$ significant wave height with a 5-year return period

k a constant of proportionality between wave height and the depth of profile adjustment

ln natural logarithm

Q volume sediment flux into the survey area

$\mathrm{R}_{\mathrm{A}}$ sediment overfill factor--the ratio of sediment volume supplied by profile recession to that retained after sediment sorting, packing, and profile readjustment

sg ( $z$ ) signum function having values of: 1 for $z>0 ;-1$ for $z<0$; and 0 for $z=0$

T time

Th thickness of volume change if spread evenly over the survey area

X average horizontal extent of profile adjustment

$\mathrm{x}$

average horizontal displacement of the profile and shoreline

Y longshore extent of survey area

Z average vertical extent of adjusting shore profile

$z \quad$ average change in elevation of the water surface

$\alpha$ the effective angle of profile response if $R_{A}=1$ and $Q=0$ (eq. 3) (also symbol for "is directly proportional to")

$\Delta \mathrm{X} \quad$ profile digitizing interval 


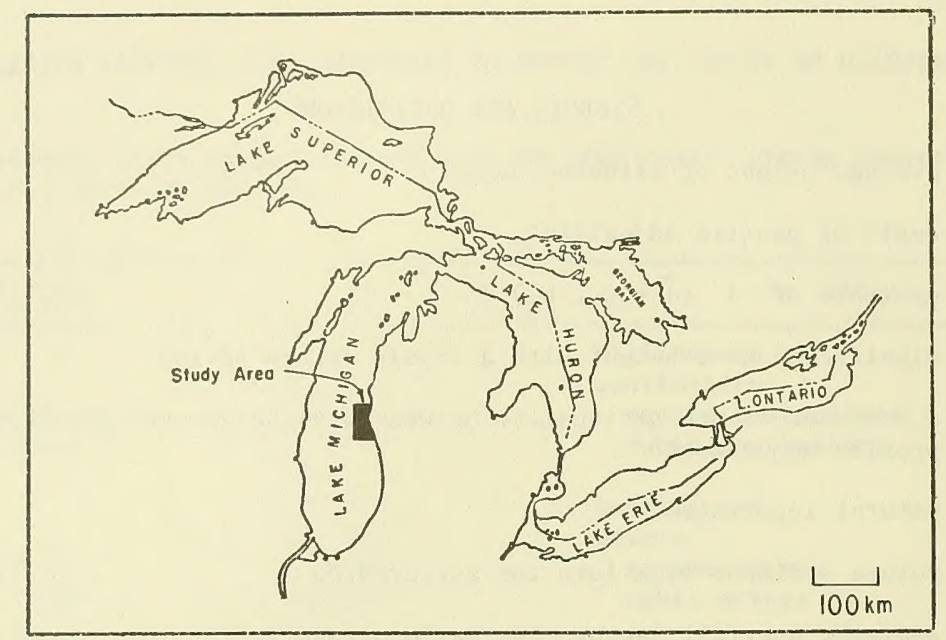

Figure 1. Location of the study area.

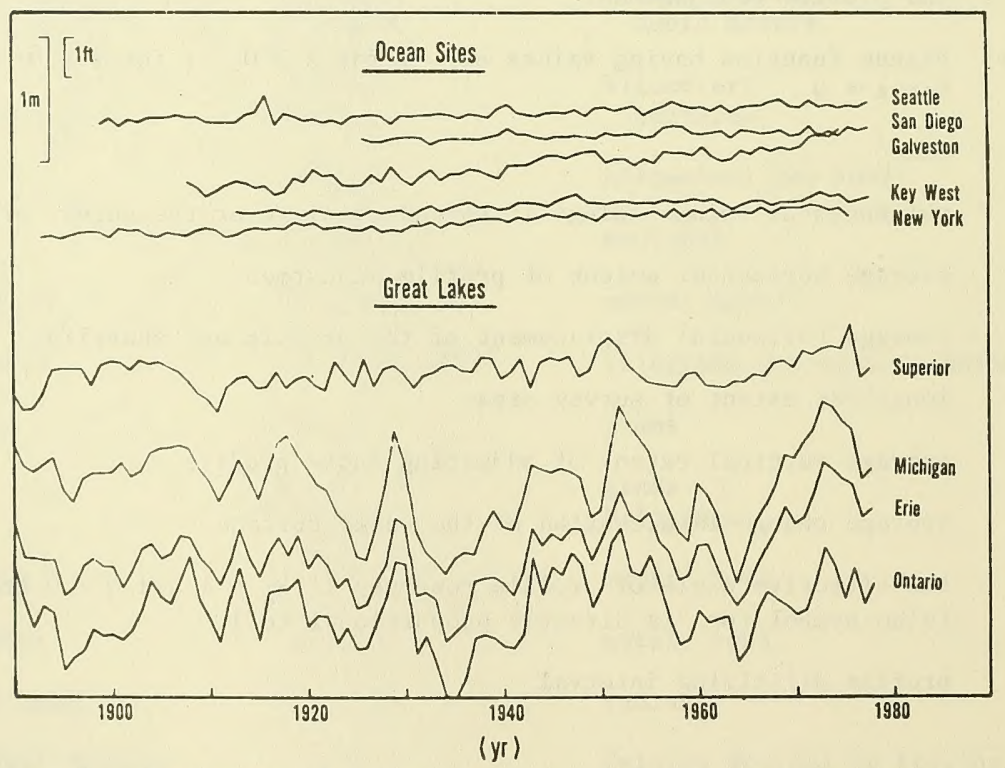

Figure 2. Comparison of annual mean water levels at ocean and Great Lakes sites. During rising lake levels the shores of the Great Lakes may be submerged more in a 5- to 10-year period than most ocean sites are in a century. Reversals in trend reduce the longer term effects on the lakes, while ocean sites are exposed to a slower but more persistent rate of submergence. 
PREDICTION OF SHORE RETREAT AND NEARSHORE PROFILE ADJUSTMENTS TO RISING WATER LEVELS ON THE GREAT LAKES

\author{
By \\ Edward $B$. Hands
}

I. INTRODUCTION

\title{
1. Purpose.
}

This report demonstrates that increased shore retreat during periods of sustained high water is merely the most visible expression of a massive adjustment affecting a much wider area offshore. An equilibrium sediment balance model realistically describes the ultimate, broad profile response to increased water levels. Beach and nearshore surveys along a section of the eastern shore of Lake Michigan (Fig. 1) in 1967, 1969, 1971, 1975, and 1976 provide the basis for this analysis. The results are generalized to provide a simple but rational approach for estimating the response of sandy shore areas throughout the Great Lakes to future long-term change in water levels.

\section{Background.}

Because of variations in climatic factors within their regional drainage basins, the Great Lakes experience water level fluctuations uncharacteristic of ocean shores (Fig. 2). Dry periods are common during which the mean elevations of the lakes decline for many years in succession. After these long periods of falling lake levels, it is easy for new property owners to overestimate the stability of the shores and build structures too close to the lakes. Storm erosion during later years of high water accelerates shore recession and creates costly property damage. The persistence of high water conditions for many years permits extensive profile adjustment via erosion and offshore sediment transport.

Recurrently during periods of extreme shore erosion there has been public interest in gaining greater control over lake level fluctuations. However, a study by the International Great Lakes Level Board (1973) concluded that regulation of the five Great Lakes, while possible, would not provide benefits commensurate with costs; outflows from Lake Superior and Lake Ontario have been controlled since 1921 and 1958, respectively. Natural variations in the water supply to these basins are too large, however, to maintain constant lake levels, so adjustments are made in the flows to benefit the many interests involved. Reliable estimates of shore erosion for various water level conditions are important in evaluating the impact of regulation plans on riparian interests. An improved understanding is also needed for the proper design of coastal construction projects and beach-fill operations, and the recommendations of setback distances, etc.

A report on recent changes in rates of shore retreat summarized data from the same set of surveys used here, but considered only the changes within 100 meters of the shoreline (Hands, 1979). Dates, types of data collected, and reports on the earlier surveys are discussed in Section II. 
Hydrographic surveys were conducted near Pentwater Harbor on the eastern shore of Lake Michigan in both the spring and fall of 1969 (Fig. 3). These surveys revealed little variation in nearshore bathymetry beyond the first 50 meters offshore. The formation, migration, and eventual welding of an ephemeral coastal bar to the subaerial beach constituted the major change during these periods of relatively limited wave action. However, when these profiles were compared with profiles from several of the same stations 2 years earlier, apparent changes in bathymetry were evident out to a depth of 5 meters. To further investigate this apparent long-term profile evolution, profile changes were monitored in 1971, 1975, and 1976 by resurveying the 10 original stations (established in 1967 within a kilometer of the jettied entrance to Pentwater Harbor) and 24 additional stations spread over an adjacent 50 kilometers (Fig. 4).

\section{Survey Periods and Earlier Reporting.}

Profiles were measured during six different survey periods over a span of 9 years. The survey periods and monthly mean lake levels are shown in Figure 5. Changes in bathymetry between 1967 and 1969 were reported in Saylor and Hands (1970). Hands (1976a) provided a description of the cross-sectional and areal geometry of the longshore bars throughout the 50-kilometer reach, as well as information on grain-size variations and some speculation on the profile adjustment between 1967 and 1971. Hands (1976b) compared profile deve1opment through 1975 with a possible relationship between regional tilting of the Great Lakes basin and variations in historic bluff recession around the perimeter of Lake Michigan over a 120-year period. Hands (1979) incorporated results from the 1976 survey to describe the effects of water level changes on the shore and on the inner parts of the profile $( \pm 100$ meters from the shoreline). The present report summarizes adjustments of the wider responding profile and recommends procedures for estimating shore and nearshore changes likely to occur in sandy regions of the Great Lakes as a result of future variations in mean water level elevations.

\section{Profile Procedures.}

In 1967 the profiles were measured by winching ashore a four-wheel leveling cart, halted every 5 meters so that elevations could be determined, using an engineer's level located on the shore. Upon reaching the shore, the cart was pulled by Jeep down the beach to the next station and then towed offshore by boat. This method limited coverage to depths less than 5 meters and required a moderately wide, unobstructed beach for efficient operations. In subsequent years, echo sounding was used to extend coverage on the outer part of the profile but instrument leveling continued to be used in shallow water to provide an overlap with the sounding record and extend the profile into the dunes. Boat positioning was accomplished by an optical intersection using two transits in 1969 and 1971 (Hands, 1976a) and by a range and azimuth microwave system in 1975. In all years a transit was locked on the profile azimuth for the individual station being sounded; radio contact between a transit man and the boat operator ensured that the boat remained on line. 


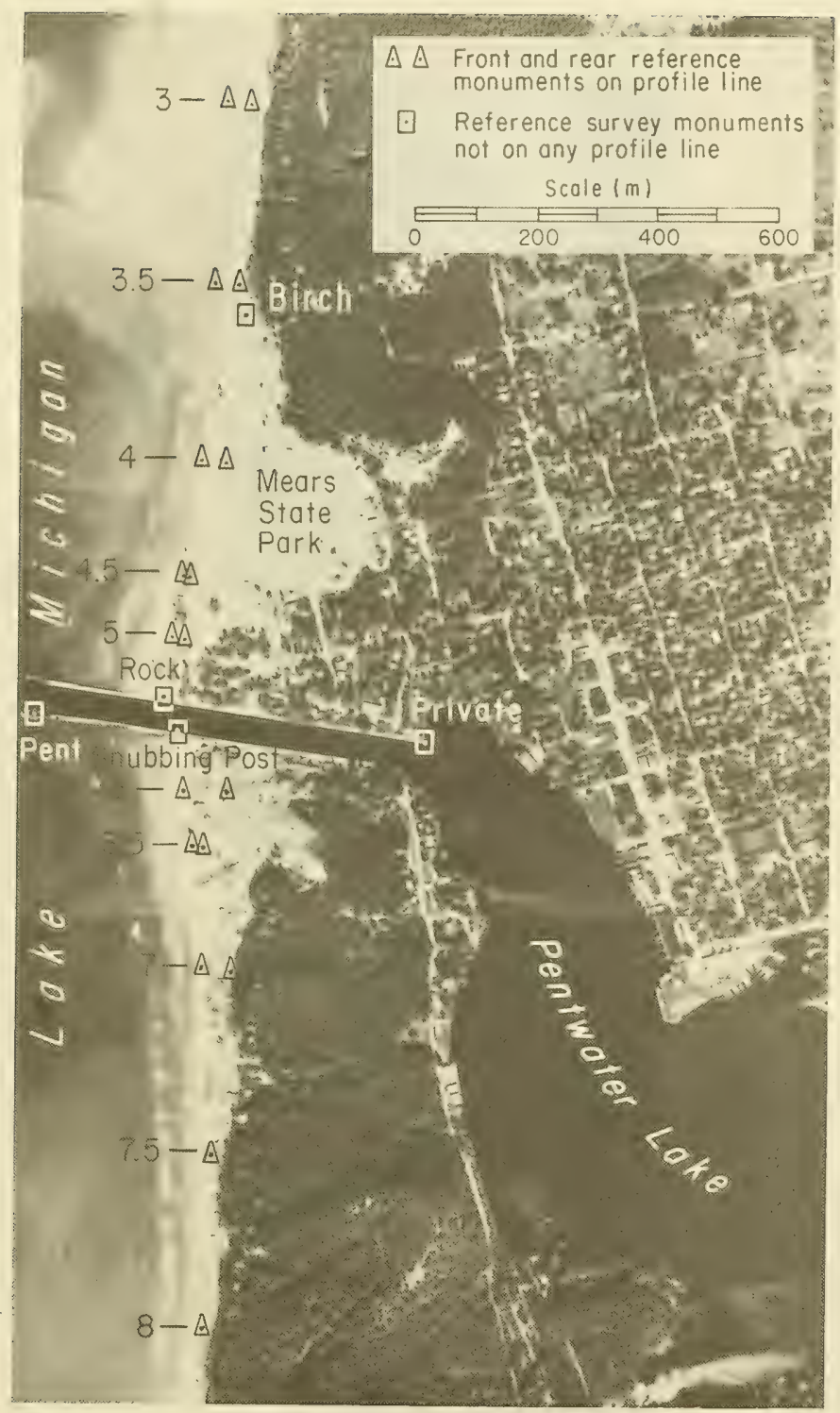

Figure 3. Profile stations in vicinity of Pentwater jetties. 


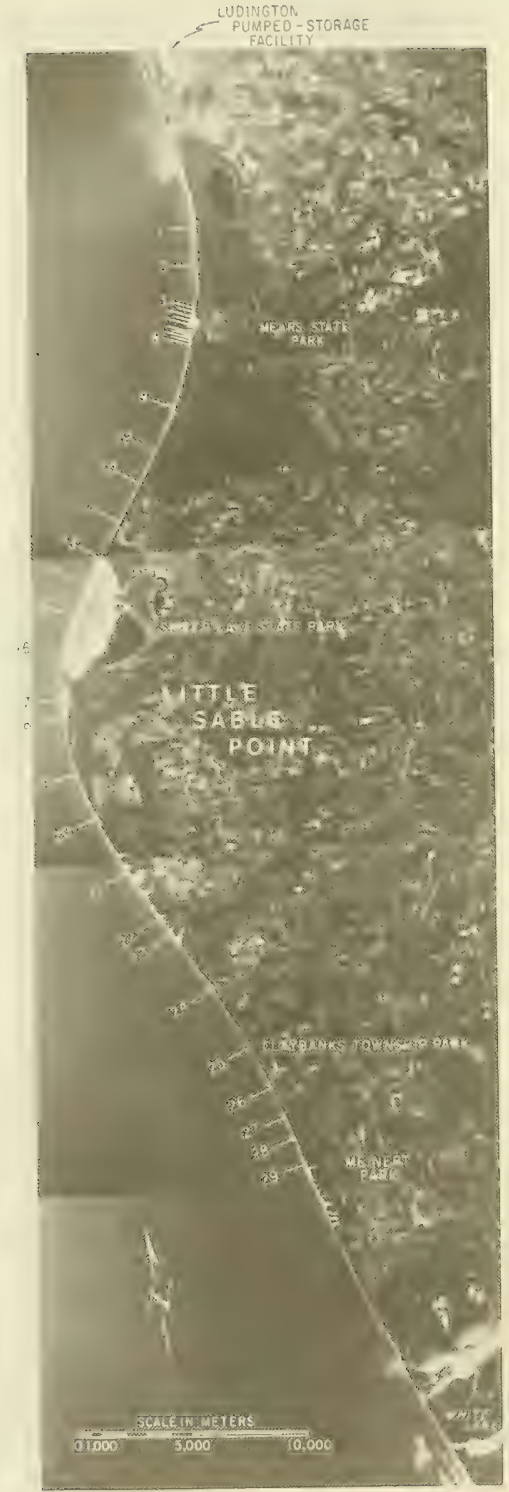

Figure 4. Station locations throughout study area. 


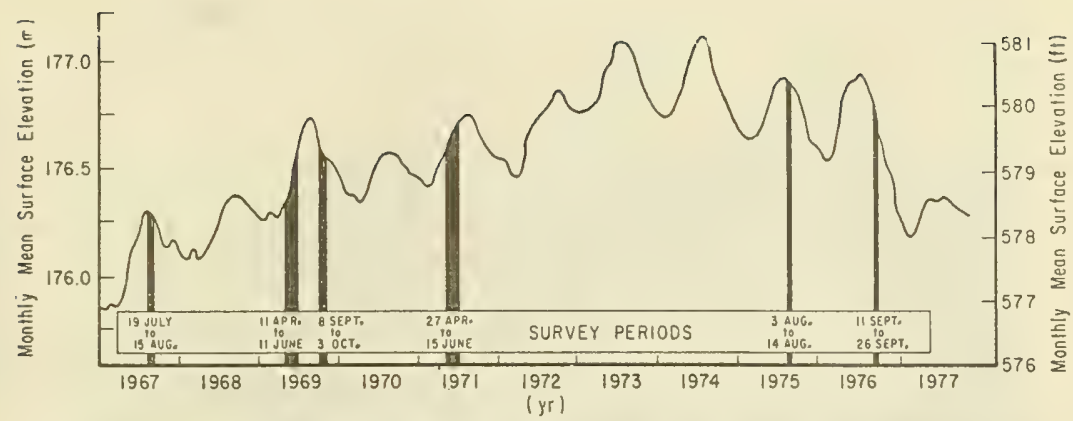

Figure 5. Hydrograph showing change in lake levels between survey periods on Lake Michigan.

All shore profiling was done with an automatic engineer's level. Distances were determined in previous years by a rodman carrying one end of a marked measuring wire which was spooled out and read from the reference monument; the standard three-wire reading method was used in 1976 . Shore monuments at each profile station were tied to one another, to surrounding bench marks, and to second-order geodetic monuments surveyed by National Ocean Survey (NOS) in 1973. Vertical reference was supplemented during profiling operations using a system of water level recorders, water surface rodreadings, and a portable stilling well which was placed near the shoreline at the station being sounded.

As mentioned, use of the leveling cart limited coverage to depths of less than 5 meters in 1967. The outer limit was extended to 11, 16, and 21 meters in 1969, 1971, and 1975, respectively. No echo sounding was done in 1976; the shore profiles terminated in about 1.5 meters of water.

\section{PROFILE CHANGES}

\section{Shore Retreat.}

The annual mean surface elevations of Lake Michigan rose 1.4 meters from a record low in 1964 to a record peak for this century in 1973. The earliest shore profiles in the study area were surveyed in 1967 after the water level rise was well underway. The rates of shore retreat from 1967 through the peak water year, and for 3 years thereafter, are contrasted with historic retreat rates by Hands (1979). The average rate of shore retreat (landward displacement of the stillwater level) during the latter part of the recent period of rising water was about six times greater than it had been during the preceding 120-year period, or about eight times greater than during the previous 50 years. This increase reflects the effect of recent high lake levels. As the lake levels rose the shore retreated roughly in proportion to the increase in lake levels. Retreat rates remained high for several years after lake levels stabilized; then as levels declined between 1975 and 1976 the beach began prograding lakeward. During the last year of study, the average advance of the shore was similarly proportioned to the drop in lake level during that period. The horizontal change in shore positions averaged about 40 times the vertical change in water level surface during those same periods. Simple 
linear regression of shore retreat against the change in lake level explained 50 percent of the variance in retreat measurements.

By 1975 the shore had retreated an average of 24 meters from its 1967 position, but variations between adjacent stations were large. The maximum difference was observed at Little Sable Point which lost 36 meters in 6 years; the loss was only 6 meters just 2 kilometers away. Shore losses in the vicinity of the Pentwater jetties were generally low due to a combination of shore protection practices in that area. Variations among the other stations were not as easily explained.

More than 80 percent of the ultimate shore retreat was due to actual recession caused by erosion and less than 20 percent was due to the immediate effect of encroachment of the high water across the sloping beach.

\section{A Qualitative Description of Nearshore Adjustment.}

Assume that an increase in water level sets the stage for an adjustment of the shore profile. The profile will tend to follow the rising water level by moving upward and landward as the shore retreats. The zone affected will extend from the point of highest wave attack down to some point of profile closure, below which the bottom is not actively shaped by surface-related forces. The point of profile closure may be close to shore if the profile is. responding to a diurnal change in water level. However, if the increase in water level persists for several years, then occurrence of the normal series of storms may extend the point of profile closure to depths of more than 10 meters.

Along almost the entire eastern shore of Lake Michigan, and at many other sites on the Great Lakes where there is sufficient sand, littoral forces have built a sequence of submerged sand ridges or longshore bars from shallow inshore to deeper offshore (Fig. 6). In the present area of study the multiple bar formation extends from shore to a depth of about 8 meters. Thus, many aspects of the long-term profile adjustment can be described in terms of changing bar positions.

\section{Bar Geometry.}

Bars in the Great Lakes have greater longshore continuity and are more regular in cross section than those on most ocean coasts. On the lakes, longshore bars are also persistent from year to year, whereas they may occur only seasonally on ocean beaches. The continuity, regularity, and persistence of longshore bars are likewise remarkable on enclosed seas (e.g•, the Baltic, see Hartnack, 1924; the Mediterranean, see King and Williams, 1949; the Caspian, see Knaps, 1966). These differences probably reflect the restricted range of wave conditions (period, direction, and height) and tidal variations on the lakes and enclosed seas.

Four to five bars are persistent from year to year at most stations in the study area. An additional smaller emphemeral sand ridge often forms closer to the shore during higher wave action, but migrates to shore and merges with the upper beach face as wave conditions wane. In the longshore direction, these ephemeral coastal bars are less continuous than the outer longshore bars. The coastal bar can be short (less than 1 kilometer) and discontinuous, or shoretied at both ends, irregular or part of a cellular pattern in the nearshore bathymetry (Hands, 1976a). Where the coastal bar ties to the shore there is usually a protrusion of the shoreline and a flanking indentation (Hands, 1979). 


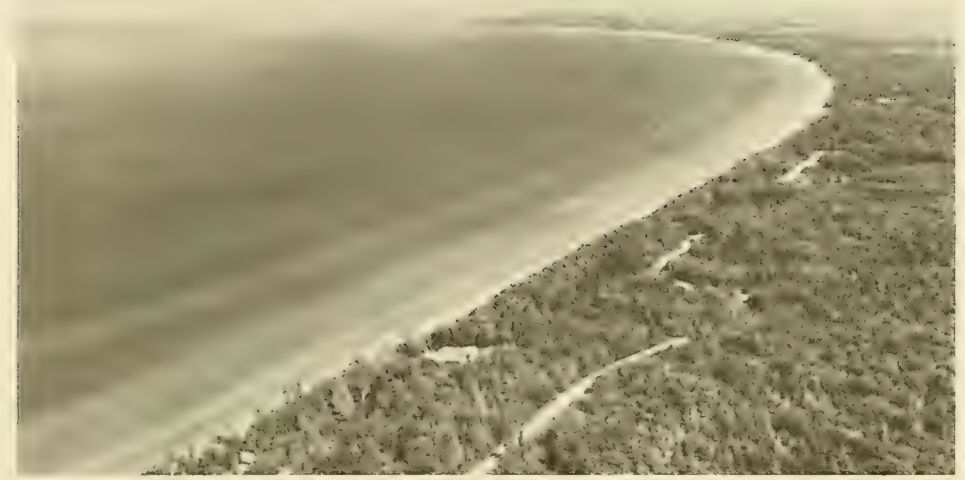

Figure 6. Longshore continuity of bars in the Great Lakes. The inner two to three bars are usually visible when viewed from high bluffs and dunes along the shore. In the above photo (taken about 900 meters above lake level) the inner three bars can be seen following the curve of the shoreline from station 10 toward Pentwater Harbor in the upper right corner (a distance of about 6 kilometers).

The continuity of the Iongshore bars is interrupted in the northern part of the study area by the Pentwater Harbor jetties. Each year the outer bars extend into the entrance channel beyond the end of the jetties. Typically, 40,000 to 60,000 cubic meters of sand is dredged annually from this entrance bay and from the inland channel where windblown sand makes an important contribution (Seelig and Sorensen, 1976). In recent years an increasing amount of this sand has been used to nourish adjacent beaches; however, most of it is taken about 1.5 kilometers offshore and dumped into 12- to 15-meter depths.

In general, jetties which penetrate the surf zone interrupt the normal longshore transport of littoral drift. There is frequent concern that long jetties divert some of the drift offshore where it accumulates in water so deep that the sand is essentially lost from the littoral system. The broad mourd of sediment opposite the Pentwater jetties lies at a depth of about 13 meters and may have originated as a result of such a diversion of longshore currents. However, the broadly symmetrical appearance and position of the mound (Fig. 7) suggest it is more likely an expression of the open water disposal of the material dredged from the channel.

An interruption of longshore bar continuity also occurs opposite Little Sable Point. The bars at this location are not only discontinuous, as observed in aerial photography, but are also much less regular and less smooth in cross section. Bathymetrically, Little Sable Point is a transition zone dividing the study area into two nearly equal stretches with distinctly different bar geometry. A sequence of four well-formed longshore bars marks both areas, but in the north these bars are shallower and closer to shore (all within the first 400 meters). South of the point the barred zone is about 600 


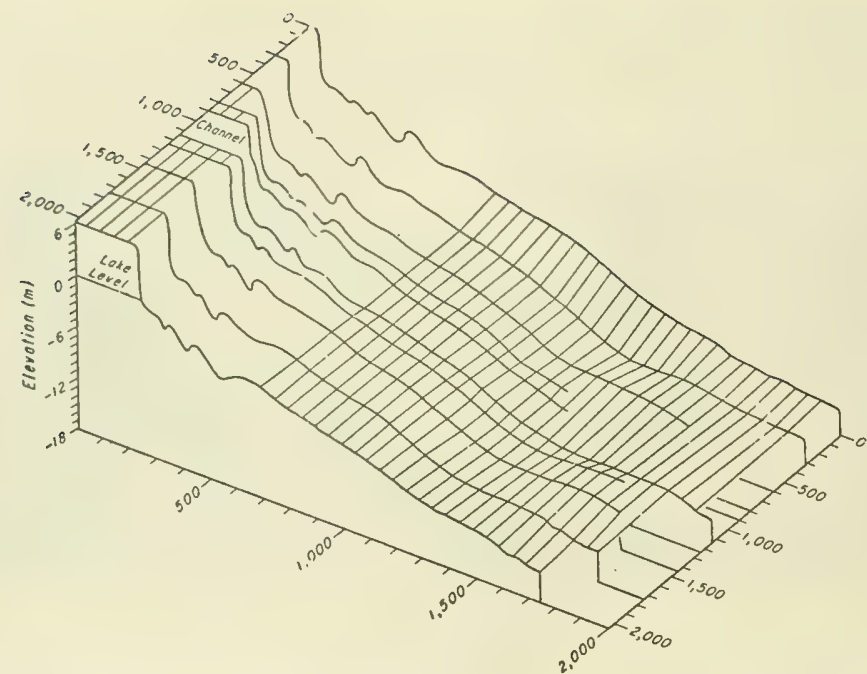

Figure 7. Beach and nearshore bathynetry in the vicinity of the Pentwater Channel which transects the beach and barred areas. Hunmocky bathymetry offshore may represent material dredged from the channel and dumped offshore in previous years.

meters wide and, as in the north, the first persistent bar has a depth of 1 to 2 meters over the crest; the increase in depth between bars in an offshore direction is faster so the outermost, well-developed bar has 5 to 6 meters over the crest as compared to 3- to 4-meter depths north of the point. The difference in shoreline orientation north and south of the point is approximately $60^{\circ}$, which, by altering the nearshore wave conditions, could be responsible for the contrast in bar geometry between these two sections.

\section{Bar Migration.}

On the basis of profile changes between 1967 and 1969 at a few stations in the immediate vicinity of the Pentwater jetties, Saylor and Hands (1970) proposed that longshore bars migrate landward as lake levels rise, and by doing so maintain constant depths beneath the gradually rising lake surface. This proposal was consistent with Keulegan's (1948) conclusions after studying the factors controlling bar formation in wave tanks. However, the proposal was contrary to all the other field studies on the Great Lakes. Reports of previous fieldwork emphasized long-term stability of bars deeper than the ephemeral bar nearshore (e.g., Davis and McGeary, 1965) or indicated that during periods of persistently rising water new bars were continually created inshore of the old series, thereby replacing outer bars which were left stranded too deep to be affected by surface wave action (Evans, 1940).

Before summarizing the bar migration observed in this study, consider that, in general, any interpretation of profile change usually entails a belief that the profile occupied only those positions intermediate between the positions determined during the actual surveys. Whether or not possible 
extreme excursions between surveys can safely be ignored depends on the energy conditions and the temporal and spatial scales involved, as well as on the application at hand. To reveal trends in long-term bathymetric adjustment to higher water levels, profiles taken even several years apart are quite useful, especially if all the profiles are obtained during similar phases in any seasonal cycles but over a period of persistent annual change (see Fig. 8). The magnitude of weekly to monthly profile changes is represented in Figure 8 by four surveys spanning the period from 19 July to 12 August 1967. Their relatively close agreement contrasts with the difference that develops between spring and fall as shown by the May and August 1969 surveys. The long-term trend in bar migration can be seen in the overall change from 1967 to 1969 and in the comparison of bar positions in those years with the final bar position determined at this location in 1975. Careful measurements are necessary to discern the small weekly changes from possible profile error. However, the cumulative effect of long-term migration clearly exceeds both the margin of error and the range of short-term fluctuations.

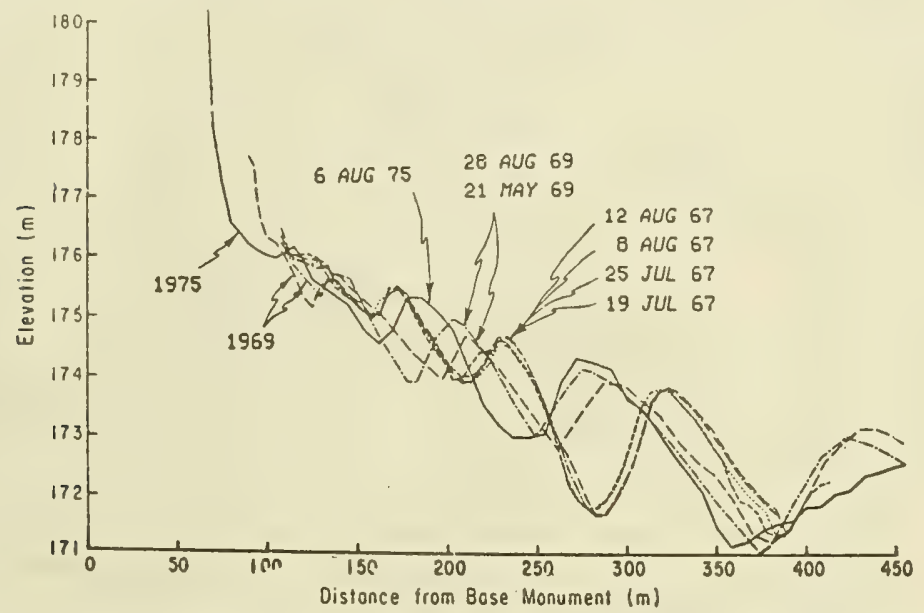

Figure 8. Short-term changes in bathymetry versus long-term bar migration. The short-term changes are illustrated by four surveys in 1967. May and August surveys in 1969 reveal larger changes. The final surveyed bar position in 1975 illustrates the effect of long-term bar migration.

Details of intermediate surveys at other stations are shown in Appendix A. To simplify the presentation of general trends, only the earliest and latest surveyed bar positions are shown in Figure 9. The original survey in 1967 covered the area in the immediate vicinity of the Pentwater jetties (stations 3 to 8). The remaining stations (1, 2, and 9 to 29), spread over the adjacent 50 kilometers, were first surveyed in 1969.

Continued monitoring of profile development throughout the remainder of the rising phase in lake levels and for several years thereafter (until 1976) confirms the original proposal (Saylor and Hands, 1970) that bars tend to rise with the water level. However, landward migration of the bars was confirmed only by the two to three inner bars within 250 meters of shore. The outer bars did not reveal the same tendency toward shoreward migration as the inner 


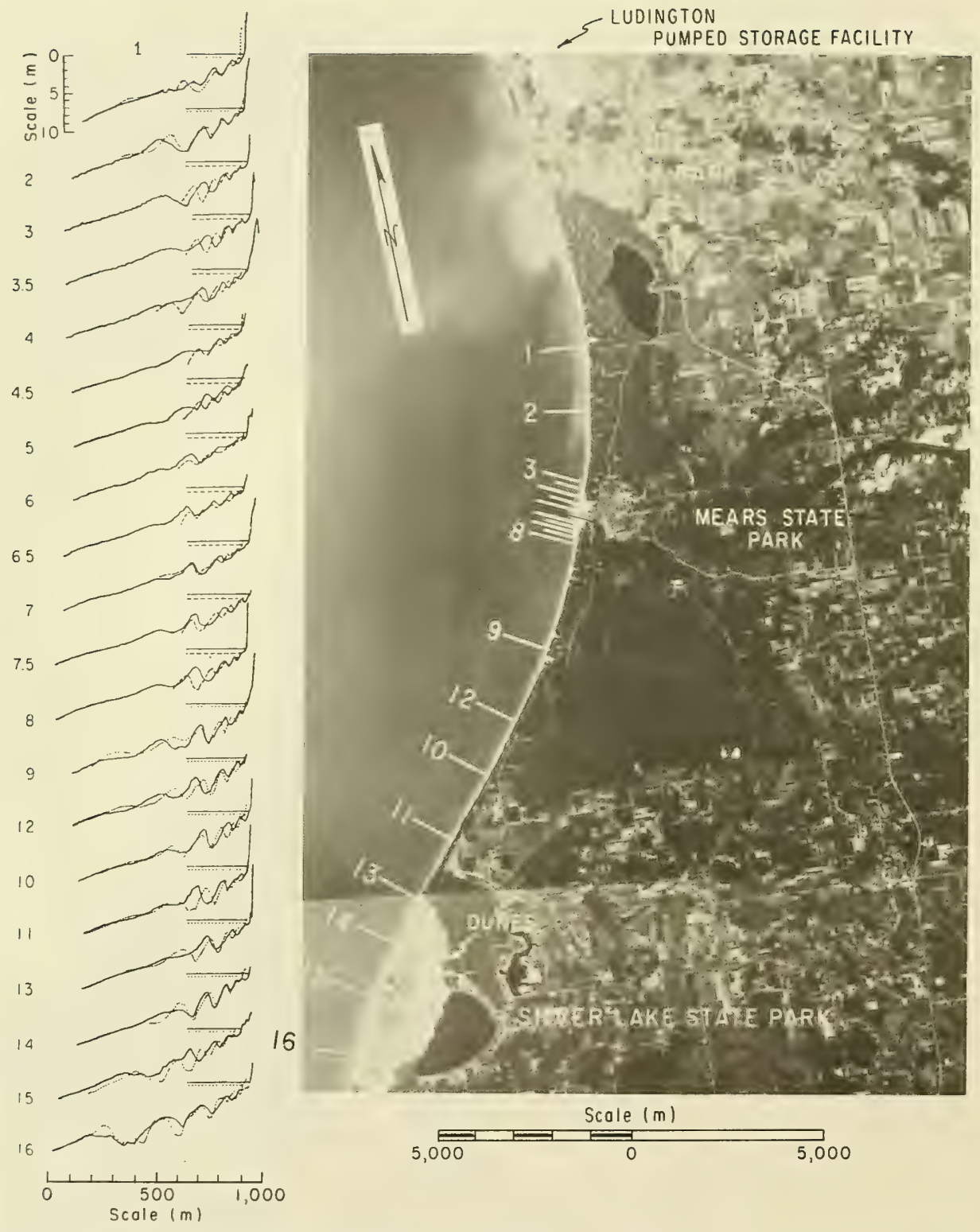

Figure 9. Net results of long-term migration. Changes in bathymetry and mean water levels are shown by profiles for the 1967, 1969, and 1975 conditions. Profile stations are arranged in order from northernmost station 1 to southernmost station 29 . 


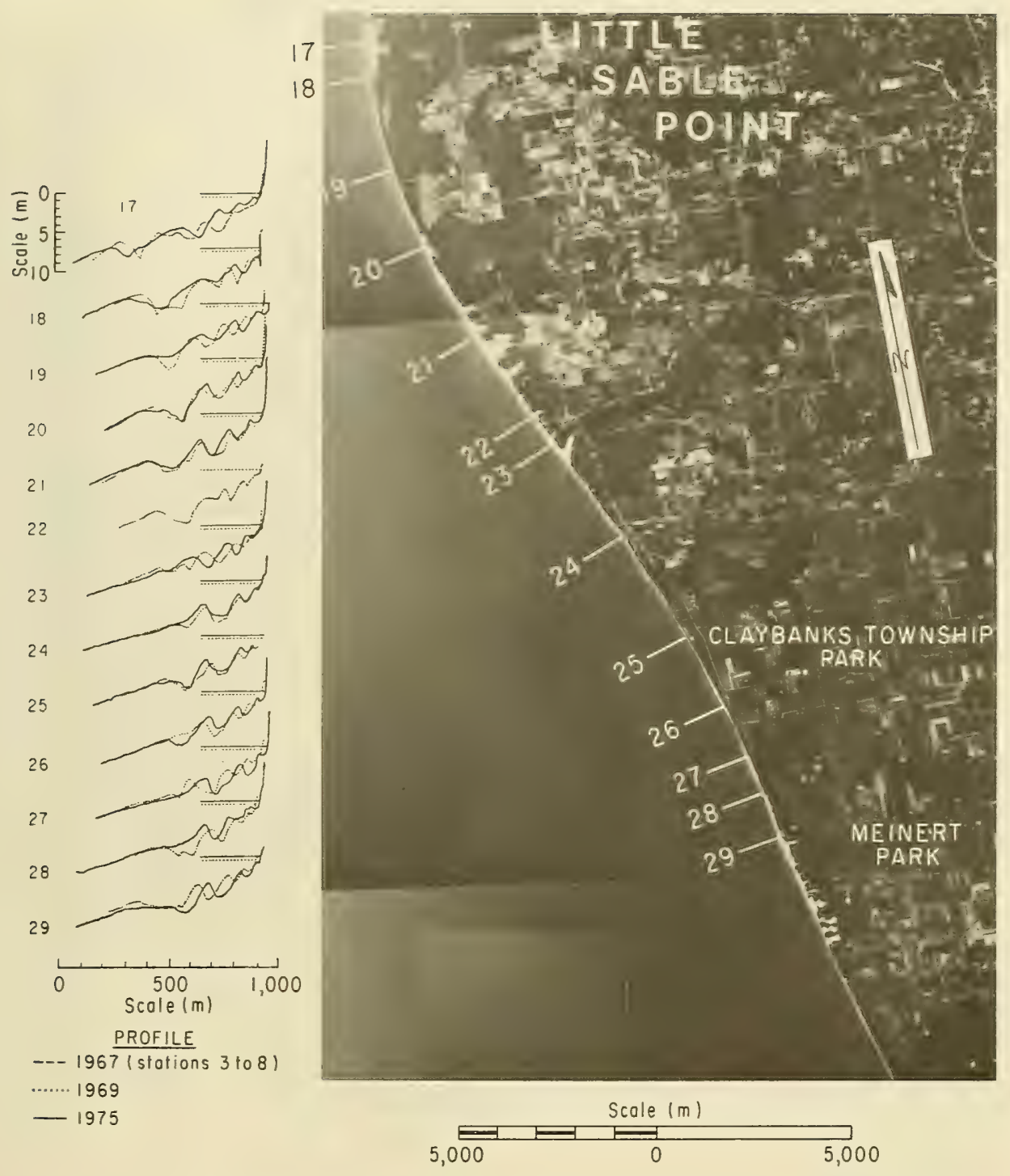

Figure 9. Net results of long-term migration. Changes in hathymetry and mean water levels are shown by profiles for the 1967, 1969, and 1975 conditions. Profile stations are arranged in order from northernmost station 1 to southernmost station 29.--Continued 
bars did, at least not between 1969 and 1975. Furthermore, the outer bar during this period generally lost relief as a result of various combinations of crest erosion (predominant at stations 2, 12, 16, and 18) and trough filling (predominant at stations 4, 8, 11, and 19). By 1975 these two processes had progressed to the point of completely eliminating the outermost bar at 6 of the 33 stations $(4,9,11,13,19$, and 24).

5. Depths of Profile Closure.

All profiles collected were examined for evidence of a limiting depth below which there were no bottom changes over the period of study. In 1967 the bathymetric surveys terminated at the 5-meter contour. Over the 2-year period from 1967 to 1969, substantial bottom changes occurred throughout the zone from the shoreline to the 5-meter contour. This evidence of deep profile fluctuation prompted the extension of surveys to greater depths--11 meters in 1969 and 21 meters in 1971 and 1975. Although probable depth error increased with distance from shore, the longer profiles converged at their outer ends.

Because relief on the longshore bars increased significantly from one bar to the next in the lakeward direction and the bars migrated yearly, the envelope of bottom change also increased from the shoreline lakeward across the barred zone (Fig. 10). Beyond the outer bar, the envelope of bottom change narrowed abruptly.

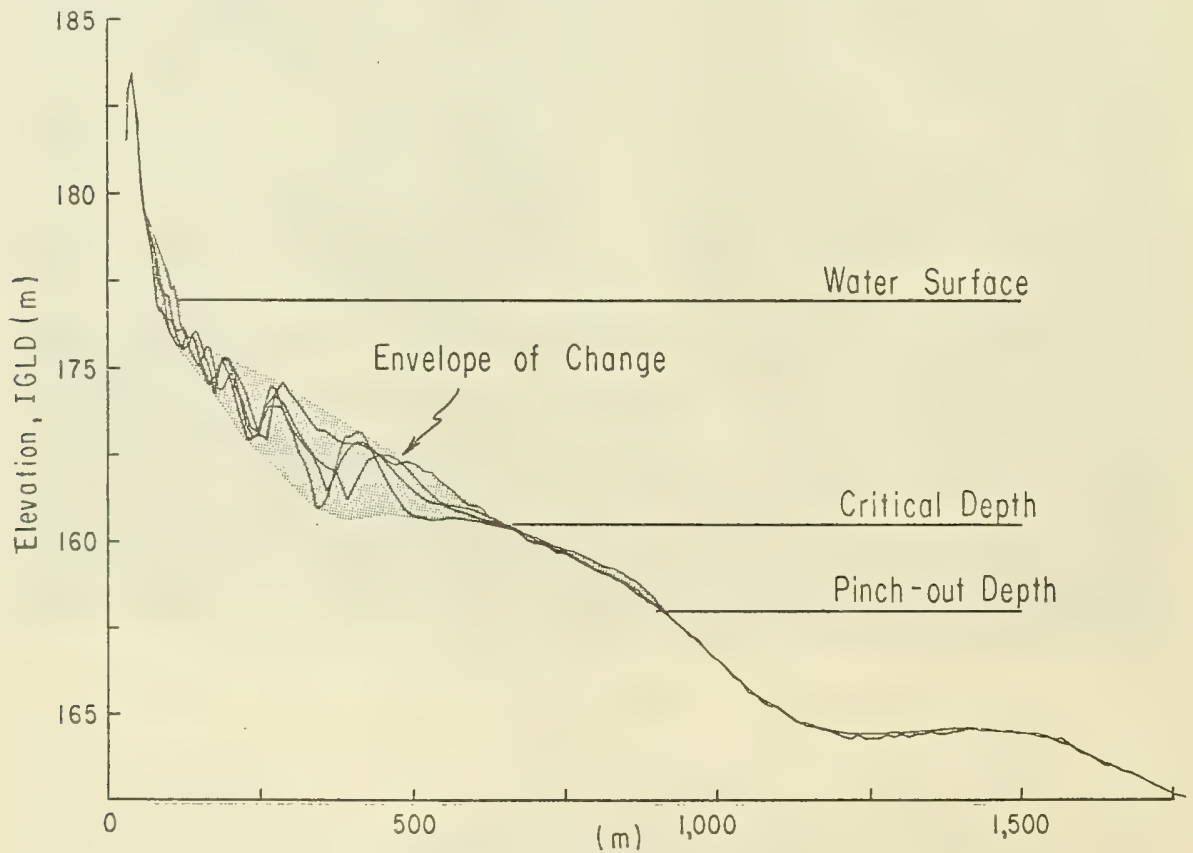

Figure 10. Envelope of bottom change, station 4 (1967-75). After several years of profile adjustment to higher water levels, the envelope of changes in bottom elevation is thickest in the zone traversed by the largest migrating bar and narrows abruptly above the wave uprush and below the barred zone. 
An examination of all profiles indicated that instead of choosing a single limiting depth, it would be more realistic to pick two depths: the critical depth, a shallower depth above which bottom changes typically exceeded 0.3 meter, and the pinch-out depth, a deeper depth below which there was no evidence of change. Between the critical and the pinch-out depths there is a small but consistent evidence of aggradation (about 0.2 to 0.1 meter in 4 years), indicating transport and accumulation of sediment beyond the barred zone. Beyond the pinch-out depth, changes were haphazard and generally less than 0.10 meter. Which of the two indicators of closure (critical or pinchout) will be the most relevant depends on the application. For example, when planning a sediment budget the bathymetric surveys should run to at least the pinch-out depth. On the other hand, when selecting a site for placement of a bottom structure or instrument package, going beyond the critical depth may be enough to preclude burial by the normal processes of sedimentation.

The selection of the closure depths involves an acknowledged subjective evaluation as to where the profiles appear to close at each survey station. The degree to which individual judgment affects these estimates is illustrated in Figure 11 by two estimates obtained independently by two different individuals at each of the profile stations. Discrepancies between individuals, while substantial at some stations, do not have an unacceptable effect on the average depth for a broad reach of shore. Thus, attempts to obtain greater apparent objectivity in the selection of the individual depths seem unnecessary

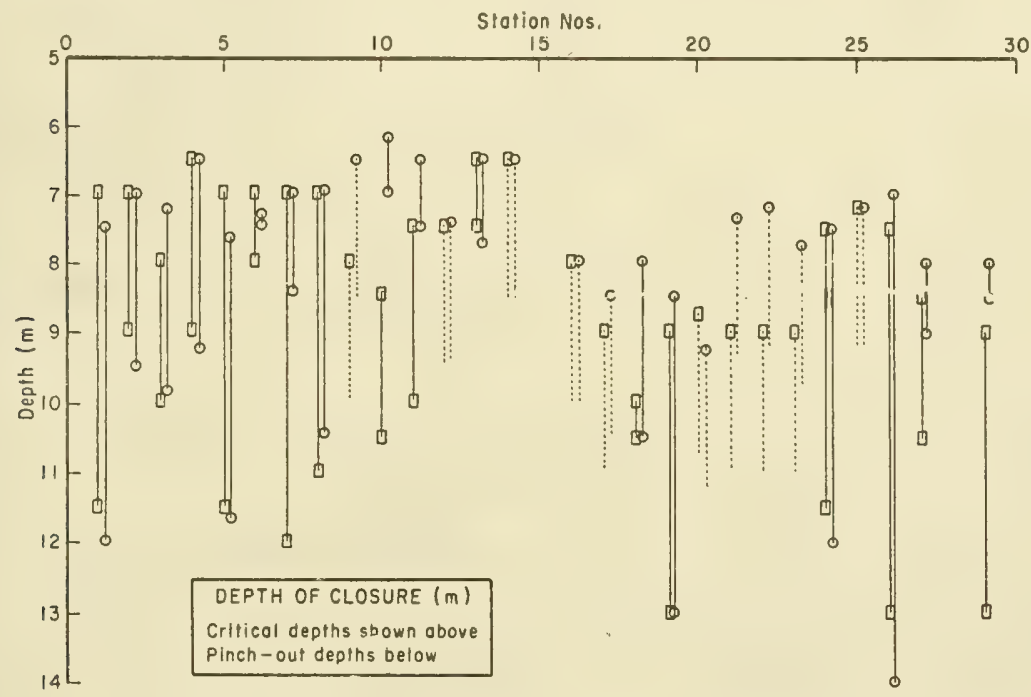

Figure 11. Depths of closure. Estimates of profile closure were made independently by two different individuals (represented as $\square$ and 0 ) at profile stations 1 to 29 . Solid lines connect their estimates of critical and pinch-out depths at the same stations. At stations where the profile did not extend deep enough to permit a confident selection of the pinch-out depth, a dotted line extends 2 meters below che critical depth estimate. 
The critical depth averaged a little more than 7 meters on the north side of Little Sable Point, and a little more than 8 meters on the south side (stations 16 to 29, see Fig. 9). North of the point, the average pinch-out depth was 10 meters. South of the point, there was no clear pinch-out on several of the stations because the 1969 profiles were too short; where the pinch-out was identified it averaged 11.5 meters. Thus, both definitions suggest deeper profile closure south of the point.

The individual profiles in Appendix A may be useful to the engineer in determining depths of measured changes.

\section{Volume Changes.}

a. Stations. To test the assumption that the volume of sand eroded from the upper beach during recession was matched by an equal volume deposited offshore, the cross-sectional area between profiles at each station was calculated. The earlier profiles were usually too short to include all of the active zone, so most area determinations are based on changes between 1971 and 1975. Because only 16 stations were reprofiled in 1971, 4 of the longest 1969 profiles were used to supplement the area change measurements.

b. Calculations. The profiles selected for volume calculations were digitized at 5-meter intervals in the horizontal from the landwardmost to the lakewardmost points common to both the earlier and later surveys (e.g•, Fig. 12). The results of all the volume calculations are given in Appendix $B$. The difference between the sequences resulting from digitization provides a sequence of changes, with positive values indicating a fill and negative values indicating a cut. Multiplying the digitizing interval ( 5 meters) times the summation of all elements in the change sequence gives a measure of the net volume change per unit width alongshore. If the elements in the difference sequence are summed from their landwardmost point to some arbitrary point offshore, the product of that sum and the digitizing interval gives the net change in volume per unit width over that arbitrary span. Below each set of digitized elevations there is a continuous curve showing the change in volume per unit width from the innermost point to each succeeding point across the entire active profile. This cumulative volumetric curve is drawn to the same horizontal scale as the profile.

A dashed curve plotted on the same axis shows the average thickness of the net volume change if it were distributed uniformly from the innermost point to the end point for which the change was summed (Fig. 12).

c. Results. Inevitably, on a receding shore the cumulative volume curve is negative from the inner point out beyond the shoreline, indicating net degradation or cutting over the upper beach. Small zones of aggradation or fill offshore cause the cumulative volume curve to increase toward zero (Fig. 12). At a point farther offshore the cumulative volume curve returns to zero. Between this balance point and the backshore the cut and fill exactly balance each other; i.e., neglecting compaction and expansion, the sediment could have been redistributed within that zone without requiring any gain or loss to the outside. Offshore from this balance point the cumulative volume curve would ideally not depart significantly from zero. With the real profiles, however, the cumulative volume curve offshore often increases about as far above zero as it was below zero inside the first balance point (App. B). 

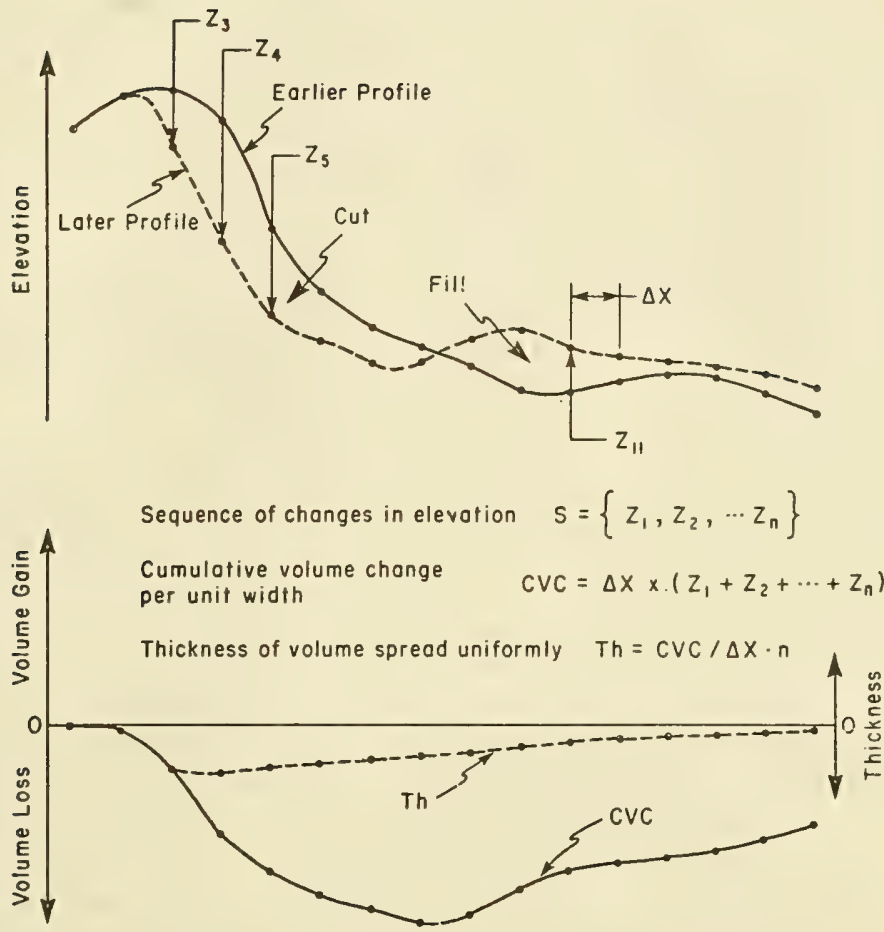

Distance Offshore

Figure 12. Schematic diagram of volume change calculations.

Farther offshore the cumulative volume curve usually crosses the zero line several times before finally smoothing out. A positive cumulative volume curve indicates additional sediment was supplied from outside the profile area. If this sediment came from offshore, the cumulative volume curve would approach zero again if extended to the pinch-out depth. As it turned out, changes in depth over the 4- to 6-year period were so small near the pinch-out depth that the total volume change summed over the entire active beach was relatively unaffected by deliberate extensions of the cunulative volune curve, and therefore, even more insensitive to actual uncertainties encountered in selecting the pinch-out depth (Fig. 11). Although the cumulative volume curve approached a constant near the pinch-out depth, it usually was not zero. The value of the cumulative volume curve at the pinch-out depth, representing the net change summed over the active profile, is tabulated by station from north to south in Table 1. The concept that equivalent volumes are eroded from the upper beach and deposited offshore (sometimes called Bruun's rule) is clearly invalid when applied to single profiles. In fact, with the given profile spacing, there is no sediment balance even when volume changes are calculated over reaches several kilometers in length. Rosen (1978) pointed out similar local imbalances in the Chesapeake Bay. 
Table 1. Volume change per unit width of shore.

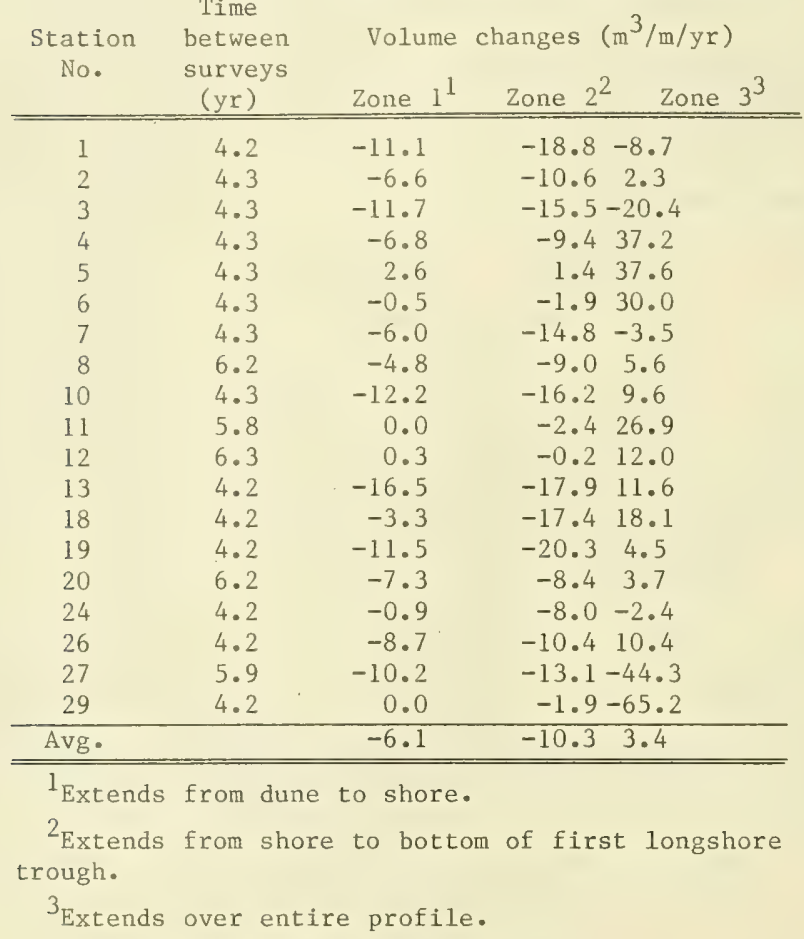

For the entire study area, the total volume lost from the upper beach in 4 years (column 4, Table 1) averaged 41 cubic meters per meter. About 59 percent of this loss reflects erosion above the water surface (column 3, Table 1), the remaining 41 percent occurs between the shore and the first longshore bar. The net volume change summed over the entire active profile produced a small positive, but statistically insignificant net gain of sediment (3 cubic meters per meter of shore per year). Thus, within the overall survey area, there was a volumetric balance between erosion on the inner part of the beach and deposition offshore. This balance suggests that future profile adjustments to different changes in water level may be predicted by a simple geometric model discussed in the next section. This situation will not exist on many open ocean coasts where eroded beach sands are transported landward by overwash or wind, or are carried into inlets and deposited on ebb or flood tidal shoals.

\section{PREDICTION MODEL}

This section presents an idealized concept of profile adjustment, discusses objections and difficulties with applying the concept, and shows how these difficulties are minimized for the present data set. Application of the concept using actual measurements is followed by generalizations and specific guidance on applying the concept to other areas of the Great Lakes. 
As described by Bruun (1962) a rise in the mean elevation of the water surface tends to shift the equilibrium sand profile landward. As water levels rise erosion prevails on the upper beach and the shoreline retreats. Conceptually, the erosion supplies material to build the outer part of the responding profile upward. It is assumed that the initial profile shape is reestablished farther inland and at a distance above its initial position equal to the change in water level $z$ as depicted in Figure 13 . Thus, the ultimate retreat of the profile $x$ can be calculated given the dimensions of the responding profiles, $X$ and $Z$, and a measure of the stability of the shore-eroded material in the outer zone, $R_{A}$.

$$
\mathrm{x}=\frac{\mathrm{zX}\left(\mathrm{R}_{\mathrm{A}}\right)^{\mathrm{sg}(\mathrm{z})}}{\mathrm{Z}}
$$

where $\operatorname{sg}(z)=1$ if $z>0$ (i.e., water rising), or sg $(z)=1$ if $z<0$ (i.e., water falling.

a. Equilibrium Profile
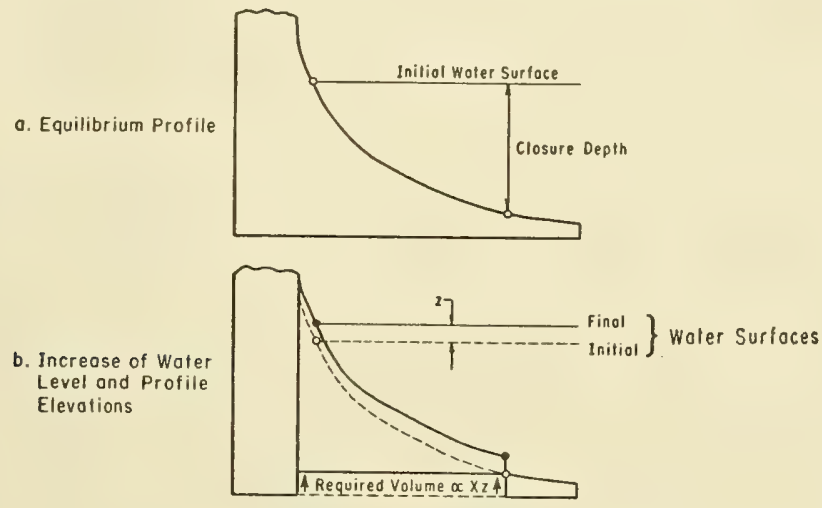

c. Recession of Profile

d. Nef Resulis $x=\frac{x_{2}}{z}$
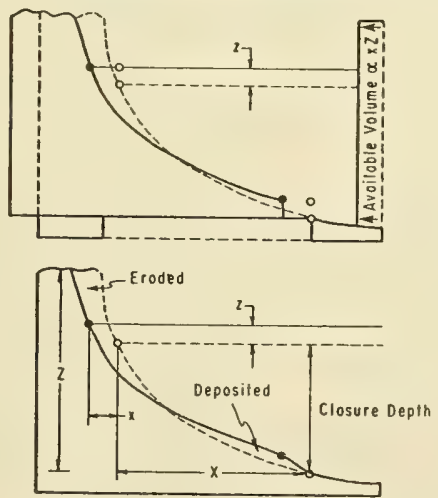

Figure 13. Schematized view of profile adjustment as two rigid translations. 
One method of estimating the proportion of shore-eroded material that will be lost is to use the textural characteristics of the active beach as a guide. If the newly eroded deposits have a size distribution identical to that of the sediment in the active zone prior to the water level change, then only insignificant amounts will be lost through selective transport processes and $\mathrm{R}_{\mathrm{A}} \sim 1$. If a part of the eroded material is finer than the overlying native beach it may be carried far offshore in suspension where it does not contribute to the building of a new profile. In which case $R_{A}>1$ and additional shore erosion must compensate for the 1oss. Thus, the situation is similar to the problem of calculating the overfill ratio for a beach nourishment project. Hobson (1977) explains how, to compute $R_{A}$ to evaluate the suitability of borrow material. The same procedures apply here except the "borrow material" characteristics must be based on a composite sample of the eroding section of the shore, i.e., the upper beach in the case of increases in lake level since it is supplying sediment to the lower part of the adjusting profile. If the water level declines the lower part of the responding profile is eroded to supply material to prograde the upper profile. In this case the "native material" characteristics must be based on a composite sample of the lower profile (i.e., the zone of offshore erosion). In either case the native material characteristics must be based on a composite sample of the entire responding profile from the limit of wave uprush to the point of profile closure.

If the engineer concludes, without specific textural data, that all of the shore-eroded material will remain in the zone of profile adjustment, then $\mathrm{R}_{\mathrm{A}}=1$. If the engineer estimates by other methods that only $\mathrm{P}$ percent of the eroded sediment will remain in the active zone then $R_{A}=100 / P$.

Equation ( 1 ) with $\mathrm{R}_{\mathrm{A}}=1$ was applied to sea level rise on Florida beaches by Bruun (1962), and in this context is often referred to now as Bruun's rule. It is not so much a rule in any formed sense, as it is a statement of a fairly simple concept based on assumptions which had been used by many early coastal geomorphologists. However, explicit applications of the concept prior to Bruun (1962) are unknown. Although references to the concept are frequent, it is still rarely used for predictive purposes.

\section{Difficulties in Applying the Sediment Balance Approach.}

Given the long-term effect of rising sea levels throughout most of the Northern Hemisphere, it may be wondered why the sediment balance approach (Bruun's rule) has not been more widely applied. The following difficulties have been encountered with this approach:

(a) Skepticism as to the adequacy of an equilibrium model for explaining short-term dynamic changes;

(b) difficulty in determining $\mathrm{R}_{\mathrm{A}}$ or the percentage of sediment lost from the active zone;

(c) problems of establishing a realistic closure depth below which water level changes have no effect on profile stability; 
(d) confusion arising from a typographic error in one of the equations defining profile retreat (Bruun, 1962); and

(e) the perplexity caused by a discontinuity in the profile at the closure depth which appeared in the original and all subsequent diagramatic sketches illustrating the concept.

The first three difficulties ( $a, b$, and c) warrant serious consideration before applying equation (1); items (d) and (e), although perhaps confusing, should in no way discourage or limit use of equation (1). The following paragraphs address each of these difficulties in reverse order.

a. Discontinuity in the Profile (Item e). Previous diagrams illustrate the adjustment of a profile to higher water levels by literally disconnecting the responding part of the bottom from the static region offshore. The apparent profile discontinuity, at the juncture between the static and responding regions, has some didactic value in diagrams to the extent it emphasizes the congruency between initial and final profile shapes in the active region. Unfortunately, it also creates the impression that the model is inadequate for explaining the transition between the active and static parts of the profile. The discontinuity is not, however, an inherent part of the concept but rather an artifice of the diagrams. Rigidly translating a profile upward and shoreward does not necessarily lead to a discontinuity nor even a change in slope as is demonstrated later in this report.

b. Error in an Equation (Item d). Bruun's equation (1a) (Bruun, 1962, p. 124) is dimensionally incorrect as published. This error may have discouraged some readers from giving Bruun's concept their full consideration. The problem equation is, however, unnecessary to the development of this concept (correctly expressed in eq. lb of Bruun, 1962). The validity of the Bruun concept and of equation (1) in the present report is demonstrated geometrically in Figure 13.

Figure 13(a) depicts a nearshore profile in quasi-equilibriun with wave and wave-related forces. Note the closure depth below which the bottom presumably does not adjust to surface wave and current conditions. To estimate the ultimate shore retreat, the adjustment of the active profile is then depicted as two rigid profile translations.

The first translation moves the active profile (i.e., the profile between the closure depth and the point of highest wave attack) up an amount, $z$, and reestablishes the equilibrium depths below the elevated water surface (Fig. $13, b)$. This step requires a volume of sediment proportional to the product of $X$ (the width of the active zone) times $z$ (change in water level); the volume is made available by the second translation which is recession of the profile (Fig. 13,c). Figure 13(c) shows that $x$ units of recession provide a volume of sediment proportional to the product of $x$ times $Z$ (the vertical extent of the active profile from the critical depth up to the average elevation of the highest erosion on the backshore). Equating the volumes produced and required per unit length of shoreline by these two translations (eq. 2) produces equation ( 1 ). 
then

$$
\mathrm{xZ}=\mathrm{zX}
$$

$$
\mathrm{x}=\frac{\mathrm{zX}}{\mathrm{Z}}
$$

In reality, both translations occur simultaneously with the result that the closure point actually migrates upslope as the water level rises. Shifting the closure point upward and shoreward will affect the outcome of volumetric calculations, and there are at least two ways to account for this small defect in the geometric justification just given for equation (1).

First, a closure depth midway between the original and final depths could be used with equation (1) to improve the accuracy of the calculation. The horizontal translation of the profile would then imply a slight irregularity or "step" where the new and old profile shapes meet. The step would consist of a wedge of surplus sediment above the closure depth and an equal volume deficiency below; therefore, a local exchange of sediment is easily imagined which would eliminate the step and completely reestablish the identical smooth profile shape without affecting the overall sediment balance expressed in equation (1). This method of accounting for the migration of the closure depth is easy to visualize and consistent with the geometric derivation given for the predictive equation.

Second, a more formal development of the sediment balance would have integrated between profiles, allowing the closure point to move in infinitesimal steps with the water surface. This approach also eliminates the step problem and results in the more precise relationship:

$$
\mathrm{x}=\mathrm{x} \text { \&n } \frac{\mathrm{Z}}{\mathrm{Z}-\mathrm{Z}}
$$

Neither method of adjusting equation (1) (by measuring the critical depth from an intermediate water level elevation or using eq. 3) is generally necessary because the change in water level, $z$, is usually so small relative to the total height, $Z$, that all three methods provide essentially the same results. For example, if $z<0.12$ all results agree within less than 1 percent.

Thus, the simple expression, $\mathrm{x} \sim \mathrm{zX} / \mathrm{Z}$, is not only valuable as a close approximation, but also most useful because it is easily (a) recalled by visualizing the adjustment of two rigid translations, (b) explained in the same manner, and (c) used as a quick mental check on the ultimate retreat expected for various values of the independent variables.

c. A Realistic Closure Depth (Item c). Determining a realistic closure depth is usually extremely difficult. The most direct approach is to compare historic bathymetric surveys of the site in question. Unfortunately, adequate survey data of this type are rare. Neither pier nor stadia surveys extend deep enough, and if a hydrographic survey does extend to deep water, allowances must be made for the fact that both sounding errors and boat-positioning errors usually increase significantly with depth and with distance from shore. It is thus often impossible to substantiate apparent offshore changes. On the 
oceans, waves and tides create difficulties in establishing a datum. At times, it is impossible to distinguish the effect of long-period swell in creating waves on the sounding record from actual sand waves on the sea floor (Magoon and Sarlin, 1970; Bruno and Gable, 1976).

Finally, if deep reliable profiles are found, evolution of the closure depth for use in equation (1) requires two surveys separated by an appropriate time period during which profile adjustment actually occurred in response to a known change in water levels. Hallermeier (1977) demonstrates the dependence of profile closure on local wave conditions. The difference between depths of closure at two sites with identical wave and sediment characteristics, one with a stable mean water level and the other with a recently displaced water level, has not been studied. It seems plausible that storm waves could cause a net profile change where equilibrium had been perturbed by the recent shift in the mean water level, and yet cause only sediment motion and (almost by definition) no net change in bottom elevation where the profile was in equilibrium with a constant water level. If this is the case, real water level changes are essential if repetitive profiles are to reveal a closure depth suitable for testing the Bruun concept. Clearly, many problems plague the deterinination of the appropriate closure depth and therefore discourage application of Bruun's concept for predicting future shore retreat.

d. $\mathrm{R}_{\mathrm{A}}$ or the Percentage of Sediment Loss (Item b). Equation ( 1 ) can be adjusted to account for any sediment lost from the active profile, but only if the volume losses can be determined. Often they cannot. Loss occurs when there is an uncompensated exchange of sediment beyond the surveyed boundaries. Losses can occur offshore, onshore, or alongshore. On the west coast, submarine canyons complicate the determination of offshore losses. On the gulf coast, hurricane processes have moved coarse sediment from as deep as 20 meters onto barrier islands (Hayes, 1967). Return currents after hurricane passage reportedly spread a 1- to 2-centimeter layer of beach sand over homogenous muds 8 kilometers from shore; even thicker layers of nearshore silts and muds reportedly moved much farther gulfward as turbidity currents (Hayes, 1967). Onshore losses are a problem on the east coast. High tides and severe storms transport beach sand to the bay side of barriers at rates ranging from more than 40 cubic meters per meter within individual overwash deposits during single storms to about 1 cubic meter per meter for long stretches of shore yearly (Schwartz, 1975). The engineer must consider the contribution of these or other processes to sediment losses over the period of his study. If QT is found to be the net exchange of sediment in time, $T$, across the boundaries of a control area with longshore length, $Y$, then the anticipated retreat should be reduced by QT/YZ:

$$
\mathrm{x}=\frac{\mathrm{zX}\left(\mathrm{R}_{\mathrm{A}}\right)^{\mathrm{Sg}(\mathrm{z})}}{\mathrm{Z}}-\frac{\mathrm{QT}}{\mathrm{YZ}}
$$

e. Adequacy of an Equilibrium Model (Item a). Use of equilibrium assumptions to model dynamic coastal changes also deserves scrutiny. The idea of an "equilibrium beach profile" has had a long history (e.g., Fenneman, 1902); however, opinions still differ as to exactly what the concept actually entails. By one definition, the profile of equilibrium is the ultimate shape which coastal processes strive to impart to a beach. Of coarse, nature seldom remains constant long enough for a strict equilibrium to develop. In the present 
context, the term, equilibrium profize refers to a curve of fixed size and shape which "adequately" represents the "average" profile shape before perturbation by a shift in water level. By assumption, shore erosion eventually returns the profile to this same shape after it is displaced as a result of the water level change (see Fig. 13).

A willingness to accept equilibrium as a reasonable approximation is not inconsistent with recognition of seasonal, storm, or other temporary profile fluctuations. Careful judgment should be made on a case-by-case basis, if field profiles claim to represent quasi-equilibrium conditions. Generally, the claim will be more reasonable the longer the time frame of the study. The spatial extent of the study is also important. Usually, the longer the stretch of shore, the more likely that longshore variations will also average out, thereby, providing an overall equilibrium.

This discussion has shown that the Bruun concept is theoretically sound but difficult to apply in the field. The next subsection examines how some of the difficulties discussed above are avoided in the Lake Michigan data.

\section{Suitability of Present Data for Testing the Sediment Balance Concept.}

The ways that previously discussed difficulties (items a to e) affect Lake Michigan data are outlined here, before an actual application of the data in the next subsection. Difficulties (d) and (e) should not limit application of the model to any data set for reasons discussed in the lasst subsection.

Establishing a realistic closure depth (item c) depends on accurate repetitive profiling. Profile errors increase with distance from shore. Fortunately, the bottom drops off to suitable depths relatively rapidly in the present study area. Furthermore, the Great Lakes are free from tidal variations as well as from long-period swell. The Great Lakes are notorious for their large storm surges and seiches; however, based on extensive water level measurements in 1969, it was concluded that these disturbances are not a significant problem in the present study. By choosing the right time of year and surveying only when conditions are calm, it is possible to avoid datum and bottom ambiguities. Note the absence of confusing wave interference on the raw fathogram in Figure 14.

The difficulty of determining sediment losses (item b) on the Great Lakes is greatly simplified by the absence of submarine canyons, hurricanes, and overwash events. Fluvial sediment input is also no problem because all rivers entering eastern Lake Michigan flow through deep inland sediment traps. Dredging at Pentwater Channel is we11 documented. On the average, 60,000 cubic meters is removed annually, and some of this is returned to adjacent beaches. Inlet losses have only a small effect on the overall sediment budget for the broad study area. Thus, in the present application Q (eq. 4) will have a negligible effect.

The only process supplying new sediment to the active profile is shore recession. Furthermore, shore deposits and backshore bluffs within the study area contain less than 1 percent silt, making it unnecessary to correct for any unstable fine fraction (i.e., $\mathrm{R}_{\mathrm{A}}=1$; eq. 1). Thus, a number of sitespecific attributes simplify sediment balance for the study area. 


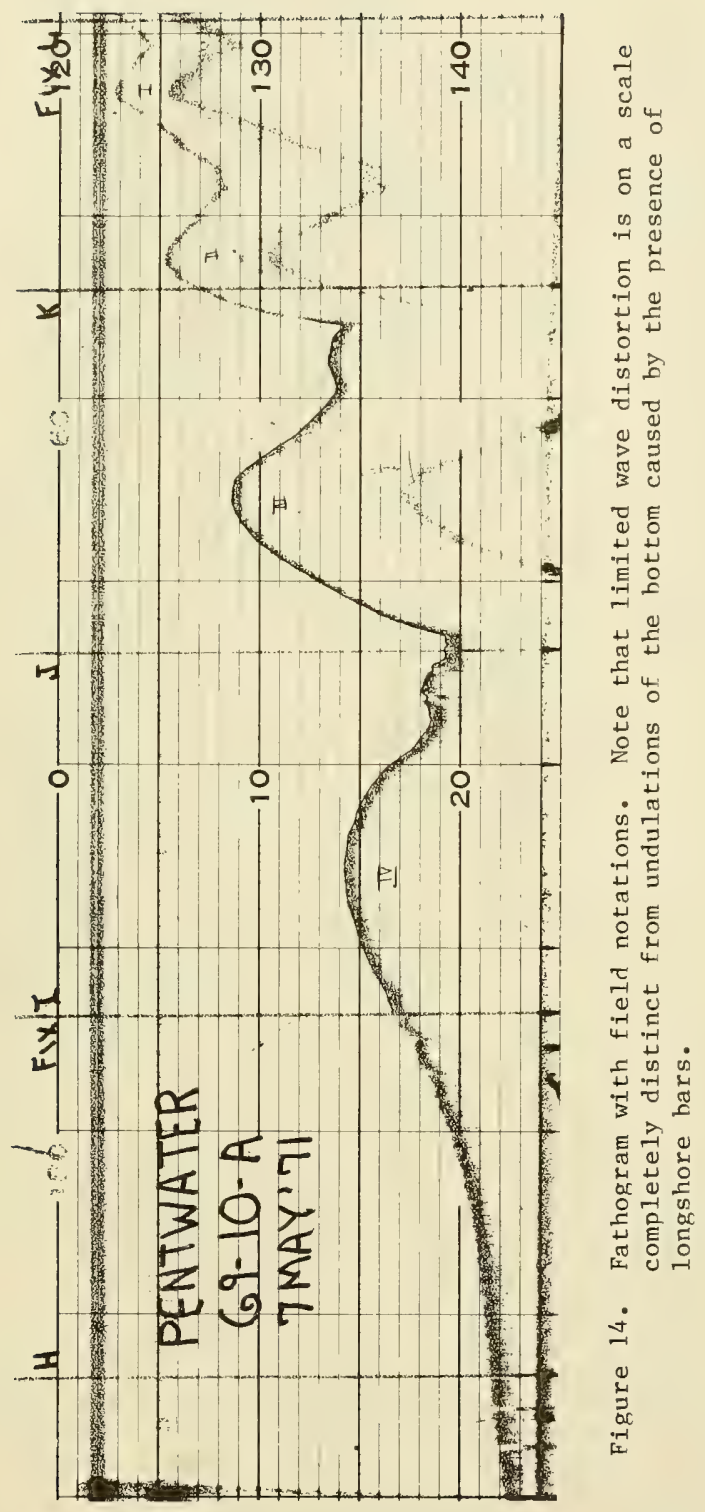


The dependence of the model on equilibrium assumptions (item a) makes it difficult to get convincing field confirmation because waves, currents, and conditions of sediment supply never remain constant for long. On the other hand, because it is an equilibrium model the potential for application is broadened. The model can even apply to situations where storms or man's influence upset equilibrium. The predicted retreat in such cases would indicate the adjustment required by just the change in water level; effects due to other changes would have to be superimposed if significant. Thus, once the concept is confirmed, equilibrium tends to make application easier.

The model itself provides no indication of the time period required for the beach to return to equilibrium. Errors in misjudging equilibrium, and failing to account for the lag between cause and effect, are all too easy to make if the data cover only a small reach of shore or a short period of time. The length of time and the number of profiles studied here are thought to be sufficient to avoid this problem.

\section{Application of the Sediment Balance Approach.}

a Longshore Contributions. Wave data suitable for prediction of longshore transport rates are not available in the study area. Various indications of the direction of transport are compiled in Figure 15. Evidence from coastal geomorphology (Hands, 1970), from longshore changes in grain size (Saylor and Hands, 1970), from the pattern of channel shoaling (Hands, 1976a), and from data hindcast for extreme storms (Resio and Vincent, 1976c) suggests that the direction of longshore transport in the vicinity of Pentwater Harbor is predominantly southward, but subject to frequent reversals; extrapolation from Saville's (1953) hindcast data suggests a northward transport. Littoral Environment Observation (LEO) data from Mears State Park were inconclusive-too short a record and subject to the effects of a large eddy and reflected waves from the Pentwater jetties. Near profile station 17, the extreme storm data and the usual deflection of Silver Lake Creek crossing the beach suggest that the direction of transport changes to northward on the south side of Little Sable Point. Beyond the southern limit of the study area, storm data from White Lake and Muskegon suggest a close balance between northward and southward flows in that region. South of Grand Haven the geomorphology and storm data indicate net southward transport for the remainder of the eastern shore. Therefore, there is a consistent pattern of drift moving toward Little Sable Point from the north (Summit Park) and from the south (White Lake) (Fig. 15).

Long-term convergence of drift toward the Silver Lake dunes would be consistent with the evolution of Little Sable Point from a shallow embayment several thousand years ago when water levels were 7 meters above modern levels (Hough, 1958) to the dune-covered coastal promontory of today.

The areas from Ludington to Summit Park and from White Lake to Muskegon appear to be natural boundary zones of longshore divergence (Eig. 15). In addition to these natural boundaries, the jetties at Ludington and at the pumped storage facility 4 kilometers farther south (Fig. 16) are also obstacles to sediment input from the north. The jetties and entrance channel at White Lake likewise reinforce the natural southern boundary. Present-day processes, storm patterns, and engineering projects thus limit the possible sources of drift converging toward the Silver Lake dunes to those beaches and bluffs primarily within the present study area (see Fig. 4). 


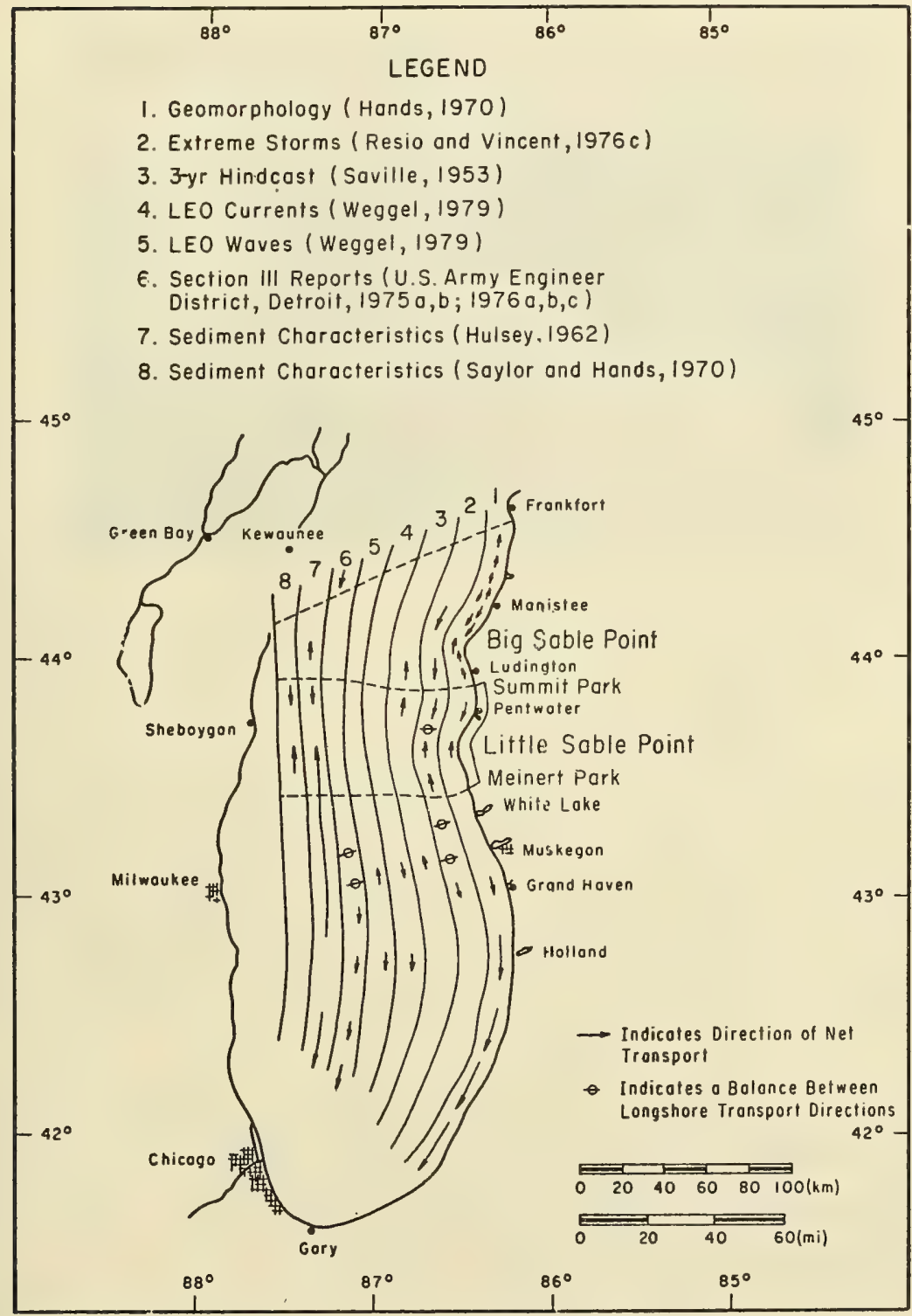

Figure 15. Direction of net longshore transport along the eastern shore. Not all sources are in agreement, but most support the hypothesis that there are areas of longshore divergence beyond the study area both to the north and south, and that longshore transport within the study area converges near Little Sable Point. 


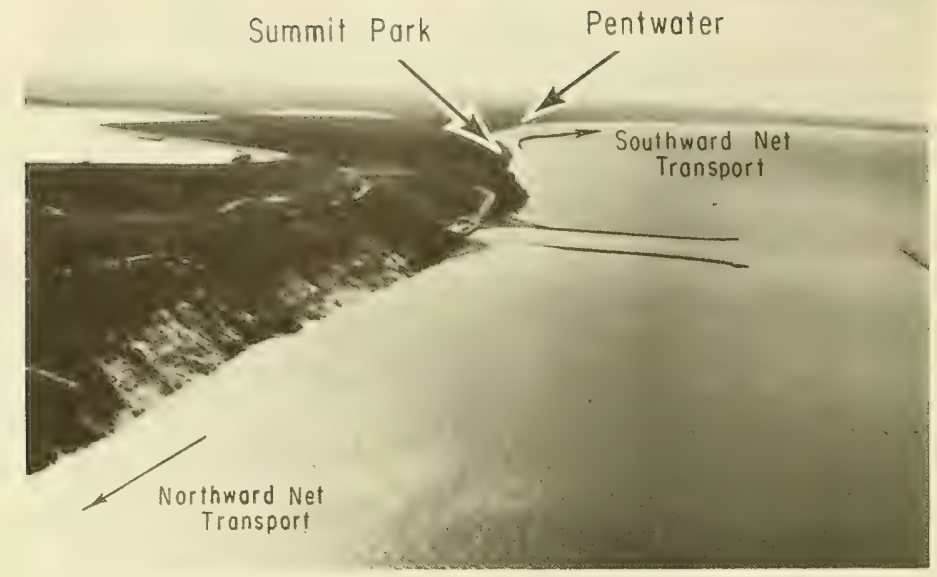

Figure 16. Pumped storage facility south of ludington. The shore south of Ludington is a zone of general longshore divergence. The jetties built at the pumped storage facility in 1971 further restrict longshore transport in this area of divergence and thus establish a specific northern limit for sources of sand to the present study area.

The assumption that there is no significant longshore input or losses beyond the present study limits is reasonable, especially considering the ninor impact any imbalance would have on the 50-kilometer stretch of shore during this period of rapid shore erosion. For example, a net inflow of 100,000 cubic meters per year (an improbably large figure) would be volumetrically equivalent to recession of only 0.2 meter per year, $\left(10^{5} \mathrm{~m}^{3} / \mathrm{yr}\right) /$ $\left(5 \times 10^{4} \mathrm{~m} \times 10 \mathrm{~m}\right)$, while the observed shore recession actually averages 2.5 meters per year. So the maximum conceivable longshore input is small relative to the enormous exchange of sediment onshore and offshore during this period of rapid profile adjustment.

b. A Possible Inland Loss. A possible inland loss on Little Sable Point complicates the otherwise simple sediment balance for this area. The Silver Lake dunes occupy about 6 kilometers of shoreline between profile stations 13 and 17 and extend more than a kilometer inland (Fig. 9). These actively migrating dunes reach heights of 35 meters along the inland half of the dune field (Fig. 17). Along the shoreline, the dune ridges crest about 7 meters above lake level (Fig. 18) and some ponded interdune areas are at approximately the same level as Lake Michigan (177 meters, International Great Lakes Datum). For many hundreds of years this dune field has been fed by the convergence of longshore transport toward Little Sable Point from both the north and south, and by the inland transport of sand by prevailing west winds. The dune shoreline receded more than any of the adjoining beaches during the study period (Fig. 19). The vastness of the dune field, the effect of 1- to 2-meter wave-cut bluffs which marked much of the dune shoreline, and the virtual 


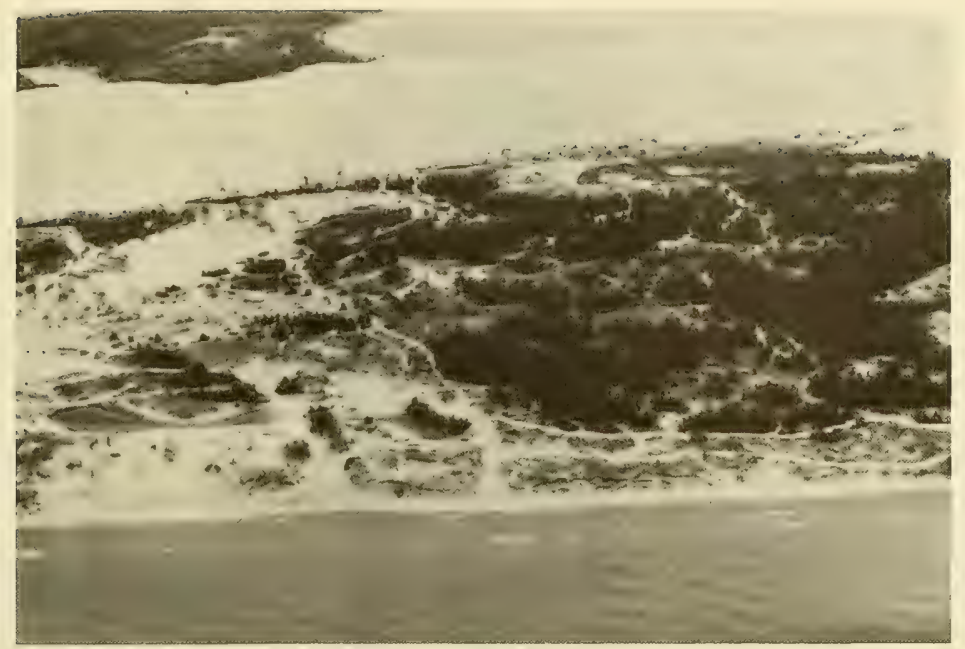

Figure 17. Silver Lake dunes, looking from lake Michigan across the dunes to Silver Lake. Spit extension probably sealed off the two bodies of water soon after the Nipissing high lake levels which, according to Hough (1958), would have been about 3,000 years Before Present (B.P.). Continued longshore transport and prevailing west winds built the dune field along the front of this low receptive embayment.

absence of an exposed beach across which the wind could blow make it difficult to estimate the volume of sand actually transferred inland during the recent period of high water. It is assumed that inland losses to the Silver Lake dunes between 1969 and 1976 exceeded the gain of sediment supplied to the adjusting profile from the dunes by only a small amount which can be neglected in the calculation of an overall sediment balance for the larger study area.

c. Measured and Predicted Shore Retreat. Because the initial 1967 survey covered only a small area in the vicinity of Pentwater Harbor, an area subject to less recession than the surrounding "undisturbed" beaches (Hands, 1979), testing of the sediment balance approach was best done by using the 1969-76 survey data and excluding measurements made within 500 meters of the Pentwater jetties. The extent of shore covered ( 25 profiles spread over 50 kilometers) and the length of time monitored ( 7 years), together with the sizable increase in mean water level during the study period and the generally near-ideal conditions discussed previously, make this application the most realistic field test of equilibrium profile migration to date.

Measurements of the width of each profile from the vegetated dune line to the pinch-out depth for each station were taken and averaged to obtain $\mathrm{X}=923$ meters. The heights of the scarps which waves had cut in the foredune were also measured at each station. As the profiles had not yet developed a 


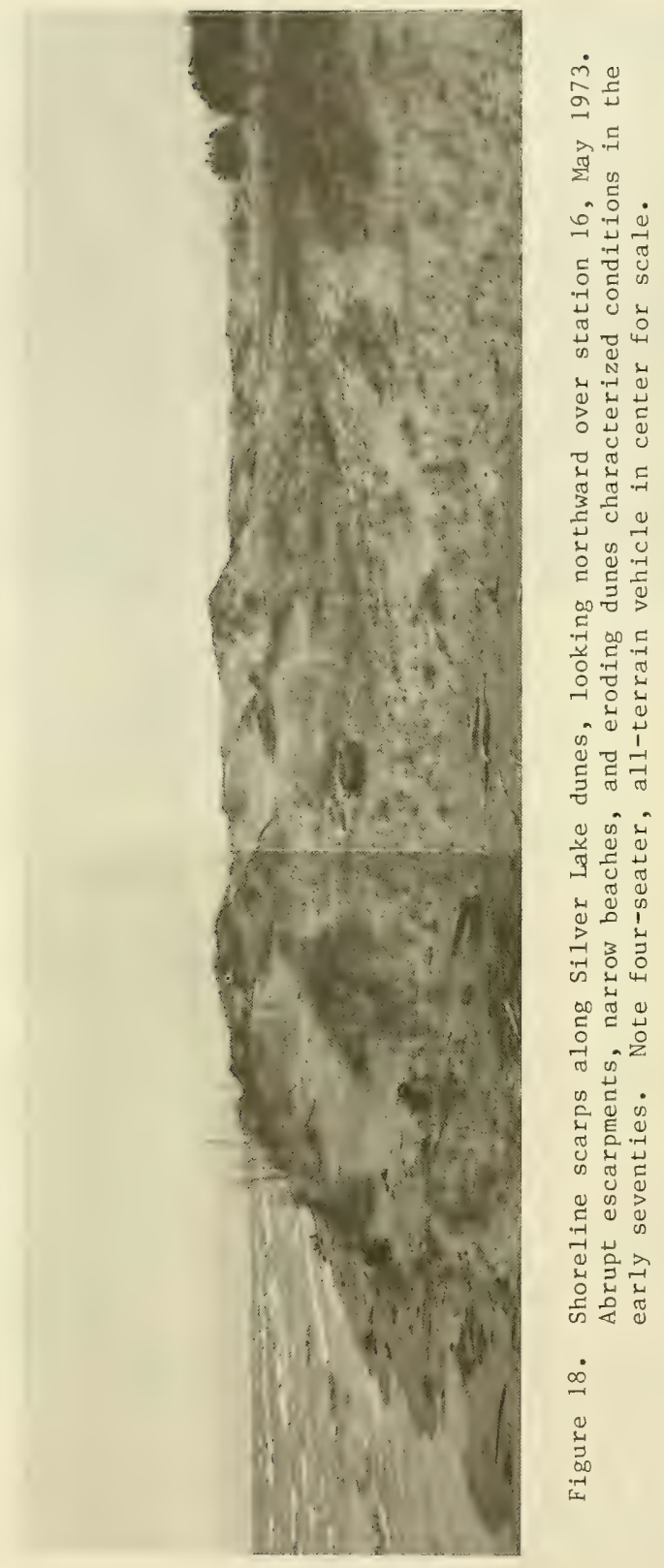




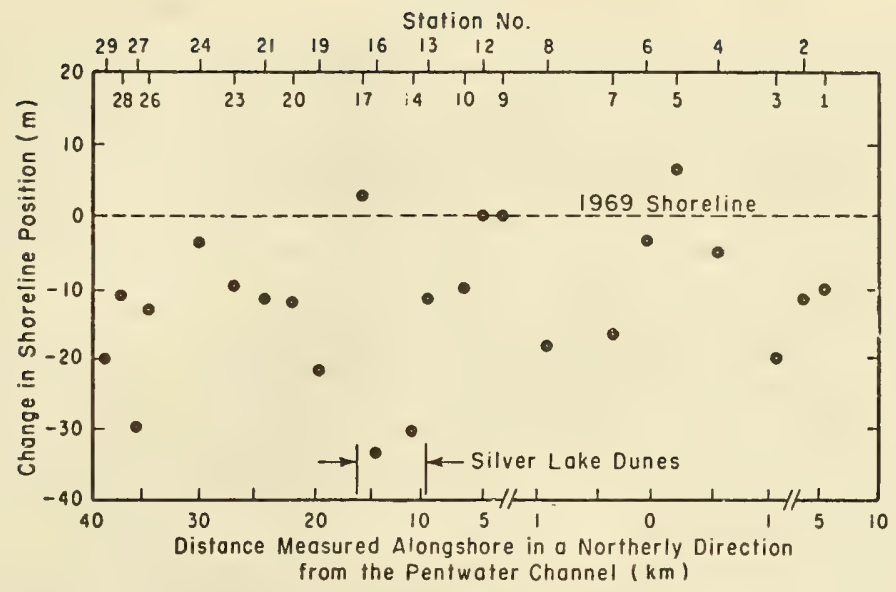

Figure 19. Longshore variation in net shore retreat from 1969 to 1976.

significant scarp in 1969, the average dune height for the period of adjustment was approximately one-half the average scarp height in 1976. Average dune height added to the average pinch-out depth taken from Figure 11 established the vertical dimension of the adjusting profile (the $Z$ in eq. 1 and Fig. 13). The resulting average value of $Z$ was 13.6 meters. Under the discussed assumption of regional sediment balance, the ratio $\mathrm{X} / \mathrm{Z}$ times the measured water level change $(z=0.20$ meter) equals the ultimate shore retreat ( -13.6 meters). The retreat actually measured between 1969 and 1976 also averaged -13.6 meters. Considering the measurement and sampling errors involved in determining each independent variable a predictive capability of less than a tenth of a meter certainly is not claimed, but the results clearly confirm the appropriateness of the equilibrium-sediment balance approach when applied in the proper setting.

As noted previously, pinch-out depths are deeper south of Little Sable Point than to the north. The eroding dunes are also higher there, which even further enlarges the vertical dimension of profile adjustment south of Little Sable Point. Consequently, the equilibrium prediction might be applied separately to the two regions. Likewise, because additional surveys were conducted in 1971 and 1975, separate predictions could be applied to these shorter time intervals (1969 to 1971 and 1969 to 1975) as well. Thus, partitioning the original data provides nine individual, though not independent tests (Table 2). The greater pinch-out depth south of Little Sable Point increases both the width, $X$, and height, $Z$, estimates in a compensating fashion so that there is little effect on the predicted outcomes. The values predicted for north of Little Sable Point are essentially the same as predicted for south of Little Sable Point for each of the three time periods (Fig. 20). Considering prediction versus measurement, the predicted retreat from 1969 to 1971 was too high for all three areas (117 percent high for the area as a whole). The prediction for 1969 to 1975 was also high, but not as far off as before ( 45 percent high for the whole area). These overestimations 
Table 2. Predicted and observed profile retreat.

\begin{tabular}{|c|c|c|c|}
\hline \multirow[b]{2}{*}{ Study area } & \multicolumn{3}{|c|}{ Survey periods } \\
\hline & $\begin{array}{l}1969-1971 \\
x=0.12 \mathrm{~m} \\
x=870 \mathrm{~m}\end{array}$ & $\begin{array}{c}1969-1975 \\
x=0.39 \mathrm{~m} \\
X=1,020 \mathrm{~m}\end{array}$ & $\begin{array}{l}1969-1976 \\
x=0.20 \mathrm{~m} \\
x=923 \mathrm{~m}\end{array}$ \\
\hline & \multicolumn{3}{|c|}{ Average height, $\mathrm{Z}(\mathrm{m})$} \\
\hline $\begin{array}{l}\text { Northern section } \\
\text { (stations } 1 \text { to } 15 \text { ) }\end{array}$ & 10.84 & 12.15 & 12.50 \\
\hline $\begin{array}{l}\text { Southern section } \\
\text { (stations } 16 \text { to 29) }\end{array}$ & 12,90 & 14.28 & 14.80 \\
\hline \multirow{2}{*}{$\begin{array}{l}\text { Whole area } \\
\text { (stations } 1 \text { to } 29 \text { ) }\end{array}$} & 11.86 & 13.21 & 13.60 \\
\hline & \multicolumn{3}{|c|}{ Predicted retreat, $\mathrm{Xz} / \mathrm{Z}(\mathrm{m})$} \\
\hline Northern secton & 9.63 & 27.93 & 13.92 \\
\hline Southern section & 9.49 & 27.86 & 13.78 \\
\hline \multirow[t]{2}{*}{ Whole area } & 9.34 & 27.25 & 13.57 \\
\hline & \multicolumn{3}{|c|}{ Observed retreat $\mathrm{x}(\mathrm{m})$} \\
\hline Northern section & 4.6 & 20.0 & 12.6 \\
\hline Southern section & 3.6 & 16.8 & 14.8 \\
\hline \multirow[t]{2}{*}{ Whole area } & 4.3 & 18.8 & 13.6 \\
\hline & \multicolumn{3}{|c|}{ Overprediction (pct) } \\
\hline Northern section & 109 & 40 & 10 \\
\hline Southern section & 164 & 36 & 7 \\
\hline Whole area & 117 & 45 & 0 \\
\hline
\end{tabular}

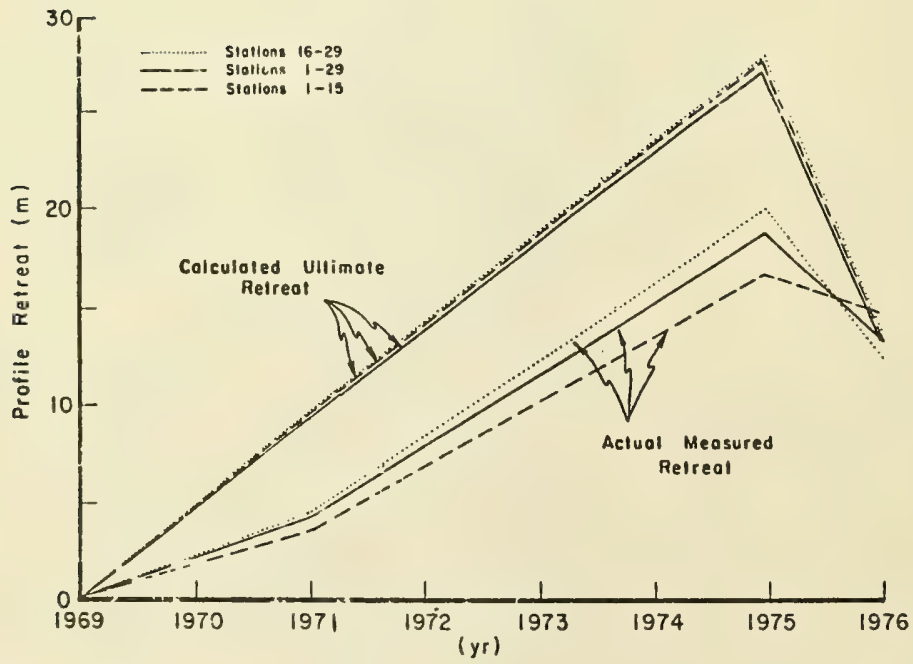

F1gure 20. Calculated versus measured retreat. The predicted ultimate retreat, in response to post-1969 changes in mean lake level, exceeded the observed retreat by more than 100 percent in 1971 and about 50 percent in 1975, presumably because the active.profile had not had time to completely readjust to the higher water'levels. Almost perfect agreement had developed by the time of the last survey, 3 years after the lake levels peaked. 
of retreat are attributed to the fact that profile retreat was actually lagging behind the lake level rise. As hypothesized earlier (Hands, 1976a), rising water levels establish a potential for erosion and realization of that potential requires sediment redistribution, i.e., work which depends on the energy being available. The convergence of measured and predicted retreat in both regions, 3 years after annual lake levels had stabilized, suggests that several storm seasons may be required to readjust the profile to changes in mean water level of several tenths of a meter.

According to the model, which works well here, the problem of predicting the effect of lake level changes is equivalent to the problem of identifying the pinch-out depth. The remarkable confirmation of theory and data in the present case highlights the need to generalize a method applicable to similar regional, long-term settings but where wave energies and therefore pinch-out depths might be significantly different.

\section{Using Wave Climate to Estimate the Pinch-Out Depth.}

In the model, the closure depth is the point below which the bottom does not adjust to changes in water surface elevation. In the field, this point was approximated by averaging the upper bounds of the region of negligible profile change in repetitive surveys (pinch-out depths). The closure depth, thus established, is not necessarily appropriate for other areas of the Great Lakes. The depth of profile closure should vary regionally with the wave climate. Unfortunately, the repetitive profile record is usually not sufficient to establish this parameter.

In these cases, knowledge of the wave climate is useful. Wave gage data obtained during profile survey periods are too short to be indicative of the important long-term conditions in the study area; however, wave climate data are available from other sources including hindcast studies (Savi1le, 1953; Resio and Vincent, 1976a, 1976b, 1976c, 1977, 1978), shipboard observations (Pore, et al., 1971; National Oceanic and Atmospheric Administration, 1975), U.S. Coast Guard reports (Liu and Housley, 1969), and the LEO program (Weggel, 1979). Considering site specificity, long-term coverage, and the availability of comparable data for the entire U.S. shoreline of the Great Lakes, Resio and Vincent's reports were chosen as the basic reference for extrapolating profile response from the present study area to those with significantly different wave environments. Their wave climate parameters were generated by a numerical hindcast model using wind data from the extreme storms recorded over a 30-year pariod. The parameters thus describe only the deepwater storm conditions. Because the maximum depth of profile response depends on the higher waves and because only a consistent; relative measure of spatial wave variability is needed, the milder waves though important in profile development need not be considered here. It is reasonable to assume that the maximum depth of intense bottom agitation depends on at least the wave period and the shoaled and refracted wave height, but Hallermeier (1977) found that the maximum depth in a number of actual design wave conditions was essentially proportional to deepwater wave height alone.

The wave height data necessary to estimate the pinch-out depth for any Great Lakes site are given in Appendix C. The average pinch-out depth established within the present study area is 2.1 times the average 5-year 
return-period wave height for the area. In the absence of direct profile change measurements, the pinch-out depth for other regions is thus estimated as :

$$
\hat{\mathrm{d}} \sim 2.1 \mathrm{~h}_{5}
$$

where $h_{5}$ is the 5-year return-period height given in Appendix C.

The accuracy of this approach is not known. For an idea of how sensitive the prediction of profile response is to errors in estimated closure, assume that this study is restricted to the area north of Little Sable Point (stations 1 to 15, Fig. 9). North of the point, the pinch-out depth (from direct measurements) averages 10 meters. With no repetitive profiles south of the point the estimate would be that pinch-out occurs at $1.96 \mathrm{~h}_{5}$. The 1.96 would be a less reliable estimate of the coefficient in equation (5). The average $\mathrm{h}_{5}$ south of Little Sable Point was 5.39 meters (Michigan stations 15 and 16, see App. C), so the estimated closure depth would have been 10.56 meters which is 1.43 meters or 12 percent too small (Table 3). Adding this value to the mean dune height, D, south of Little Sable Point produces a new estimate of $\mathrm{Z}$; the distance of the 10.56-meter contour from shore produces a new estimate of $X$ (Table 3). Using these new values, the estimated response to a 0.2 -meter increase in lake level would be 13.9 meters which is only 1 percent over the value obtained from actual measurements south of the point. This exercise illustrates the self-compensating tendency which errors in the pinch-out depth have on equation (1). The depth estimate was 12 percent too small when the procedure was applied to data different from those used to estimate the coefficient $\mathrm{k}$ in $\mathrm{d}=\mathrm{kh}_{5}$. The effect, however, was to introduce less than 1 percent error in the predicted shore retreat.

Tab1e 3. Cross-validation indicates the effect of estimating pinch-out depth from wave climate data. Calculated estimates (hatted) are compared to measured values (nonhatted).

\begin{tabular}{|c|c|c|c|c|c|c|c|c|c|c|}
\hline & $\mathrm{h}_{5}$ & k & d & $\hat{\mathrm{d}}=1.96 \mathrm{~h}_{5}$ & Z & $\widehat{z}=d+D$ & $x$ & $\hat{x}=f(d)$ & $x=\frac{z X}{z}$ & $\hat{x}=\frac{z \hat{x}}{z}$ \\
\hline $\begin{array}{l}\text { Whole area } \\
\text { (stations } 1 \text { to } 29 \text { ) }\end{array}$ & 5.3 & 2.1 & 11 & ---- & $-\infty$ & - & $-\infty$ & -- & - & \\
\hline $\begin{array}{l}\text { Northern section } \\
(\text { stations } 1 \text { to } 15)^{1}\end{array}$ & 5.1 & 1.96 & 10 & $\cdots$ & --- & $-\infty$ & $-\infty$ & - & - & \\
\hline $\begin{array}{l}\text { Southern section } \\
\text { (stations } 16 \text { to } 29)^{2}\end{array}$ & 5.4 & -- & 12 & 10.56 & 14.8 & 13.36 & 1,020 & 928 & 13.78 & 13.89 \\
\hline Error & --- & $-\infty$ & - & $12 \%$ & --- & $10 \%$ & - & $9 \%$ & $--\infty$ & $<1 \%$ \\
\hline
\end{tabular}

${ }^{1}$ Used for an Independent determination of $k$.

${ }^{2}$ Used for error check by comparison with est1mates based on data from the northern section only.

To be realistically applied, the model should have input from many profiles spaced along a section of coast; as a consequence, there is little point in partitioning the present data set any further. The cross validation shown above does not reflect all the drawbacks of estimating the pinch-out depth from wave climate because, using adjacent sections of coast, it does not introduce the full range of bathymetric variability nor the range of wave environments within the lakes. How well wave climate estimates from widely different environments will perform remains uncertain. However, the prospects seem good and alternatives nonexistent. The model, should be applied cautiously, and wherever there is any indication of how well or poorly it worked, the results should be reported. 
a. Preliminary Check. Prior to any detailed evaluation of the variables required as input to the model, a preliminary examination of the profile shape near the presumed closure depth, d, will indicate how reliable these evaluations need to be. If the profile shape changes abruptly near this depth, then the choice of $d$ may strongly affect the resulting prediction, depending on whether the exact value chosen is above or below the break in slope (see Fig. $21, a)$. If, however, the bottom is planar and sloping at the right angle, the ratio of $\mathrm{Z} / \mathrm{X}$ and therefore the predicted retreat will be unaffected by variations in $d$ over a wide range. In such cases the exact value of $d$ used to evaluate equation (2) will be unimportant (Fig. 2l,b).

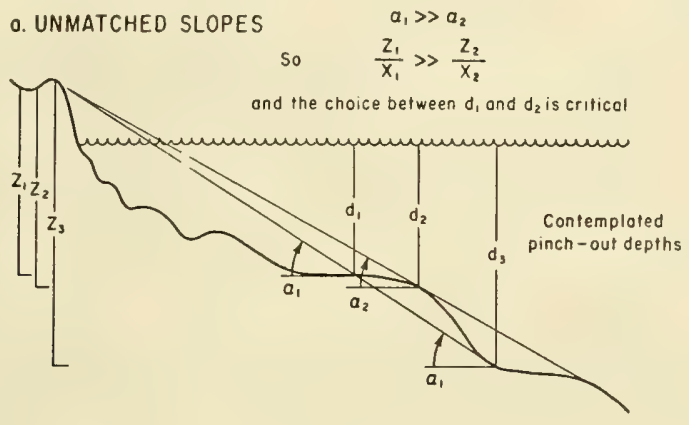

b. UNIFORM SLOPE $\quad a_{1}=a_{2}$

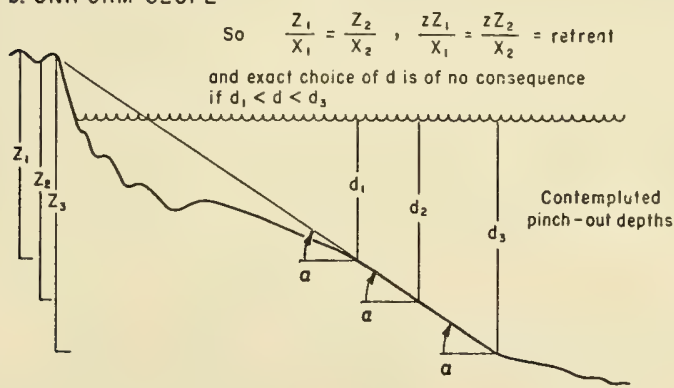

Figure 21. Importance of offshore slope. In case a the prediction of retreat will be much more sensitive to the correct selection of a pinch-out depth than in case b.

b. Is the Prediction Conservative? The evaluation of $d$ on the basis of wave data may result in an estimate of closure which the engineer feels is either too low or too high. Yet he may have no specific evidence on which to base another choice. The engineer should determine if the suspected error strengthens or weakens arguments based on the sediment balance model. Examination of profile shape resolves the possibilities as shown in Figure 22. 


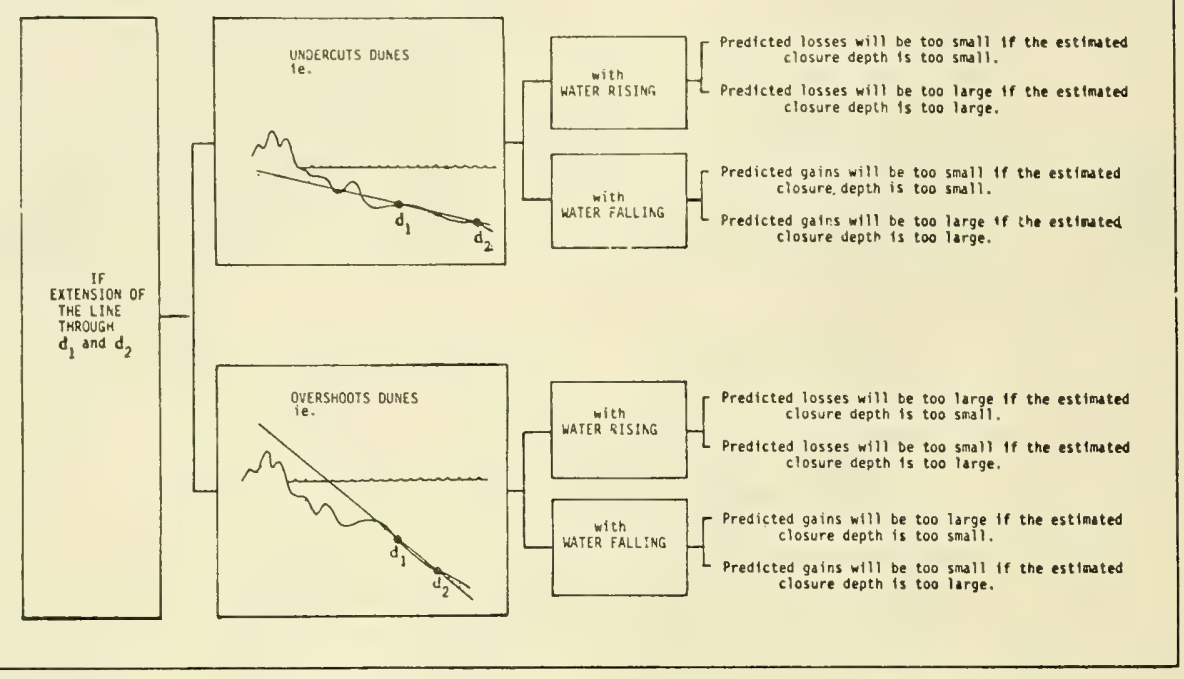

Figure 22. Diagram for determining if a suspected error weakens or strengthens arguments based on the sediment balance prediction.

If a line connecting two comtemplated closure depths extends below the average height of the dunes throughout the section of shore under study, then overestimating the closure depth causes equation (1) to overpredict the response; underestimating the closure causes equation (1) to underpredict the response. But, if the line extends above the dune height, then overestimating the closure underpredicts response and underestimating the closure overpredicts response. If the extended line intersects the dune crest, the prediction remains unaffected by the error in $d$. These relationsips will apply regardless of whether the predicted response is a retreat or an advance of the shore.

c. Idea1 Long-Term Development. The longshore variability in slope near a depth of $d$ is another item to check. If all profiles have the same offshore slope, $\alpha$, and if it is assumed that long-term recession unearthed deposits similar to the modern substrate and the wave climate has been stationary, then $\tan \alpha=\mathrm{Z} / \mathrm{X}$; i.e., $\alpha$ is not only the actual bottom slope, but also Hick's (1972) effective angle of shore response. Profile migration in response to rising water levels under these conditions would ideally leave a slope below its trailing edge which could serve as a clue to past recession. If the shore formerly supplied a greater volume of littoral material per unit of recession (because dunes or bluffs were higher or contained a larger percentage of suitable littoral material), then the slope beyond the trailing edge would tend to be convex. An increasing supply of sand would tend to produce a concave slope as erosion provides more and more sediment for each unit of recession. 
To simplify profile representation, many engineers fit a smooth curve to their data. Several possible physical mechanisms that would give rise to equilibrium profiles of the power-curve type have been described (e.g・, Bruun, 1964; Dean 1977). Other forms that sometimes fit profile data (e.g., logarithmic, parabolic, etc.) are, like the power curve, everywhere concave upward. There is a problem inherent in the use of such curves to represent profile response to changes in water level; e.g., Bruun (1964) found that the expression for offshore deposition, based on his adopted power curve, indicated an unrealistic thickening of the deposit offshore. Figure 23 and the following paragraph show why this and similar problems occur when a curve which is everywhere concave upward is adjusted according to equation (1).

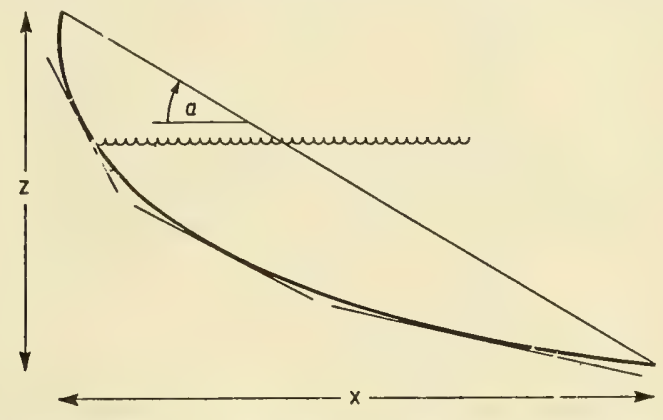

Figure 23. Limitations of analytical models with profiles everywhere concave up. Tangents will have only one point of intersection. On the other hand, the idea of exposing a trailing edge implies that the offshore slope equals $Z / X$, 1.e., the extension of the offshore slope must intersect the profile above the water surface. This is impossible if the profile is everywhere concave upward.

Adjusting an equilibrium curve to higher water leaves a trailing edge offshore. By assumptions, the projection of this surface toward the shore must intersect the profile again at the highest point of wave adjustment (see Fig. 21 ), but the tangent of any concave-upward profile will intersect it at only one point and everywhere else will be below the curve.

If it is assumed that the offshore slope gradually approaches $Z / X$ near the closure depth, then concave shapes only represent the inner part of the active profile. Manipulating such curves to represent adjustments to higher water levels inevitably leads to unrealistic consequences offshore.

d. Inferring Angle of Profile Adjustment from offshore Slope. As discussed previously, a uniformly sloped trailing edge suggests steady-state conditions (i.e., no significant change in wave climate, profile dimension, or sediment type). In such cases, direct inference from slope to retreat $(\mathrm{X} / \mathrm{Z} \sim \tan \alpha)$ is risky because forces other than wave-induced currents may have modified bottom slopes over the long timespan of profile recession. Furthermore, where the retreat is small relative to total width of the responding profile, the mean slope over this short distance is difficult to measure precisely. Lastly, exrors in estimating the critical depth would lead to measuring the slope at the wrong place. Nevertheless, it may be useful to consider the types of geometry implied by idealized profile adjustment, compare them with actual profile shapes, examine alternate explanations for 
observed shapes, and then evaluate the results in light of all the other evidence and indications at hand.

In cases where the only data are hydrographic surveys (and possibly wave climate but no data on backshore deposits) a crude first guess at the ratio of retreat to submergence could be made directly from the slope of an apparent trailing edge.

Uniformity of slope over a broad section of the critical depth on adjacent profiles is striking in present study areas (Fig. 24). The fact that this slope equals the ratio of measured retreat to lake level change $(x / z)$ does not necessarily follow from the observation that $x / z=X / Z$ (shown in Table 2), but it is an additional observation that further confirms the appropriateness of the sediment balance approach for long-term predictions on the Great Lakes.

The regional variation of profile slopes above the pinch-out depth (Fig. 25) reflects active processes which are not uniform alongshore. Rip currents and shoreline undulations are other expressions of such lateral variations. The marked divergence of slopes below the critical depth reflects deeper modern processes unrelated to surface wave action or relict processes inherited from a much earlier period of lake evolution.

\section{EXAMPLE PROBLEMS}

The following problems are evaluated on the basis of limited amount of available survey data. They provide examples of the basic steps in applying the proposed method for profile prediction. If these predictions were intended to support actual design or management decisions, a more careful evaluation of conditions at the field sites would be required.

$* * * * * * * * * * * * * * * *$ EXAMPLE PROBLEM $1 * * * * * * * * * * * * * * *$

GIVEN: A contemplated change in the regulation plan controlling the water supply to Lake Ontario would raise the long-term surface elevation 0.3 meter.

FIND: What effect would the higher stages have at the eastern end of Lake Ontario?

ANALYSIS: The barrier beaches and high dunes which characterize this stretch of shore are of special ecological and scenic value. Being downwind from the major storm paths across Lake Ontario these barrier beaches are exposed to the highest storm waves on the Great Lakes, but because of relatively low land development, few protective structures exist along this reach of the shore. Sand extends lakeward across a series of longshore bars. There are no known rock outcrops, and there is a close balance between southward and northward longshore transport.

EVALUATION OF TERMS:

$$
\begin{array}{rlrl}
\mathrm{z} & =0.3 \text { meter } & \text { Given } & \\
\mathrm{h}_{5} & =6.4 \text { meters } & \text { From site } 16 \text { (App. C) }
\end{array}
$$




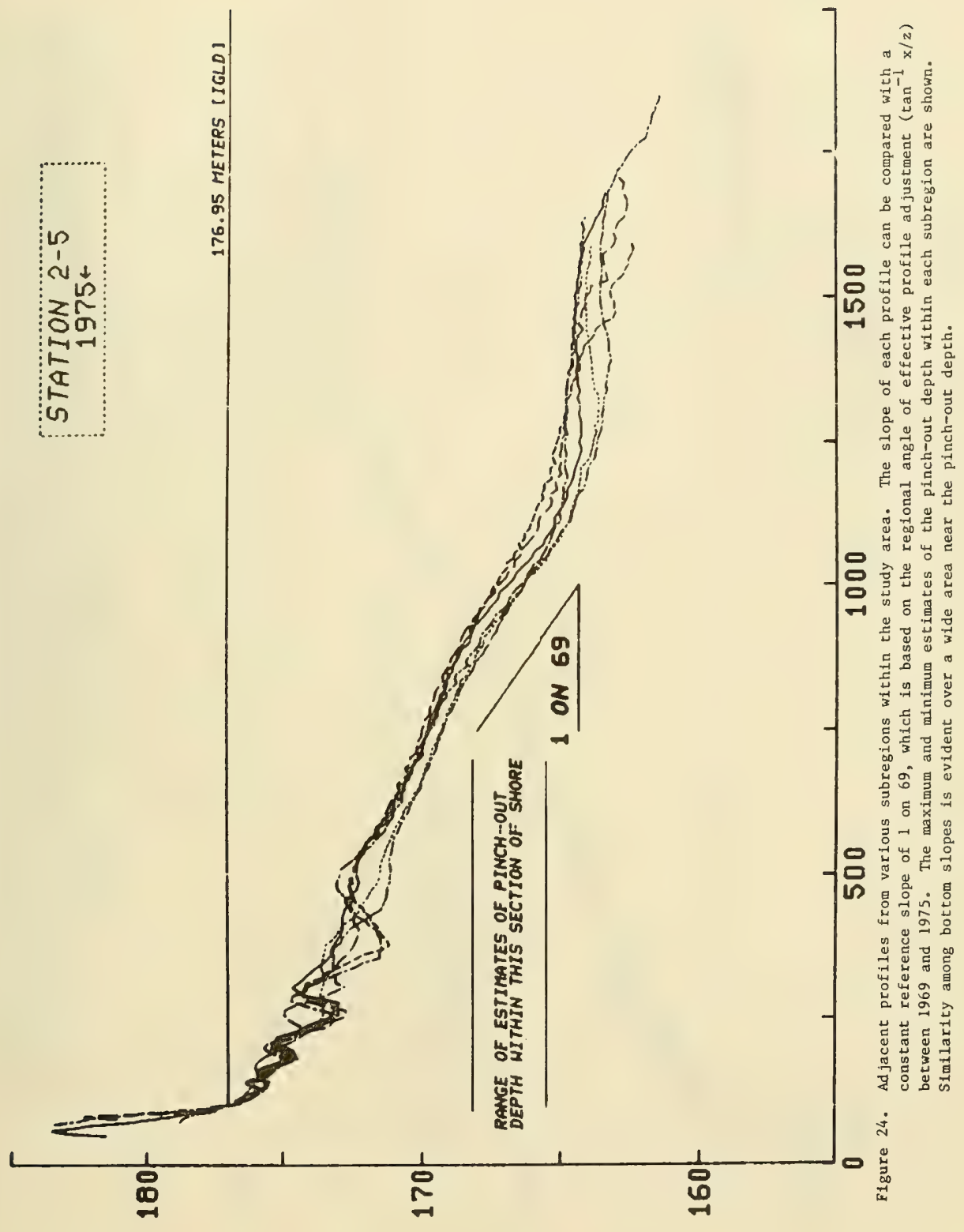




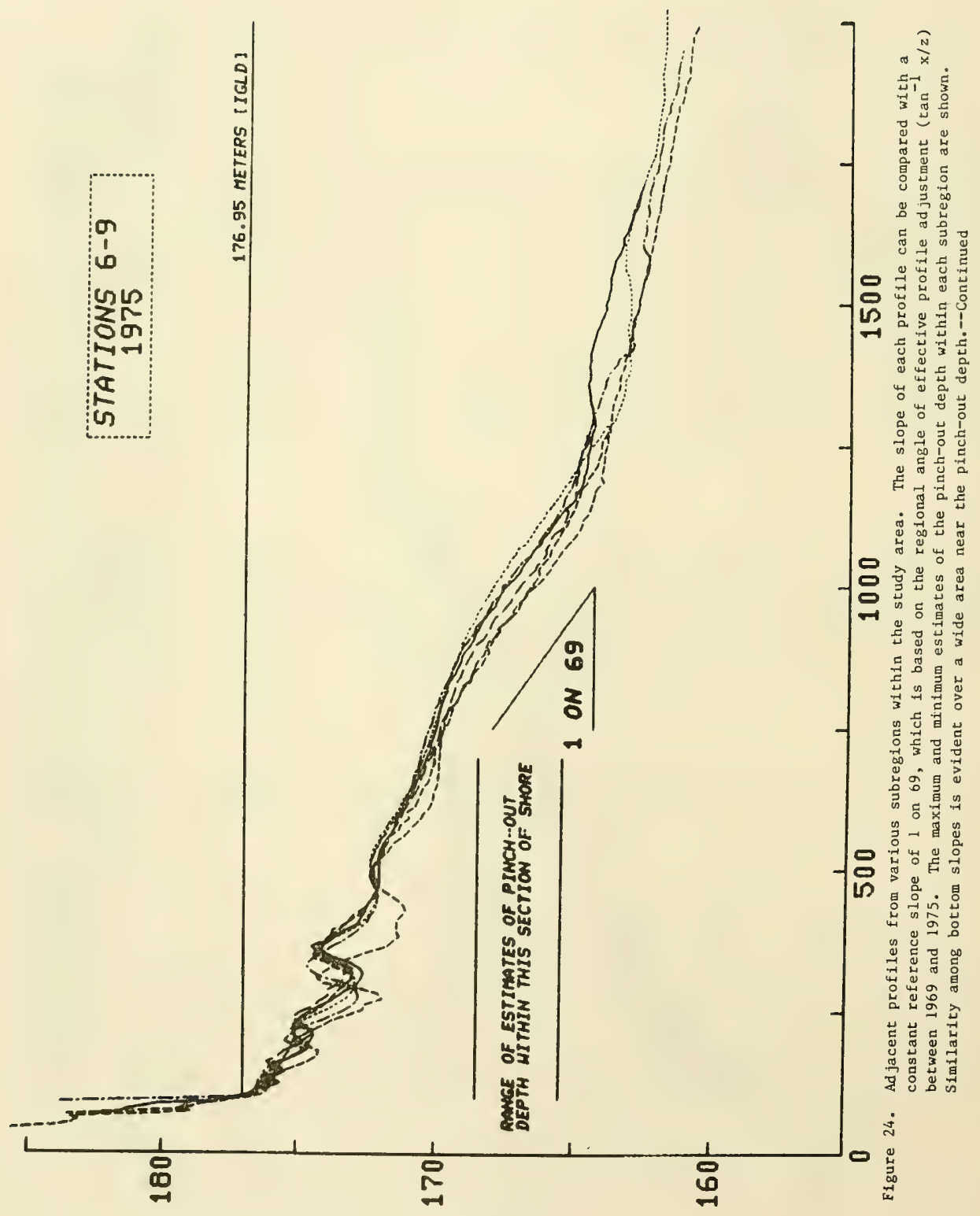




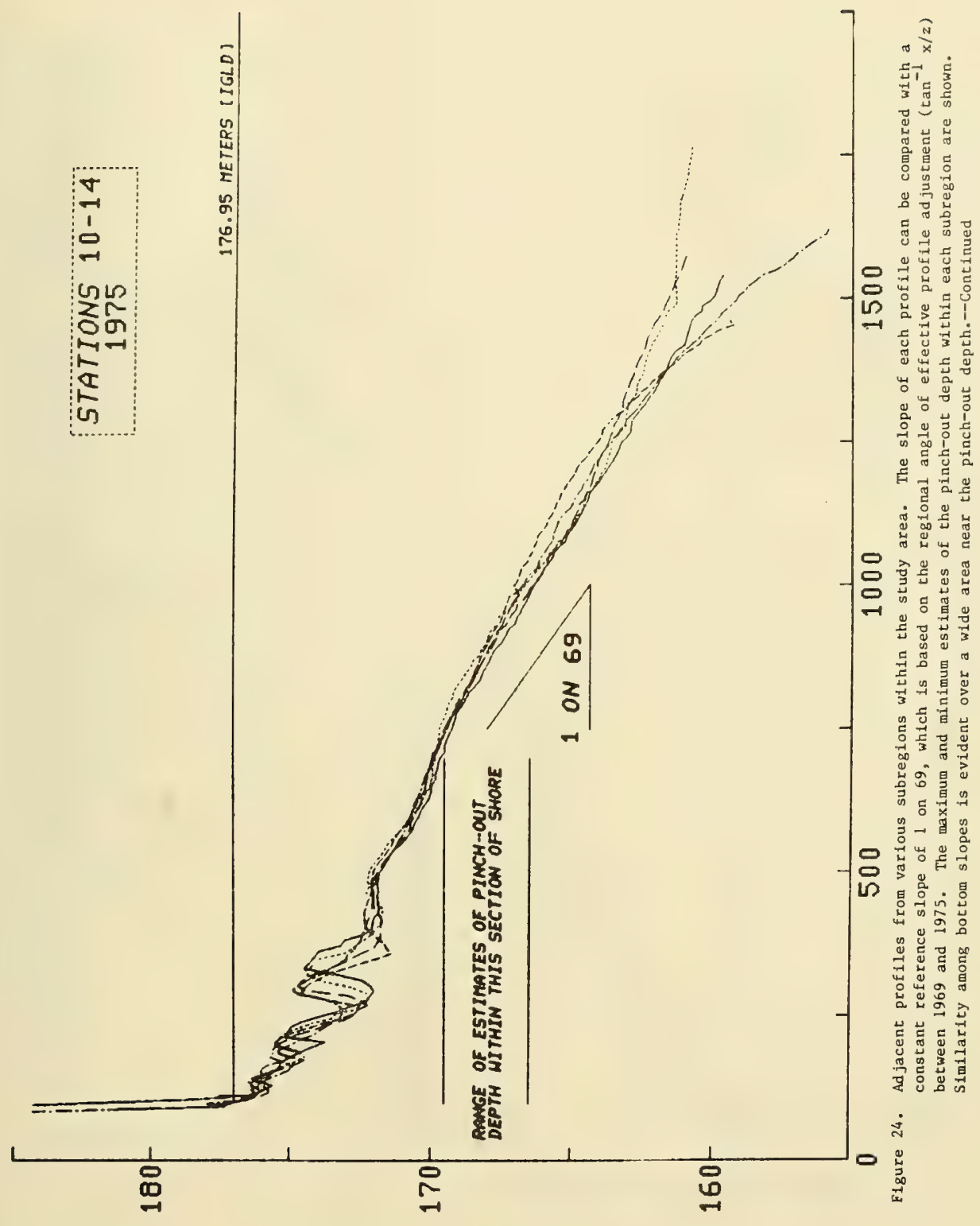




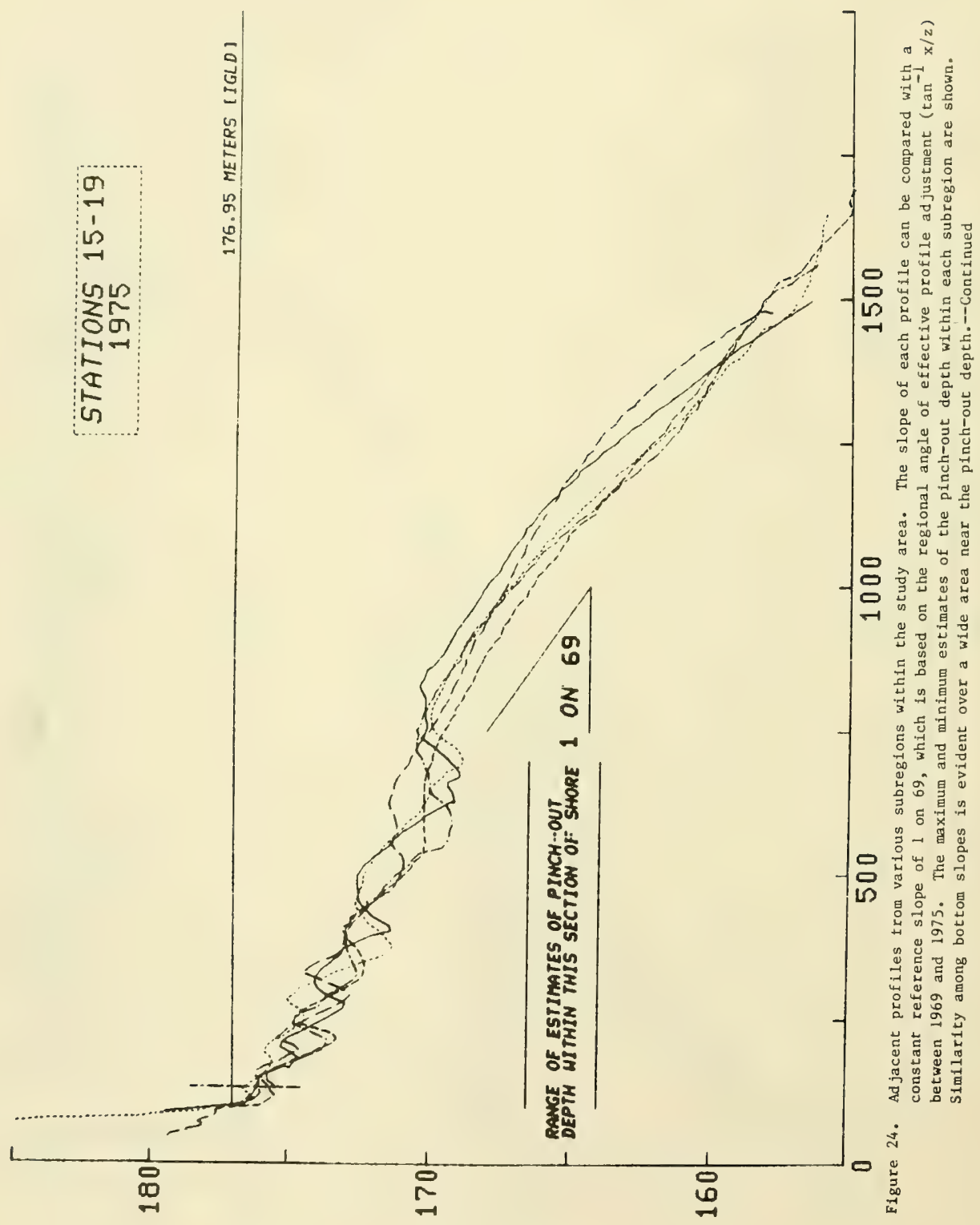




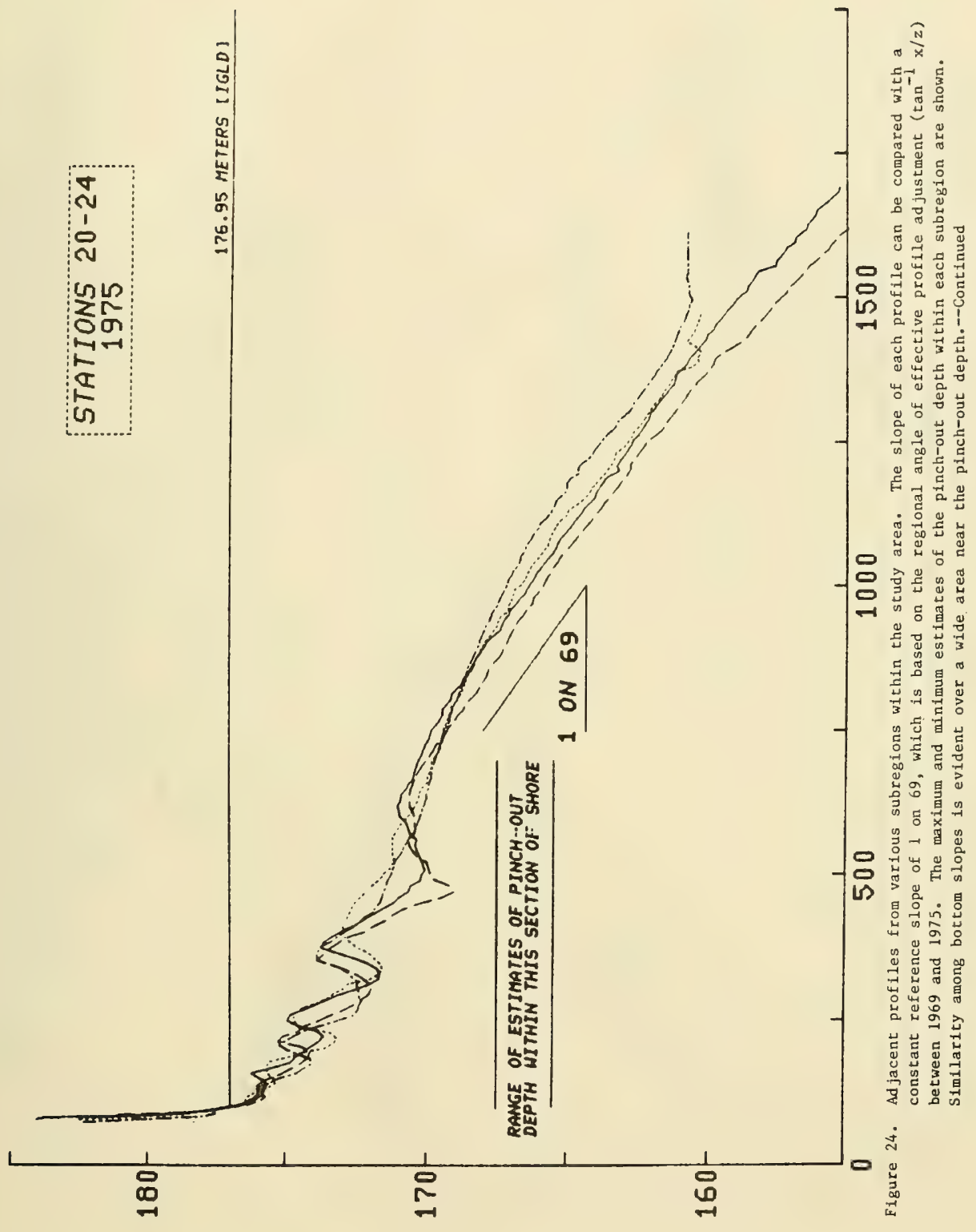




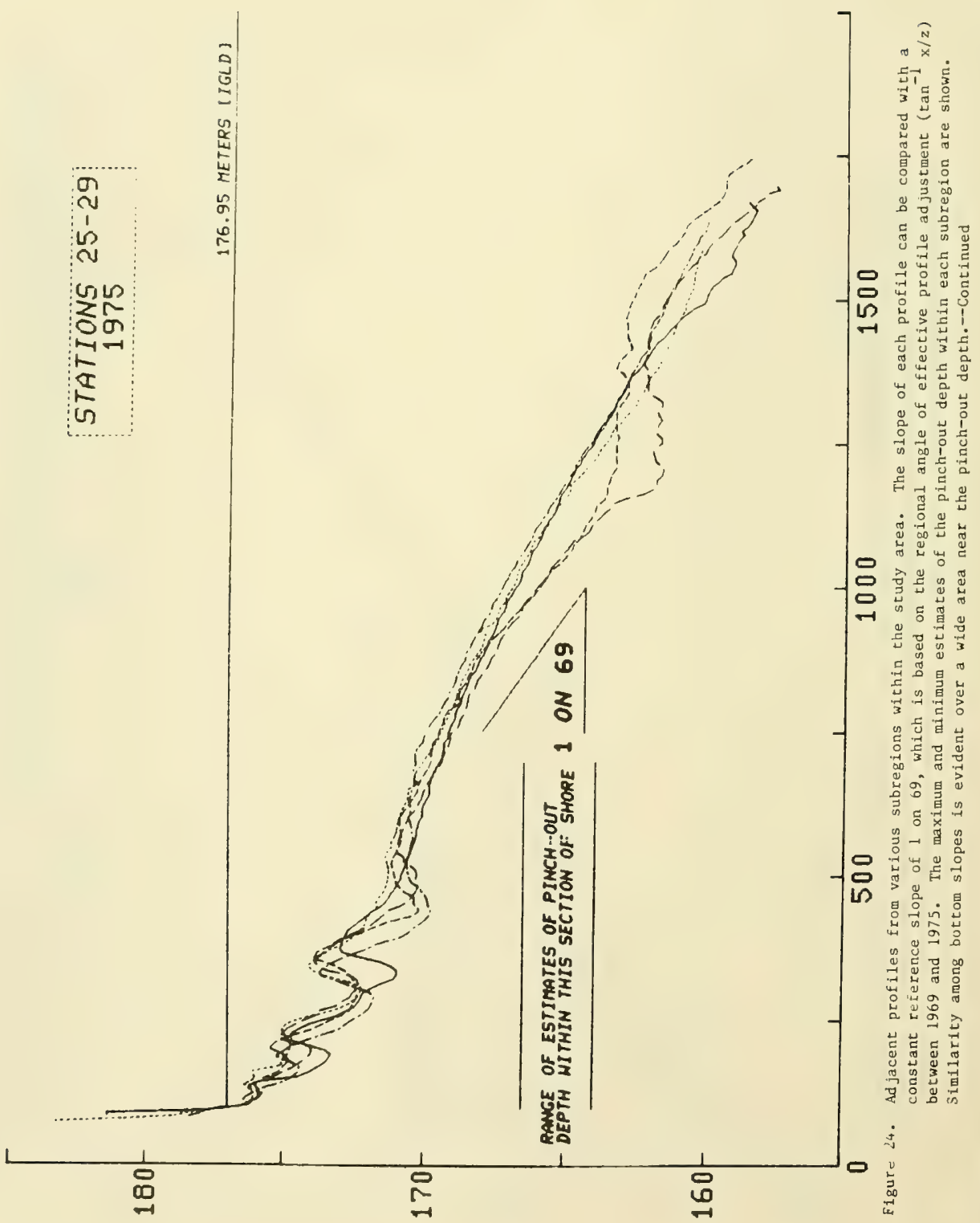




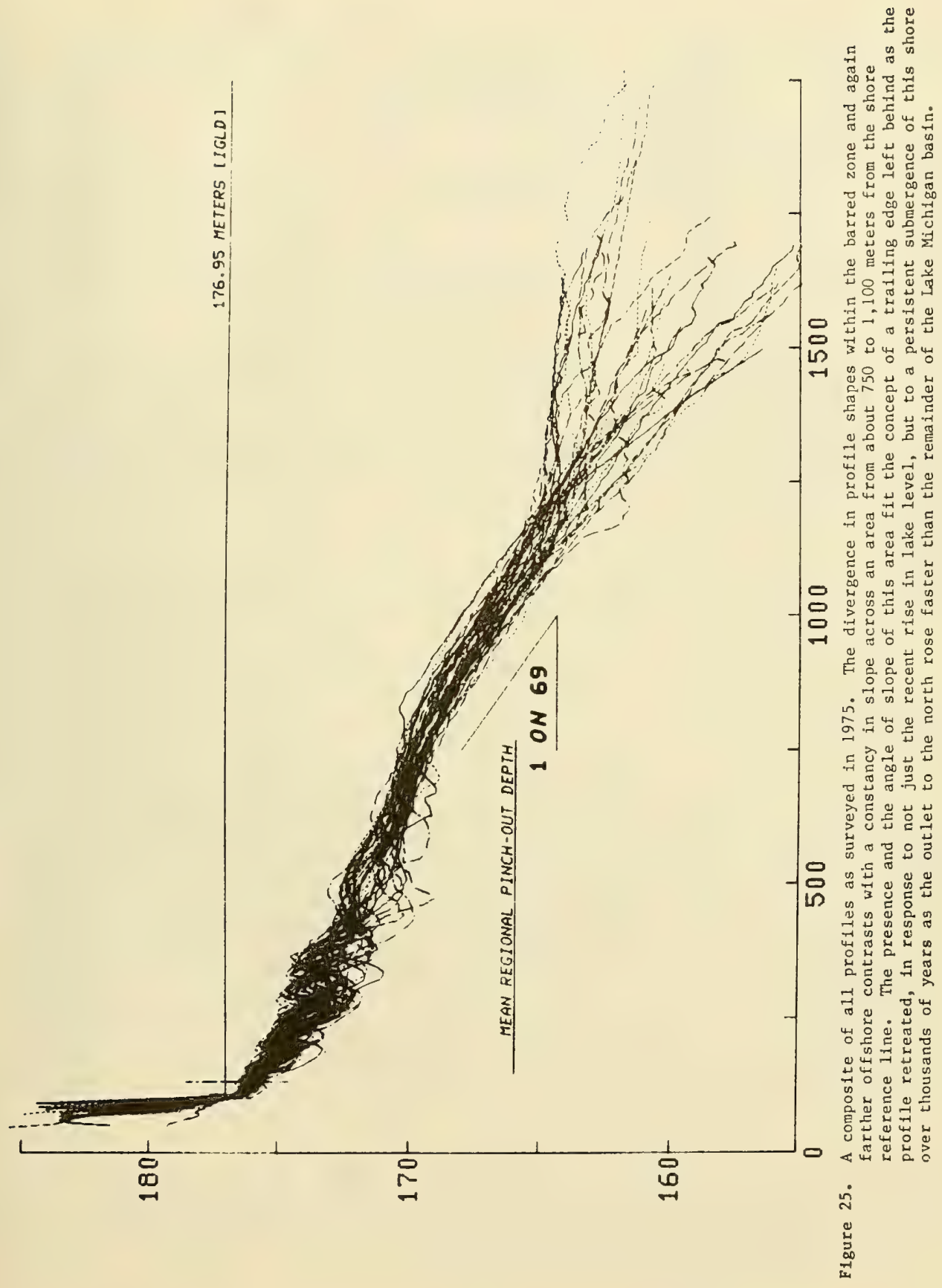




$$
\begin{aligned}
& 13.4 \text { meters } \\
& +7.6 \text { meters } \\
& Z=21 \text { meters } \\
& X=2,414 \\
& R_{A}=1 \\
& \text { Estimated closure depth } \hat{\mathrm{d}}=2.1 \mathrm{~h}_{5} \text { (from eq. 5) } \\
& \text { Average height of the eroding dunes above } \\
& \text { stillwater level. } \\
& \text { Sum of the two values obtained above. } \\
& \mathrm{x}=\frac{\mathrm{zX}\left(\mathrm{R}_{\mathrm{A}}\right)^{\mathrm{sg}(\mathrm{z})}}{\mathrm{Z}}=\frac{0.3(2,414) 1^{1}}{21}=34 \text { meters Evaluating equation }
\end{aligned}
$$

It is estimated that the higher stages shift the equilibrium shore profile an average of 34 meters inland and raise it 0.3 meter above present conditions.

$* * * * * * * * * * * * * * *$ EXAMPLE PRUBLEM $2 * * * * * * * * * * * * * * *$

GIVEN: Assume a new regulation plan is proposed to modify the inflow to Lake Michigan and Lake Huron via the St. Marys River. If adopted, this plan would lower the long-term mean surface elevation of Lake Michigan and Lake Huron by 0.3 meter.

FIND: What effect will the lower water levels have on shore erosion at the Indiana Dunes National Seashore?

ANALYSIS: The dredged channel and navigation structures at Michigan City, updrift of the Indiana Dunes National Seashore, block some of the potential sediment input from the east. Westward longshore transport out of the dune area thus creates a sand deficit and contributes to a long-standing erosion problem in the park. As lake levels fall the shoreline withdraws and the beach widens. Assuming lake currents and waves are not altered, they tend to reestablish the previous profile shape at a lower and more lakeward position. Longshore losses to the west continue to exceed the net supply from the east. However, offshore where the bottom slope is gradual, lowering of the water surface brings bottom sediments into a shallower hydraulic regime. This results in offshore sediments moving landward to steepen nearshore slopes, to build dunes on the widened beach, and to feed the longshore currents leaving the dune area to the west. The cumulative effects of these adjustments can be estimated using equation (1). See Hands (1979) for documentation of shore accretion during period of declining lake level.

EVALUATION OF TERMS:

$$
\begin{aligned}
& z=-0.3 \text { meter } \\
& h_{5}= 5.3 \text { meters } \\
& 11.1 \text { meters } \\
&+\quad 2.9 \text { meters }
\end{aligned}
$$

Given

Average from sites 28 and 29 (App. C)

Depth of profile closure $=2.1 \mathrm{~h}_{5}$ (from eq. 5)

Estimated average height of dunes expected to

form on the widened beach lakeward of the present foredune. 


$$
z=14 \text { meters Sum of the two values obtained above. }
$$

$$
\begin{aligned}
X=3,030 \text { meters Average distance of the 11.1-meter contour } \\
\text { from shore, based on field surveys. }
\end{aligned}
$$

$\mathrm{R}_{\mathrm{A}}=1 \quad$ Offishore sands are expected to move onshore, and the wind is not expected to carry sand inland past the present foredune.

$$
\mathrm{x}=\frac{\mathrm{zX}\left(\mathrm{R}_{\mathrm{A}}\right)^{\mathrm{Sg}(\mathrm{z})}}{\mathrm{Z}}=\frac{-0.3(3,030) 1^{-1}}{14}=-65 \text { meters Evaluating equation }(1)
$$

It is thus estimated that lowering the lake level 0.3 meter effectively shifts the equilibrium position 65 meters lakeward. As discussed, there will still be a net loss of sand due to net transport to the west; therefore, the actual shoreline is not expected to advance 65 meters lakeward. A reasonable interpretation is that there will be a long-term gain of 65 meters of beach that otherwise would have been lost by erosion at the previous water levels. Dividing 65 meters by the appropriate recession rate provides an estimate of when the avoided erosion would otherwise have occurred.

If 15 percent of the offshore sediments are in the clay- or silt-size range and are thought to be too fine to remain in the active shore zone, the width of shore saved should be reduced to $(1-0.15) \times 65$ meters $=55$ meters. Note that a liberal estimate of future dune heights, D, would also make the predicted savings more conservative.

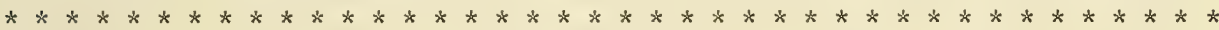

\section{SUMMARY}

Adjustments of the beach and the nearshore zone to long-term changes in lake level were monitored between 1967 and 1976 along a 50-kilometer stretch of shore centered on Little Sable Point, Michigan. The bathymetry of this region is marked by a sequence of four to five longshore bars which are persistent from year to year. The bars are continuous over tens of kilometers, though the pattern is disrupted in an area opposite Little Sable Point. In the cross section the bars are much less regular and snooth in an area 4 to 5 kilometers around this broad protrusion of the shoreline. The bars south of the point are deeper than to the north. Grain sizes throughout the study area, both on the beach and along the bar crests, decrease toward the point. The longshore transport converges toward the point. The tendency of profiles to be irregular in areas with an overabundance of sand has been noted elsewhere by Bruun (1962). The similarity and symmetry of the other patterns suggest a common dependence of all the discussed variables on long-term directional wave characteristics.

The longshore drift which converges on Little Sable Point is prinarily from areas encompassed by the study. So the fact that the longshore transport rates within the study area are not well known does not hinder the calculation of a net sediment balance for the overall region. The volume of material eroded from the upper beach over 4 years averaged 41 cubic meters per meter-length of 
shore. Zones of deposition of the material found offshore caused the cumulative volume measurement made along the profiles to increase toward zero. The cumulative volume curve typically crossed zero and displayed high positive values before settling toward a constant value far from shore. There was no tendency for imbalances on one profile to cancel opposite imbalances on directly adjacent profiles. However, considering the overall region, onshore losses closely matched offshore gains; there was no evidence of significant exchange beyond the surveyed area.

The general sequence of response to increased water levels includes immediate inundation, gradual migration of the longshore bar sequence up the beach slope, and increased shore recession (but at a rate dependent on storm events). Bar migration occurs even under relatively mild wave conditions. This tends to maintain constant bar depths even while the mean water elevation is changing. Consequently, the barred profile becomes compressed toward shore. The erosion of shore deposits and their redistribution lag behind the migration of the bars. Shore recession eventually reestablishes a wider separation between inner bars and the waterline. In the present instance, reversal of the lake level trend occurred before all the material deposited offshore was reshaped to reestablish relief on the outer bar comparable to that observed at the beginning of the study.

\section{CONCLUSION AND RECOMMENDATIONS}

Hands (1979) presented a set of shore retreat measurements made at the present profile stations over various periods of water level change. The average shore retreat for a given change in water level was approximately proportional to the amount which the water level had risen over that period of time. It was suggested that this linear dependence be used as a guide in estimating the effects of future lake level changes, not at a single profile station but for a reasonable stretch of similar shoreline responding to a similar submergence. Qualitative guidelines suggested how the estinates should be modified to reflect differences in sediment characteristics, erosional forces, and the length of time considered. Because the lake level and shoreline measurements referred to changes over the same time period, no allowance was made for the fact that the shore was probably out-of-phase or lagging behind the water level change. - It was, however, pointed out that some lag was inevitable and that the evidence indicated it could be on the order of a few years. The time required for complete readjustment would depend on the energy available for sediment redistribution.

A more comprehensive method of estimating profile response to high water is developed here using hydrographic survey data to extend the same beach profiles to depths of more than 12 meters. A simple sediment balance equation predicts the amount of retreat ultimately necessary to reestablish an equilibrium profile. Remackable agreement was found between the estimated ultimate retreat and that which actually accrued 3 years after lake levels stabilized. Realistically, the equilibrium model also overpredicted shore retreat for the shorter periods of sustained lake level rise before stabilization.

The choice of whether to adopt a linear relationship between retreat and submergence, making the qualitative adjustments as discussed in Hands (1979), or to apply the sediment balance approach presented here will depend on the timespan of interest, the amount of site-specific data available, and the 
similarity between test and problem conditions. Initial consideration of both estimates may be useful for placing high and low bounds on the expected response. Of the two, the equilibrium approach is more objective and flexible as it takes site-specific characteristics directly into account.

Both approaches must be qualified, however, for the possible exposure of nonsandy substrates, for the possibility of local intervention halting erosion and changing longshore balances, and for the conditions that existed before the period of application.

Results reported here are promising. However, the contrast between the extreme simplicity of the model and the intractable complexities of actual beach and nearshore processes emphasizes the need for careful application and further evaluation of these methods. Careful application during future lake level cycles should provide a clear indication of weaknesses and usefulness of these methods. If further research is then deemed necessary, the section of shore studied here would serve as a good test site, for reasons discussed in the text and because of the available past record. If such a study is necessary, plans should be made to extend the study over at least a full cycle of rising and falling lake levels with biennial surveys. The full longshore unit should be covered from the Ludington pumped storage facility to the White Lake jetties. The positions of station monuments used in the past studies are well documented and can be reoccupied, but supplementary profiles should be established between these sites because of the large variation in shore response observed between adjacent stations.

Because of the required profile length, boat positioning is critical. Methods other than the usual siting on surveyed range markers are necessary. The time of year for surveying is also important. A change in water temperature from $24^{\circ}$ to $13^{\circ}$ Celsius within 2 hours was noted during sounding operations in this study. Extreme temperature changes can affect the reproducibility of soundings. In the spring, as waters warm, a sharp temperature and acoustic gradient develops near the shore. Significantly cooler water is sometimes trapped in a series of pools between the longshore bars.

Even in late summer, when the thermocline is typically near 15 meters, a change in wind direction can quickly flush the nearshore zone of warm water and replenish a series of longshore pools with cold bottom water. Calibration of the sounding instrument with a reflector suspended over the side of the boat (a bar-check) should be done from the surface to the maximum profile depth, and in a water column essentially like that at the profile site. Variations which cannot be eliminated by field adjustments can be corrected during data reduction stages if careful notes are kept of bar-check results.

A good evaluation of the simple profile response model presented here should be relatively easy after the lakes have undergone another long-term cycle. However, obtaining the field data to significantly improve the situation would be a more difficult and expensive undertaking. 
BRUNO, R.O., and GABLE, C.G., "Longshore Transport at a Total Littoral Barrier," Proceedings of the 15th Coastal Engineeming Conference, American Society of Civil Engineers, 1976, pp. 1203-1222 (also Reprint 77-6, U.S. Army, Corps of Engineers, Coastal Engineering Research Center, Fort Belvoir, Va., NTIS A042 473).

BRUUN, P., "Sea-Level Rise as a Cause of Shore Erosion," Joumal of the Watemays, Harbors and Coastal Engineering Division, Vol. 88, No. WWl, Feb. 1962, pp. 117-130.

BRUUN, P., "Offshore Dredging Influence on Beach and Bottom Stability," The Dock and Harbor Authority. Vol. 45, No. 530, Dec. 1964, pp. 241-247.

DAVIS, R.A., Jr., and McGEARY, D.F.R., "Stability in Nearshore Bottom Topography and Sediment Distribution, Southeastern Lake Michigan," Proceedings of the Fighth Conference on Great Lakes Research, International Association for Great Lakes Research, Vol. 13, 1965, pp. 222-231.

DEAN, R.G., "Equilibrium Beach Profiles: U.S. Atlantic and Gulf Coasts," Ocean Engineering Technology Report No. 12, University of Delaware, Newark, Del., Jan. 1977.

EVANS, O.F., "The Low and Ball of the Eastern Shore of Lake Michigan," Joumal of Geology, Vol. 48, No. 5, July 1940, pp. 476-511.

FENNEMAN, N.M., "Development of the Profile of Equilibrium of the Subaqueous Shore Terrace," Toumal of Geology, Vol. X, 1902, pp. 1-32.

HALLERMEIER, R.J., "Calculating a Yearly Limit Depth to the Active Beach Profile," TP 77-9, U.S. Army, Corps of Engineers, Coastal Engineering Research Center, Fort Belvoir, Va., Sept. 1977.

HANDS, E.B., "A Geomorphic Map of the Lake Michigan Shoreline," Proceedings of the 13th Conference on Great Lakes Research, Part 1, 1970, pp. 250-265.

HANDS, E.B., "Observations of Barred Coasta1 Profiles Under the Influence of Rising Water Levels, Eastern Lake Michigan, 1967-71," TR 76-1, U.S. Ariny, Corps of Engineers, Coastal Enyineering Research Center, Fort Belvoir, Va., Jan. 1976a.

HANDS, E.B., "Some Data Points on Erosion and Flooding for Subsiding Coastal Regions," Proceedings of the Second Internationat Symposizm on Land Subsidence, Dec. 1976b (also Reprint 78-11, U.S. Army, Corps of Engineers, Coastal Engineering Research Center, Fort Belvoir, Va., NTIS A051 796).

HANDS, E.B., "Changes in Rates of Shore Retreat, Lake Michigan, 1967-76," TP 79-4, U.S. Army, Corps of Engineers, Coastal Engineering Research Center, Fort Belvoir, Va., Dec. 1979.

HARTNACK, W., "Uber Sandriffe, Jabresber," Geogr. Ges. GrisswaZd, XL-XLIII, 1924.

HAYES, M.0., "Hurricanes as Geologic Agents: Case Studies of Hurricanes Carla, 1961, and Cindy, 1963," Report 61, Bureau of Economic Geology, University of Texas, Austin, Tex., 1967. 
HICKS, S.D., "On the Classification and Trends of Long Period Sea Level Series," Shore and Beach, Vol. 40, Apr. 1972, pp. 20-23.

HoUGH, J.L., Geology of the Great Lakes, University of Illinois Press, Urbana, I11., 1958.

HULSEY, J.D., "Beach Sediments of Eastern Lake Michigan," Ph.D. Thesis, University of Illinois, Urbana, I11., 1962.

INTERNATIONAL GREAT LAKES LEVELS BOARD, "Regulation of Great Lakes Water Levels," International Joint Commission, Chicago, Ill., Dec. 1973.

KEULEGAN, G.H., "An Experimental Study of Submarine Sand Bars," TR-3, U.S. Army, Corps of Engineers, Beach Erosion Board, Washington, D.C., Aug. 1948.

KING, C.A.M., and WILLIAMS, W.W., "The Formation and Movement of Sand Bars by Wave Action," Joumal of Geography, Vol. 113, June 1949, pp. 70-85.

KNAPS, R.J., "The Development of Submarine Bars," Proceedings of the Second Intemational Oceanographic Congress, Moscow, U.S.S.R., 1966, pp. 196-197.

LIU, P.C., and HOUSLEY, J.C., "Visual Wave Observations Along the Lake Michigan Shore," Proceedings of the 12 th Conference on Great Lakes Research, International Association for Great Lakes Research, 1969, pp. 608-621.

MAGOON, 0.T., and SARLIN, W.0., "Effect of Long Period Waves on Hydrographic Surveys," Proceedings of the 12th Coastal Engineering Conference, American Society of Civil Engineers, 1970, pp. 2251-2265 (also Reprint 8-71, U.S. Army, Corps of Engineers, Coastal Engineering Research Center, Washington, D.C., NTIS 732 609).

NATIONAL OCEANIC AND ATMOSPHERIC ADMINISTRATION, "Summary of Synoptic Meteorological Observations for Great Lakes Areas," Vol. 3, National Climatic Center, Ashville, N.C., Jan. 1975.

PORE, N.A., et al., "Wave Climatology for the Great Lakes," Technical Menorandum NWS TDL-40, National Oceanic and Atmospheric Administration, National Weather Service, Silver Spring, Md., Feb. 1971.

RESIO, D.T., and VINCENT, C.L., "Lake Erie," Report 1, Technical Report H-761, Design Wave Information for the Great Lakes, U.S. Army Engineer Waterways Experiment Station, Vicksburg, Miss., Jan. 1976a.

RESIO, D.T., and VINCENT, C.L., "Lake Ontario," Report 2, Technical Report H-76-1, Design Wave Information for The Great Lakes, U.S. Army Engineer Waterways Experiment Station, Vicksburg, Miss., Mar. 1976 b.

RESIO, D.T., and VINCENT, C.L., "Lake Michigan," Report 3, Technical Report H-76-1, Design Wave Information for the Great Lakes, U.S. Army Engineer Waterways Experiment Station, Vicksburg, Miss., Nov. 1976c.

RESIO, D.T., and VINCENT, C.L., "Lake Huron," Report 4, Technical Report H-76-1, Design Wave Information for the Great Lakes, U.S. Army Engineer Waterways Experiment Station, Vicksburg, Miss., Sept. 1977. 
RESIO, D.T., and VINCENT, C.L., "Lake Superior," Report 5, Technical Report H-76-1, Design Wave Information for the Great Lakes, U.S. Army Engineer Waterways Experiment Station, Vicksbury, Miss., June 1978.

ROSEN, P.S., "A Regional Test of the Bruun Rule on Shoreline Erosion," Marine Geology, Vol. 26, Jan. 1978, pp. M7-M16.

SAVILlE, T., Jr., "Wave and Lake Level Statistics for Lake Michigan," TM-36, U.S. Army, Corps of Engineers, Beach Erosion Board, Washington, D.C., Mar. 1953.

SAYLOR, J.H., and HANDS, E.B., "Properties of Longshore Bars in the Great Lakes," Proceedings of the 12th Conference on Coastal Engineering, American Society of Civil Engineers, Vol. 2, 1970, pp. 839-853.

SCHWARTZ, R.K., "Nature and Genesis of Some Storm Washover Deposits," TM-61, U.S. Army, Corps of Engineers, Coastal Engineering Research Center, Fort Belvoir, Va., Dec. 1975.

SEELIG, W.N., and SORENSEN, R.M., "Shoaling of a Great Lakes Inlet," Shore and Beach, Vo1. 44, Apr. 1976, pp. 20-24.

U.S. ARMY ENGINEER DISTRICT, DETROIT, "Section IIL Detailed Project Report on Shore Damage at Holland Harbor, Michigan," Detroit, Mich., May 1975a.

U.S. ARMY ENGINEER DISTRICT, DETROIT, "Section III Detailed Project Report on Shore Damage at Muskegon Harbor, Michigan," Detroit, Mich., Nov. 1975 .

U.S. ARMY ENGINEER DISTRICT, DETROIT, "Section III Detailed Project Report on Shore Damage at Grand Haven Harbor, Michigan," Detroit, Mich., Jan. 1976a.

U.S. ARMY ENGINEER DISTRICT, DETROIT, "Section IIL Detailed Project Report on Shore Damage at White Lake Harbor, Michigan," Detroit, Mich., Feb. 1976b.

U.S. ARMY ENGINEER DISTRICT, DETROIT, "Section III Detailed Project Report on Shore Damage at Frankfort Harbor, Michigan," Detroit, Mich., Sept. 1976c.

WEGGEL, J.R., "Results of Littoral Environmental Observations for the East Shore of Lake Michigan," U.S. Army, Corps of Engineers, Coastal Engineering Research Center, Fort Belvoir, Va., unpublished, Apr. 1979. 


\section{APPFNDIX A}

SHORE AND NFARSHORF PROFTLES IN THF ARFA OF LITTLF SARLE POLNT, MICHIGAN, 1967 to 1976. 


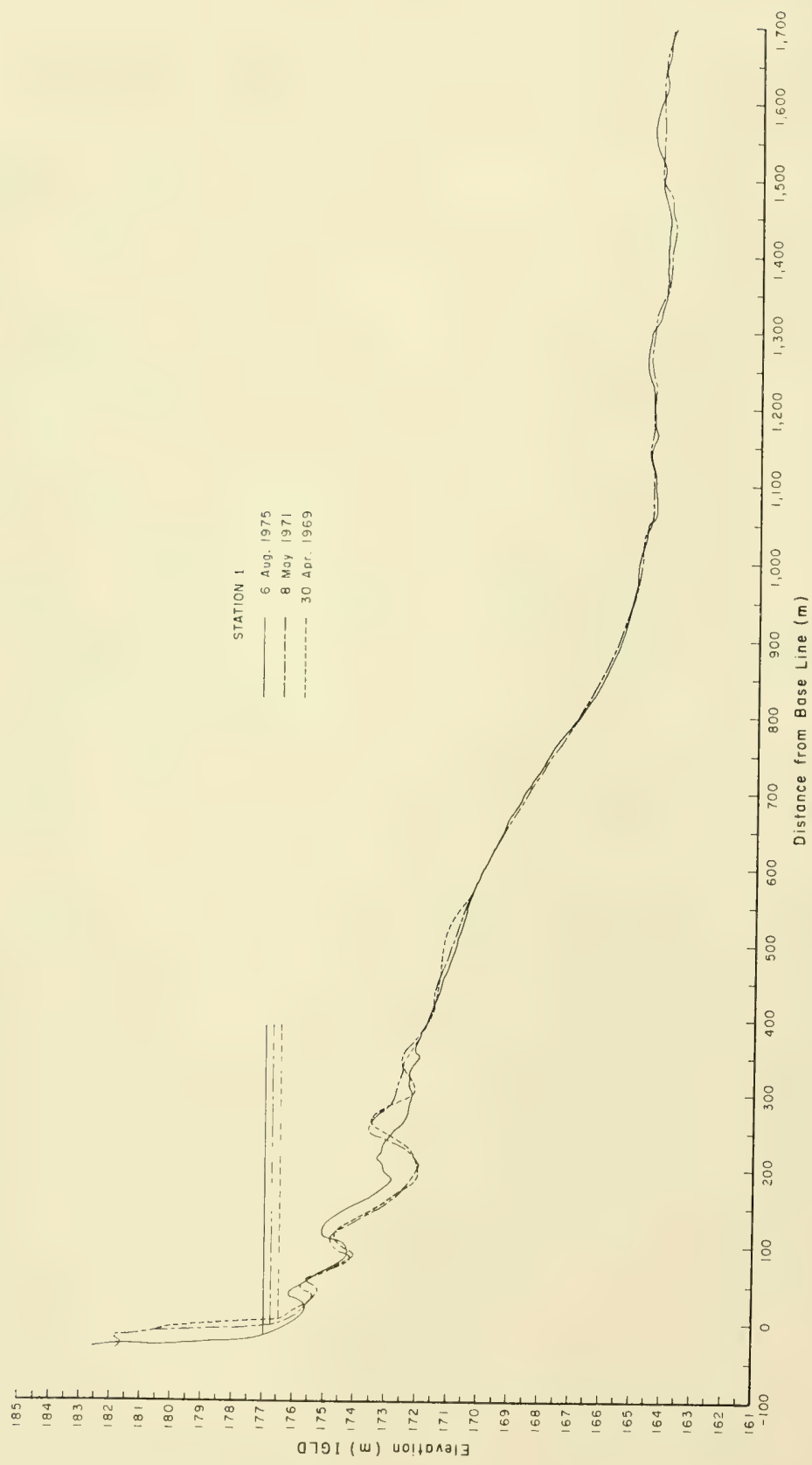




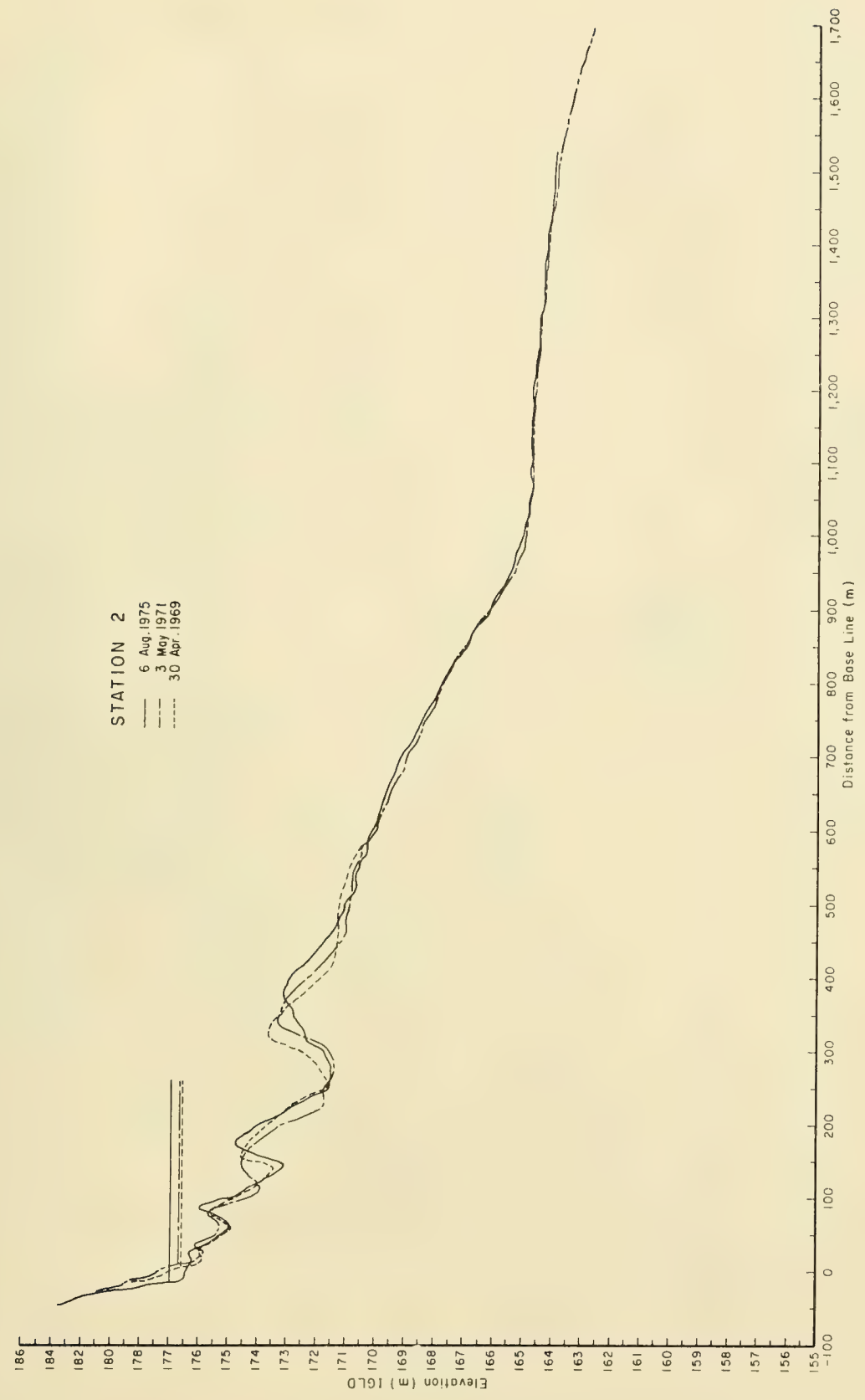




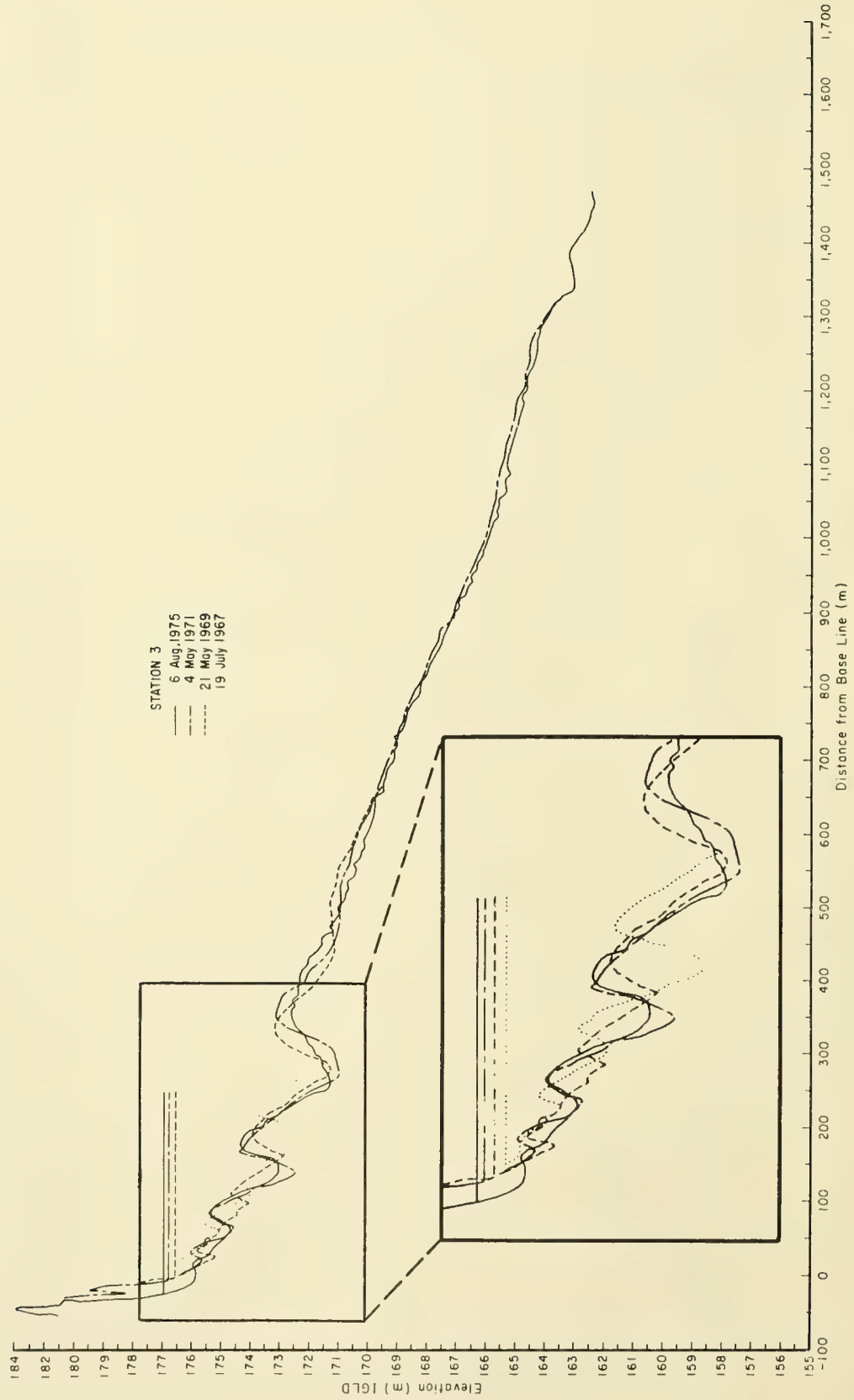




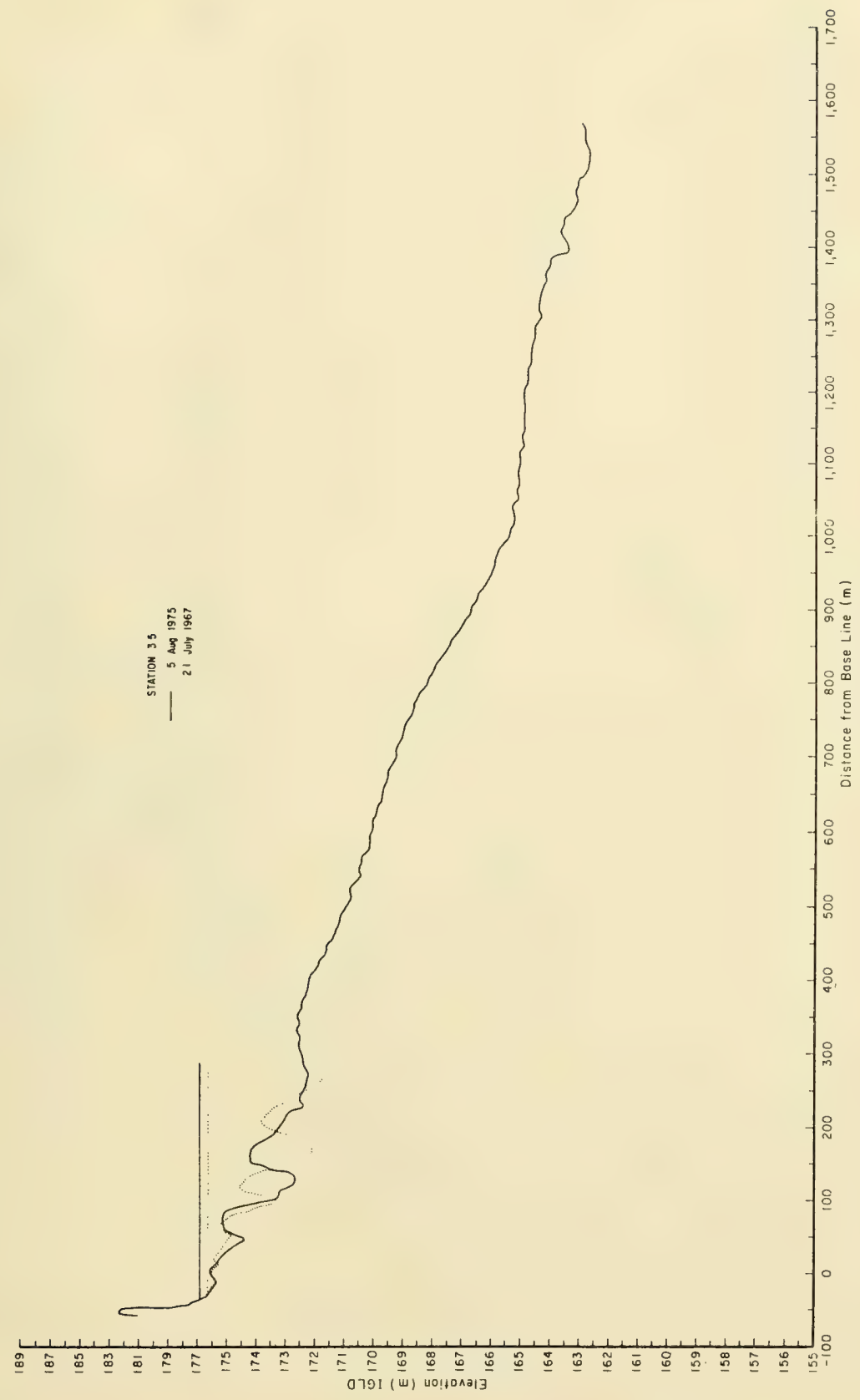




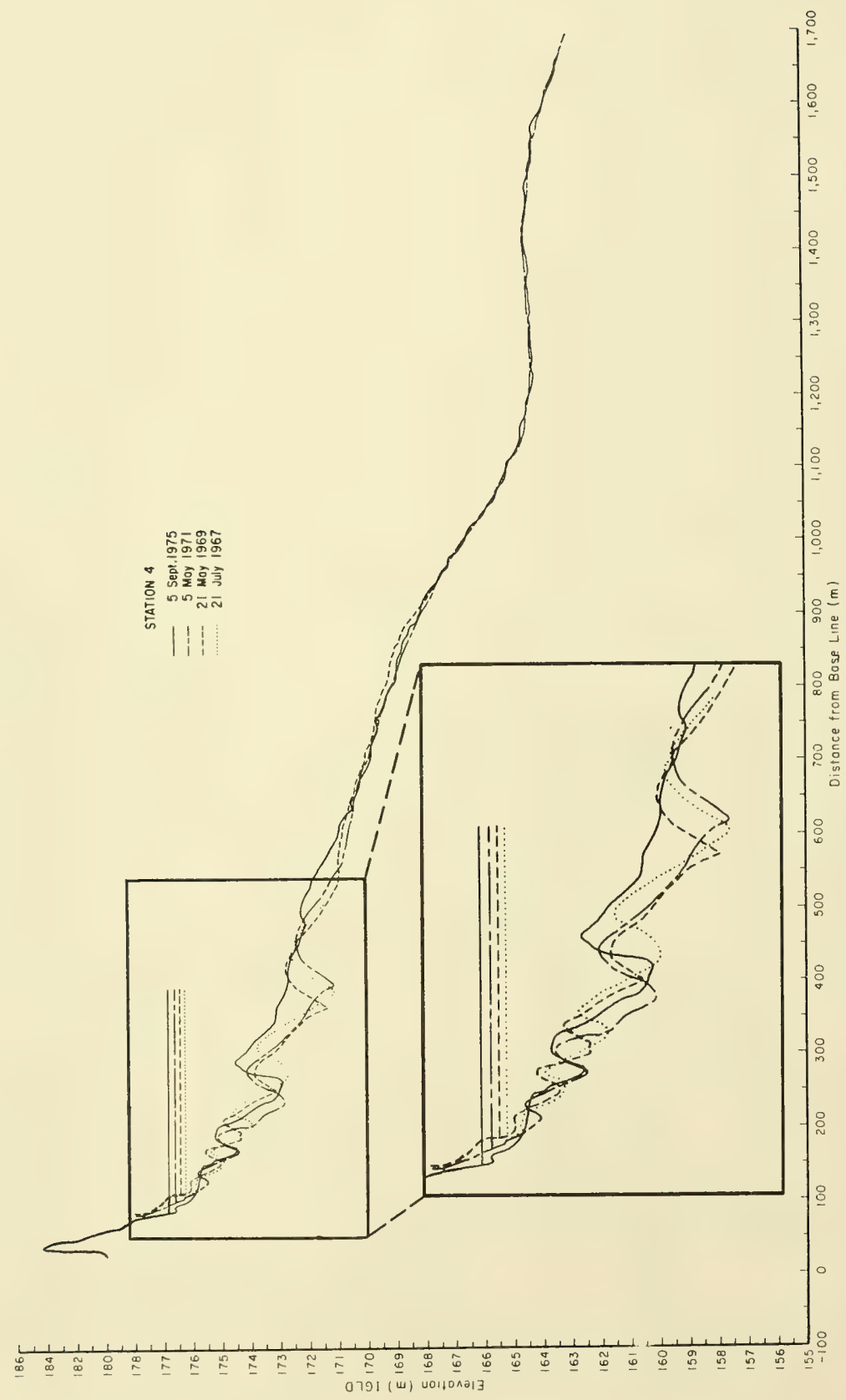




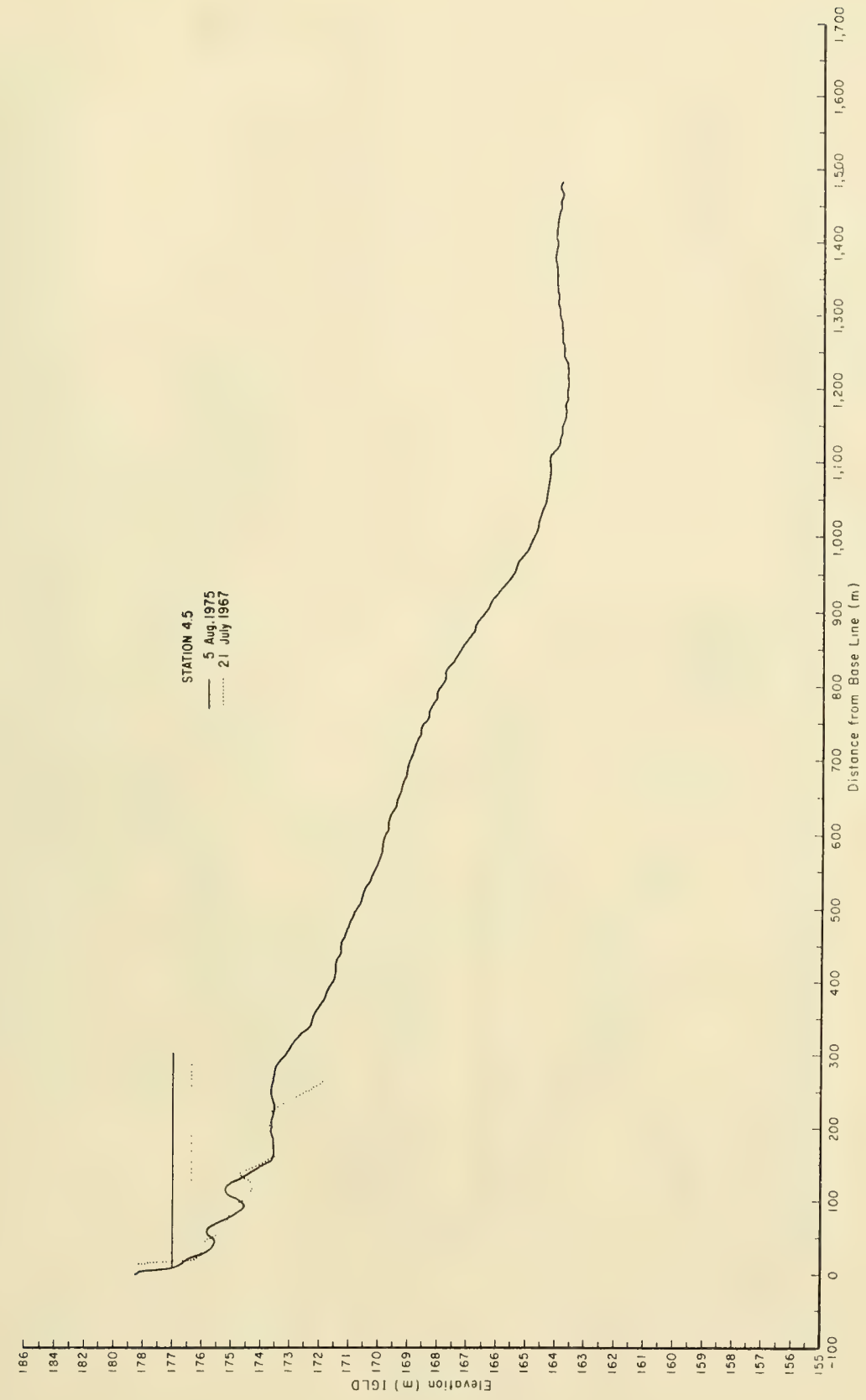




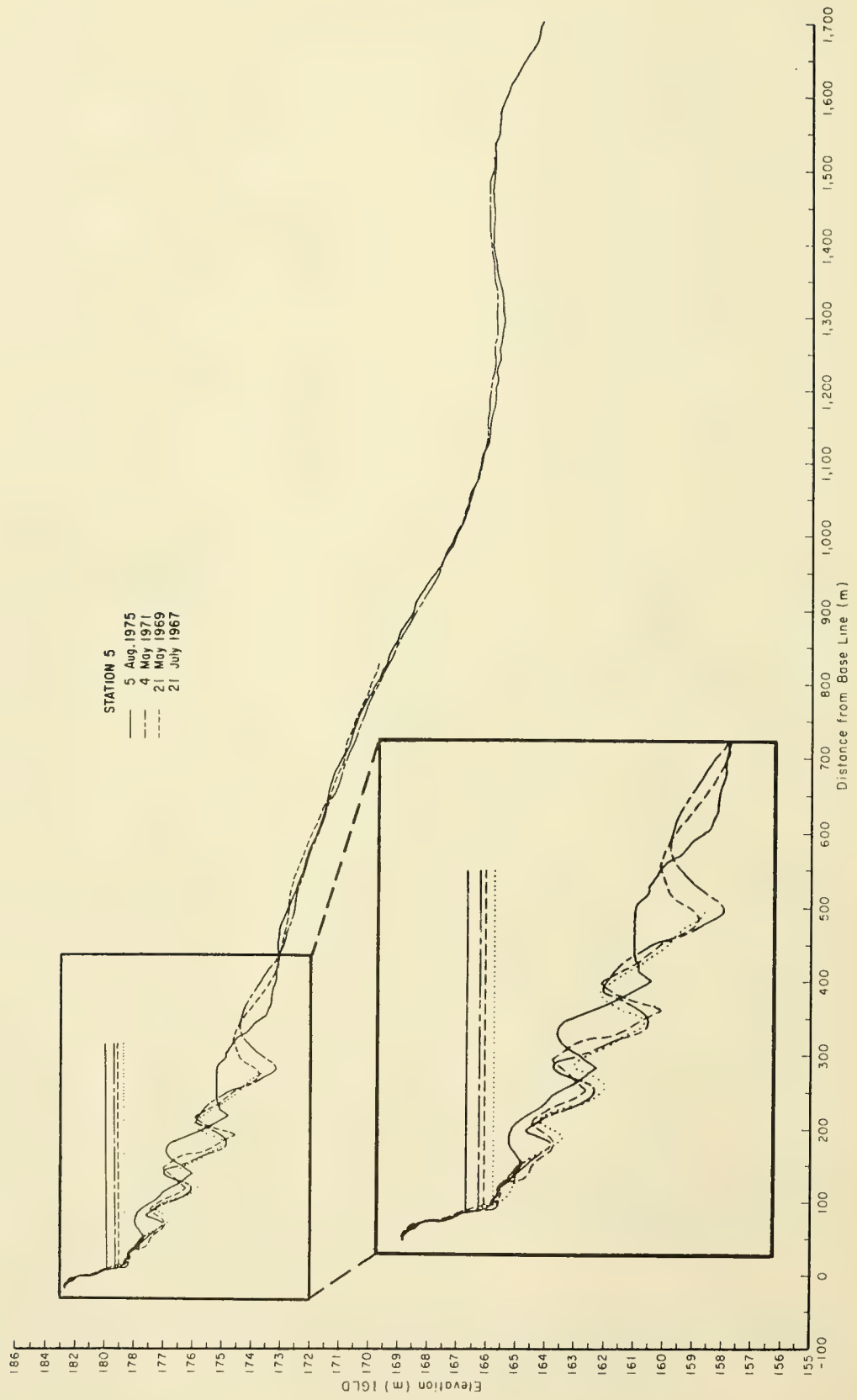




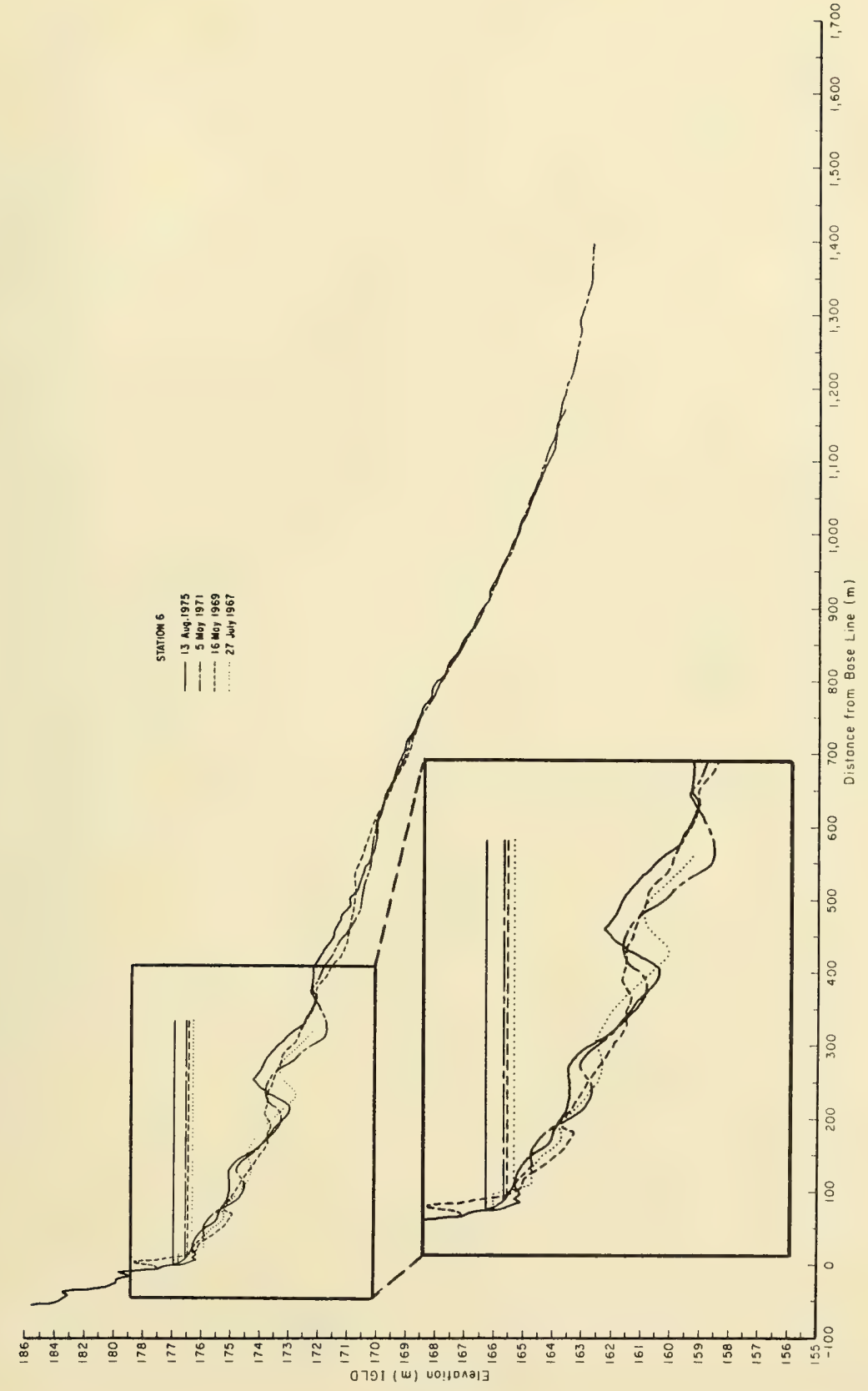




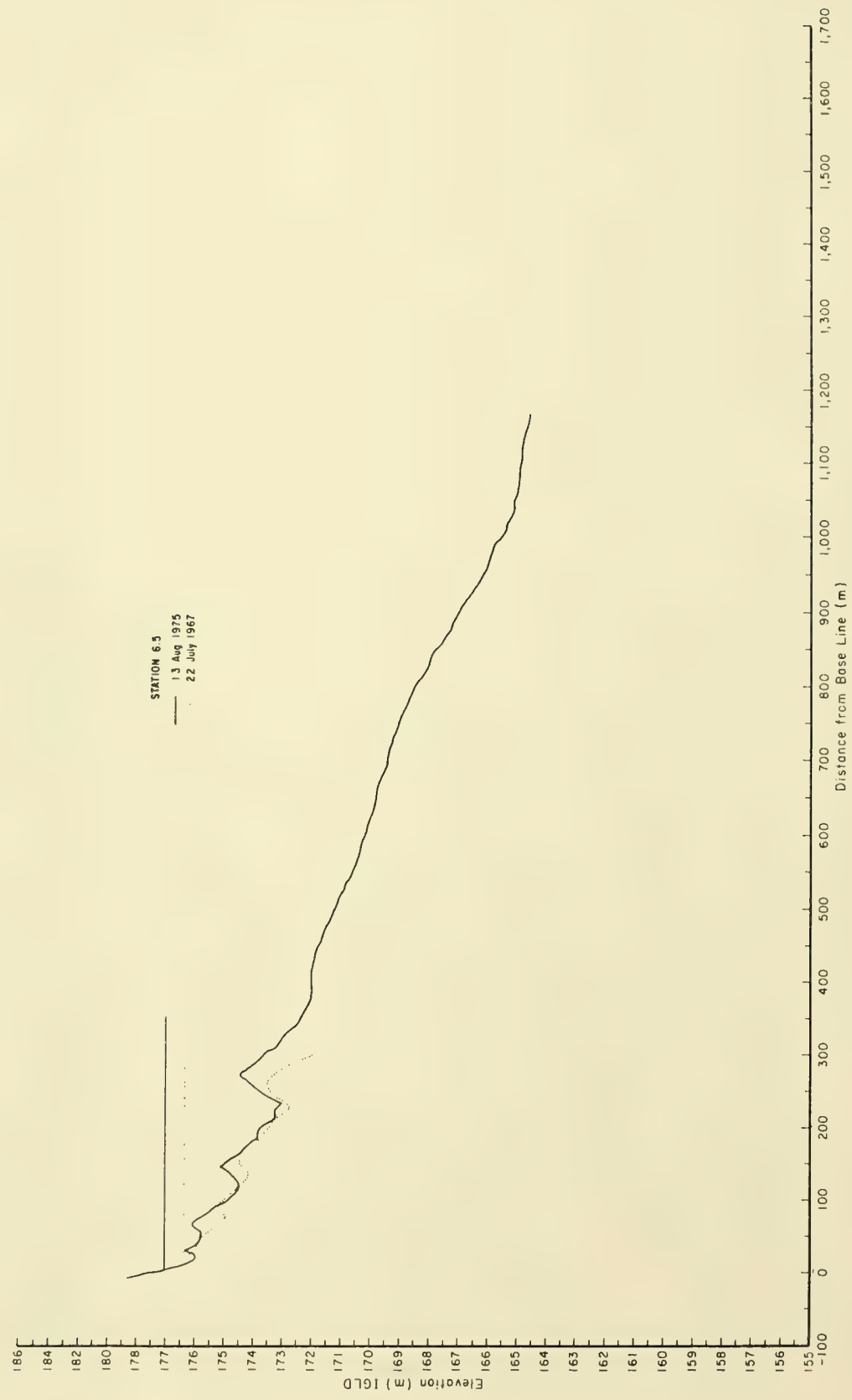




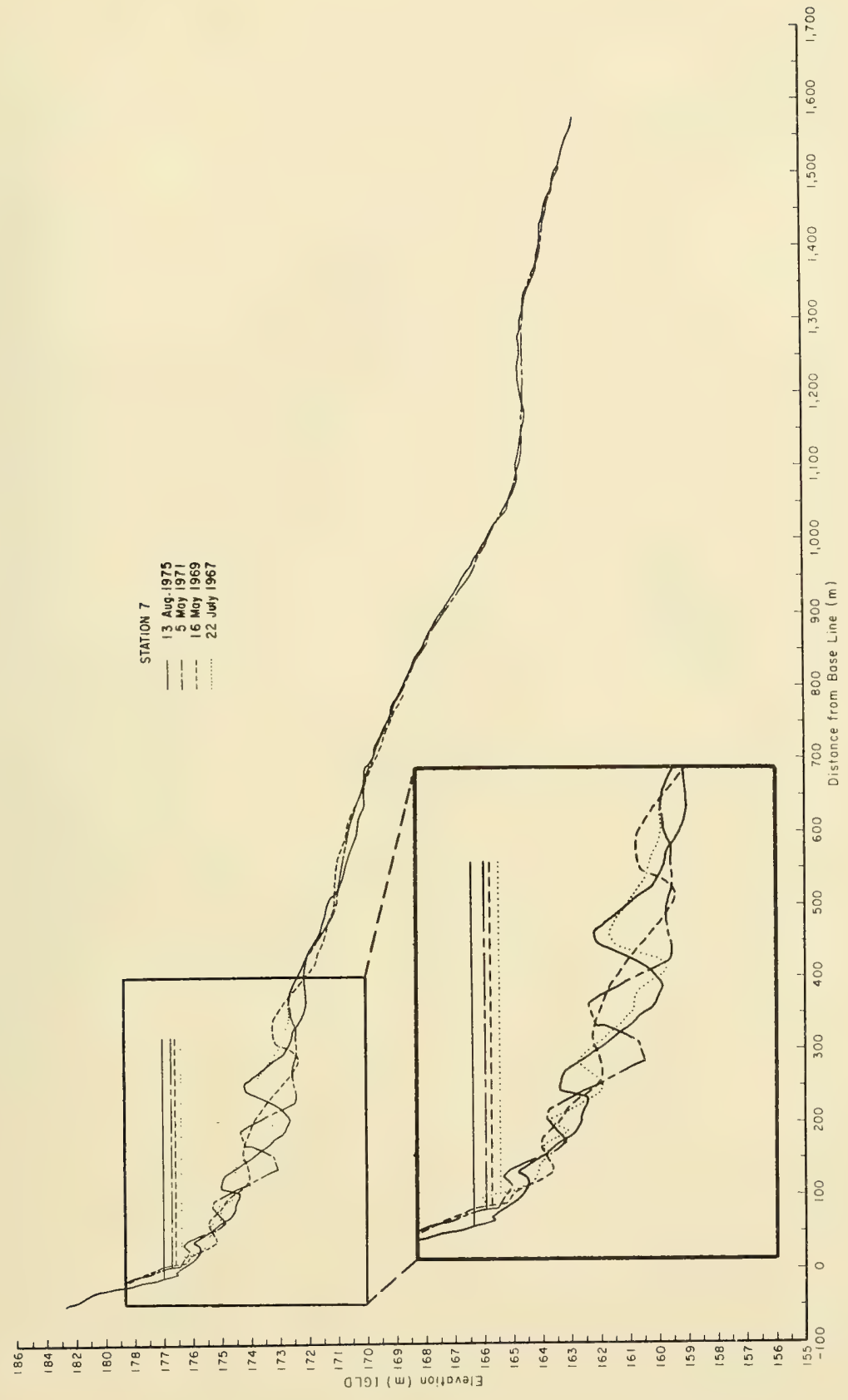




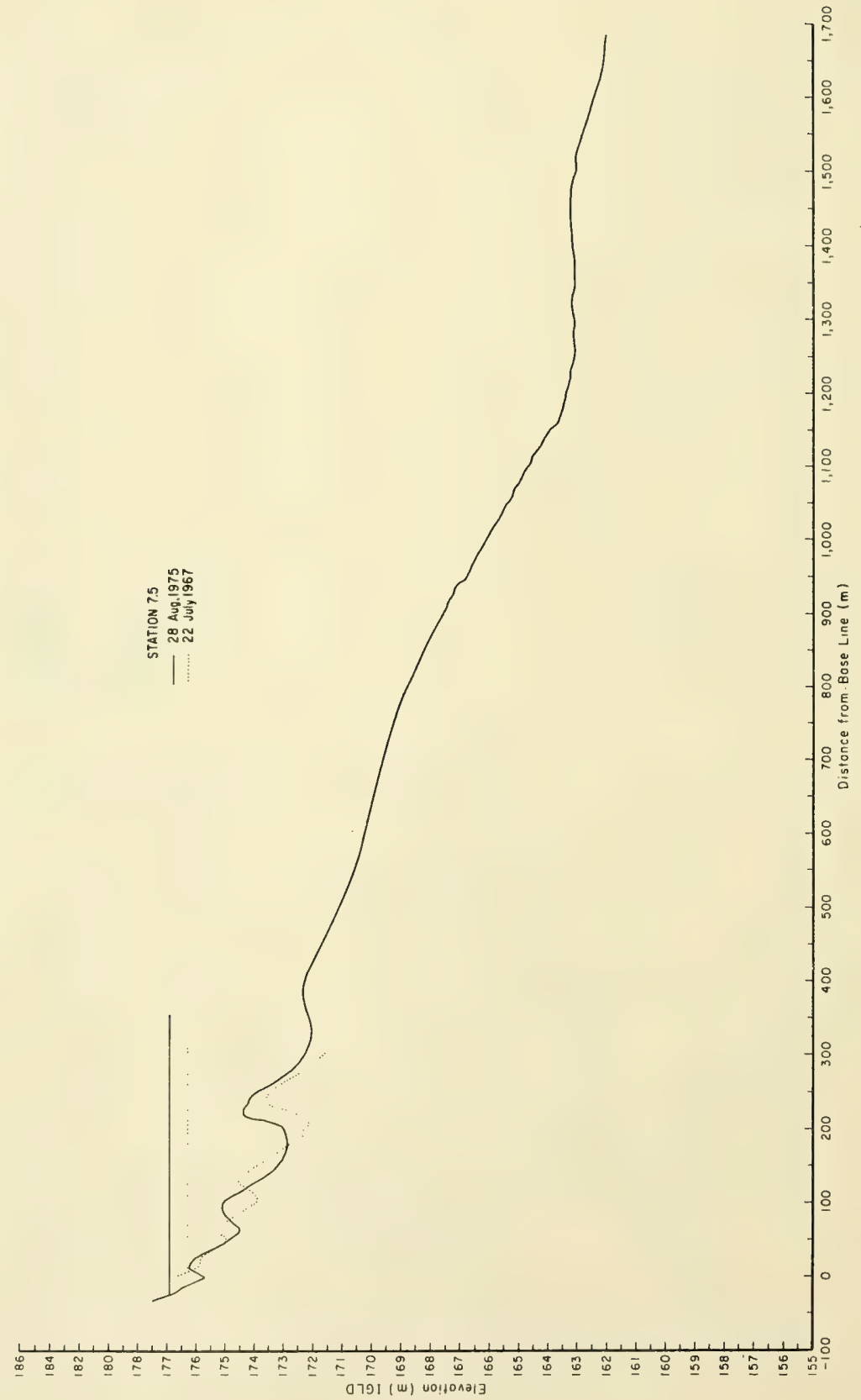




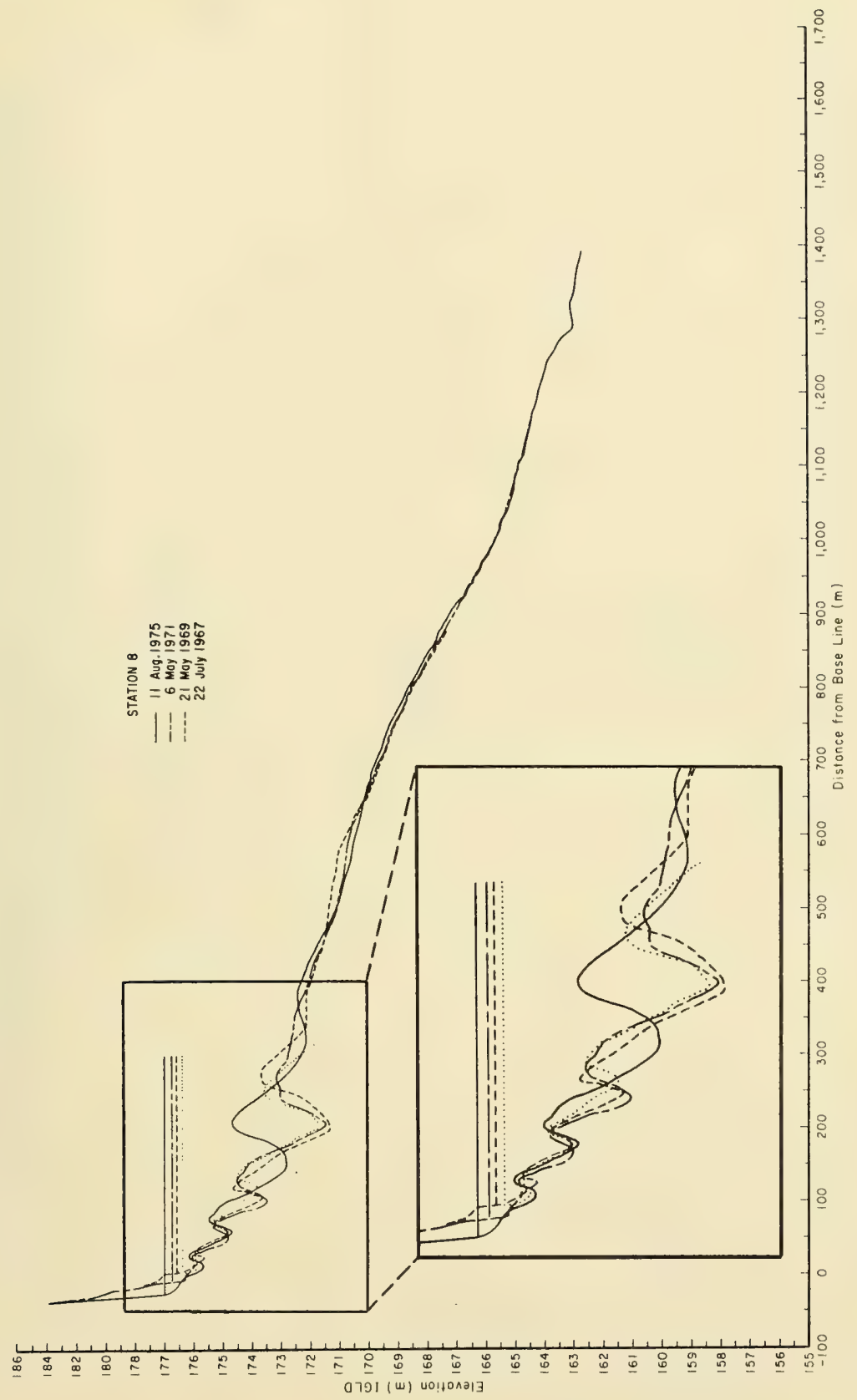




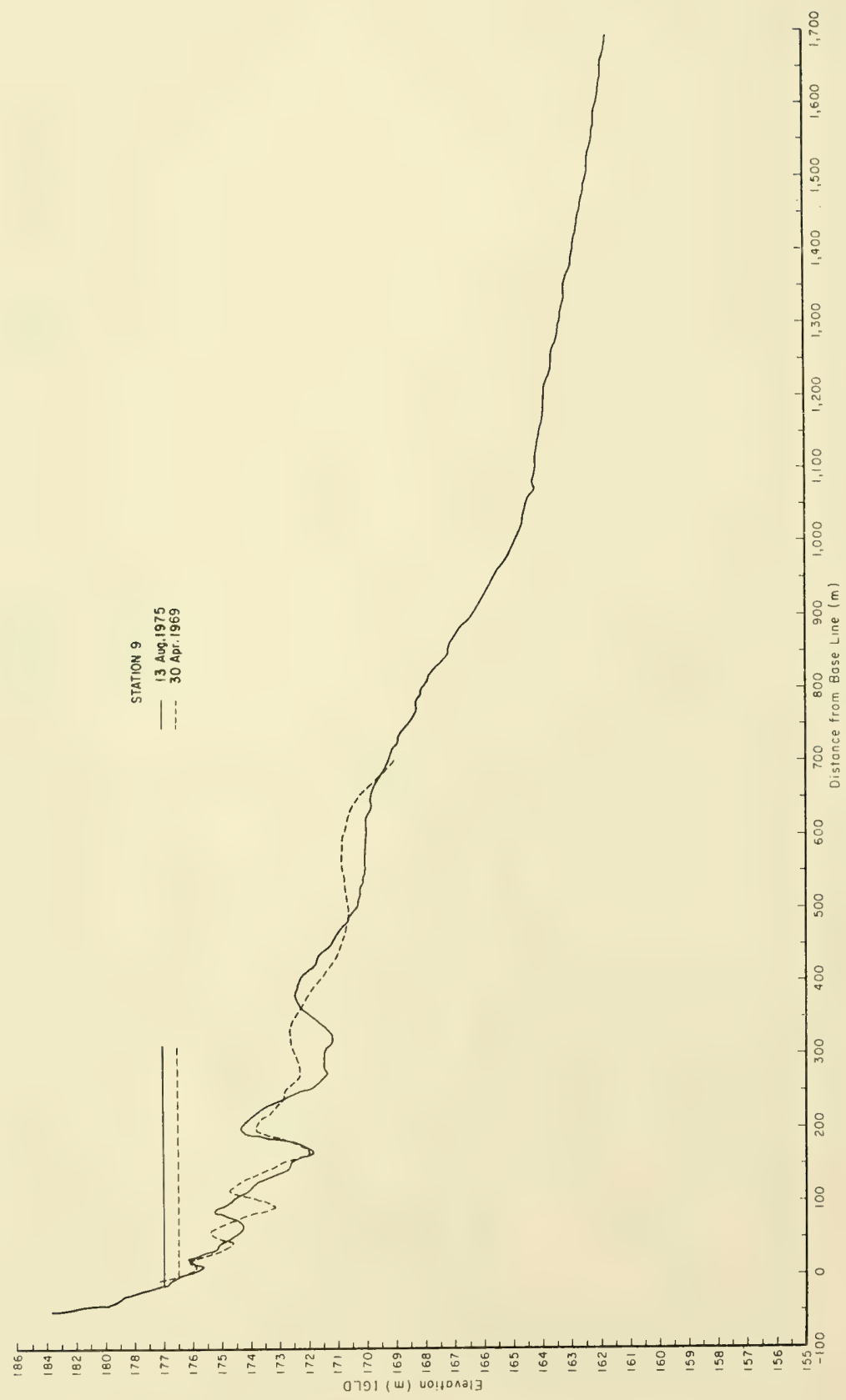




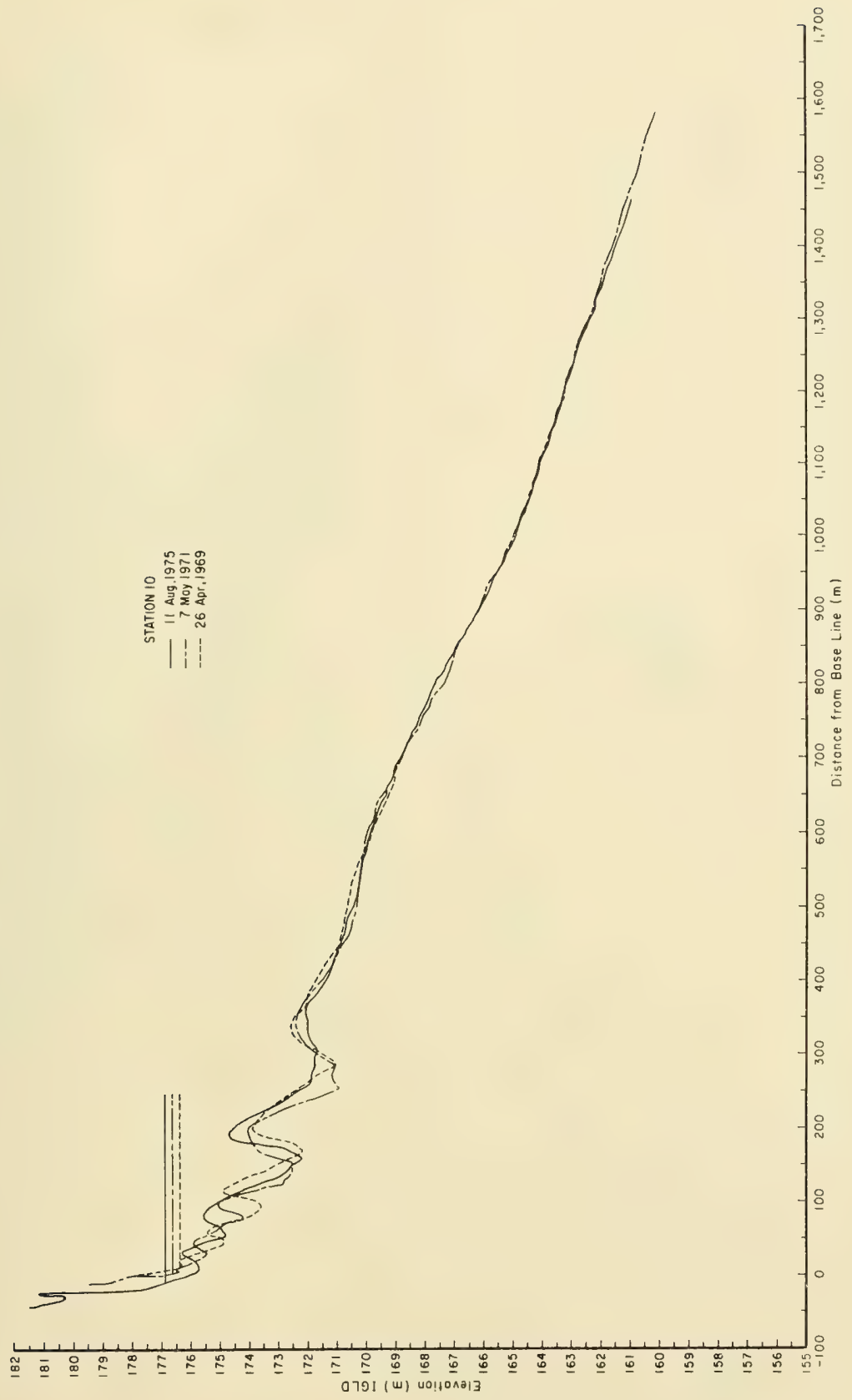




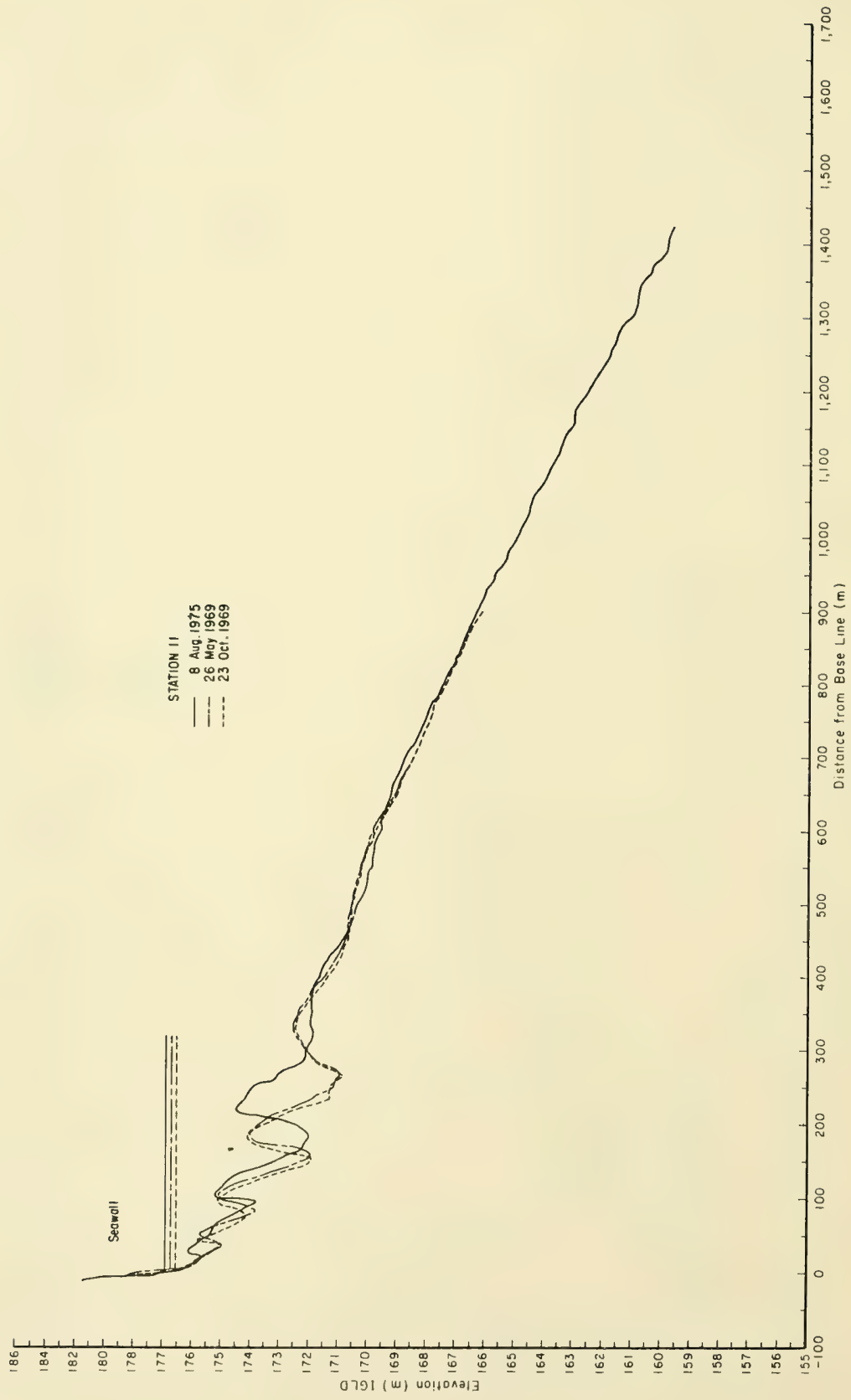




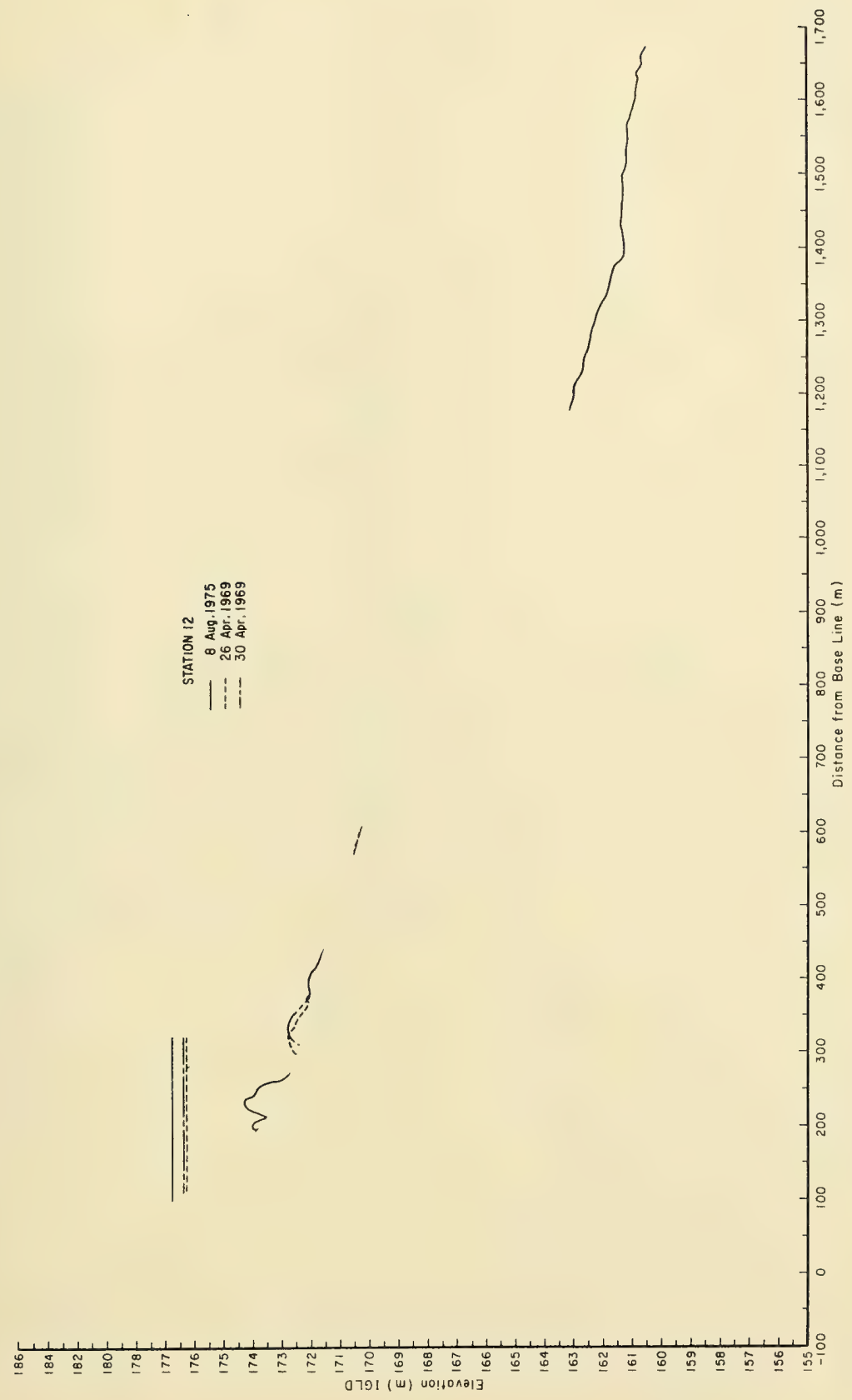




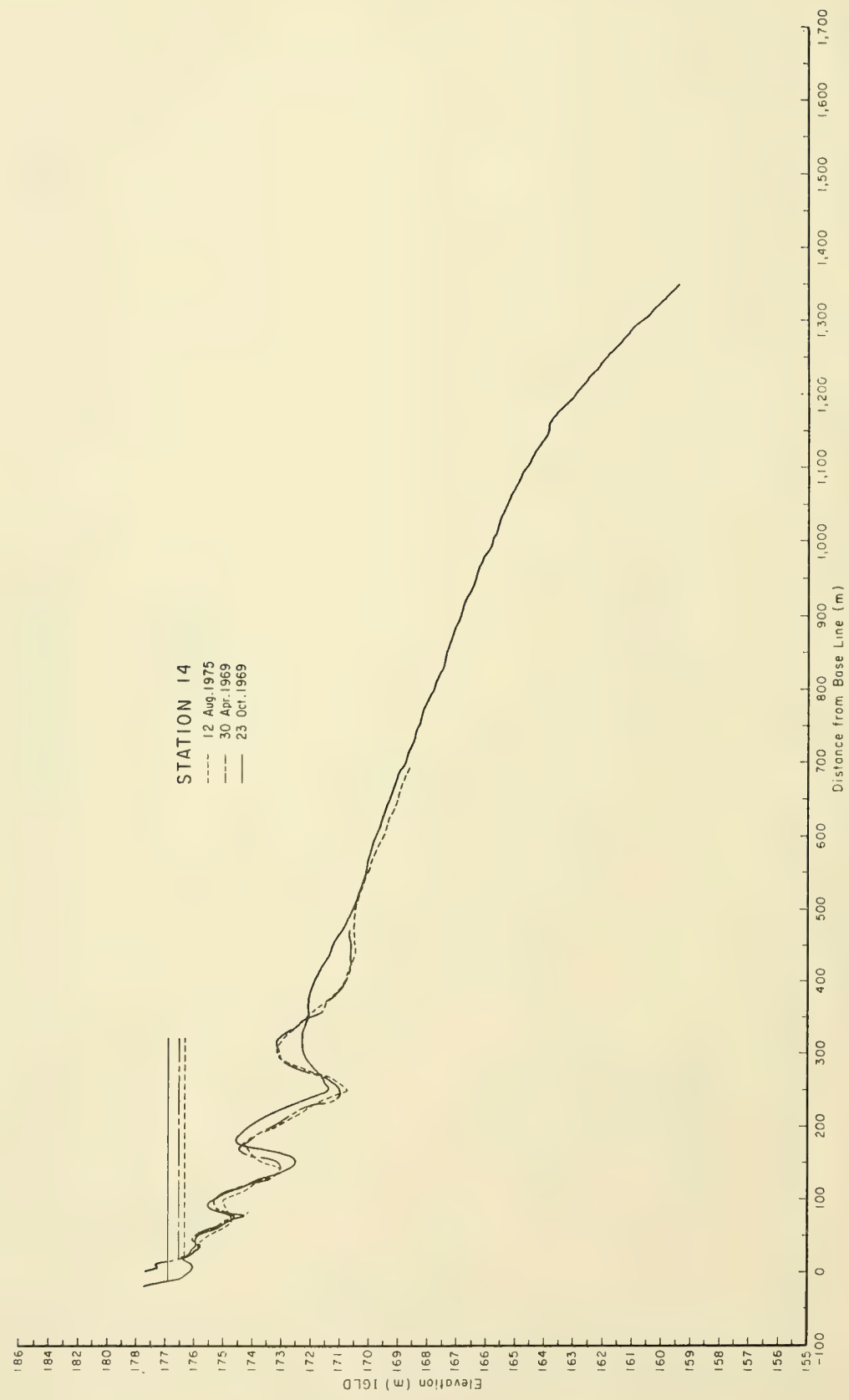




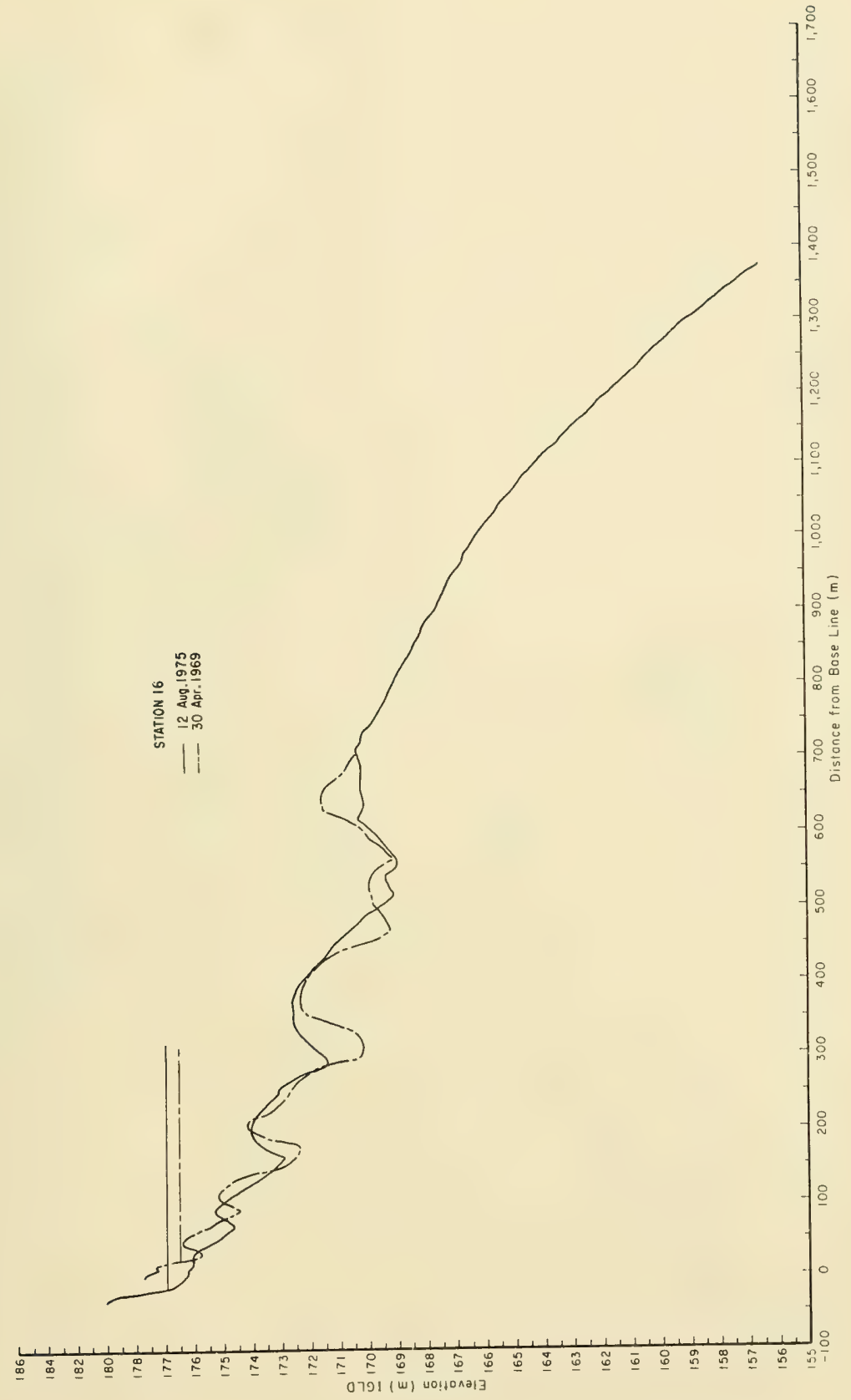




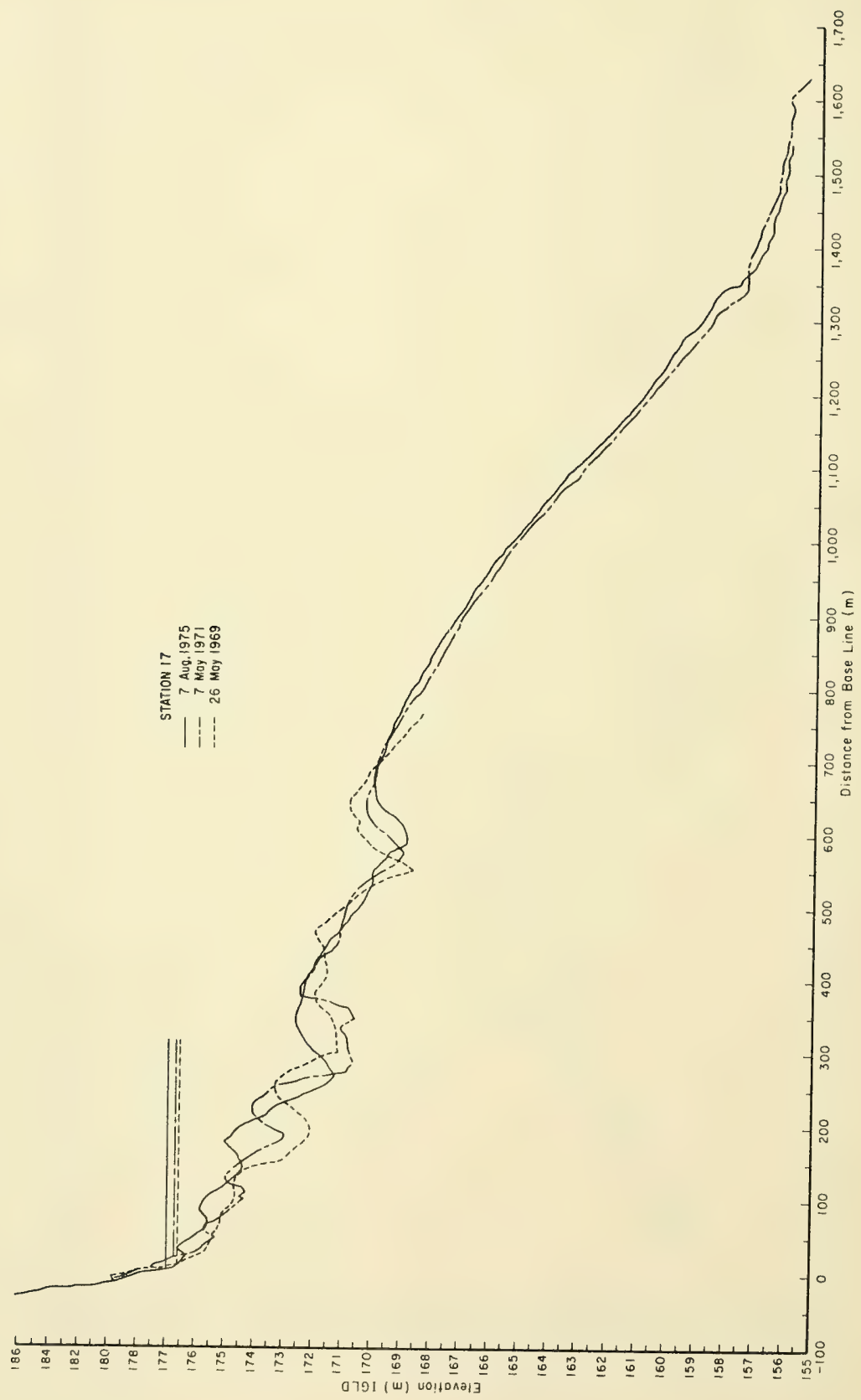




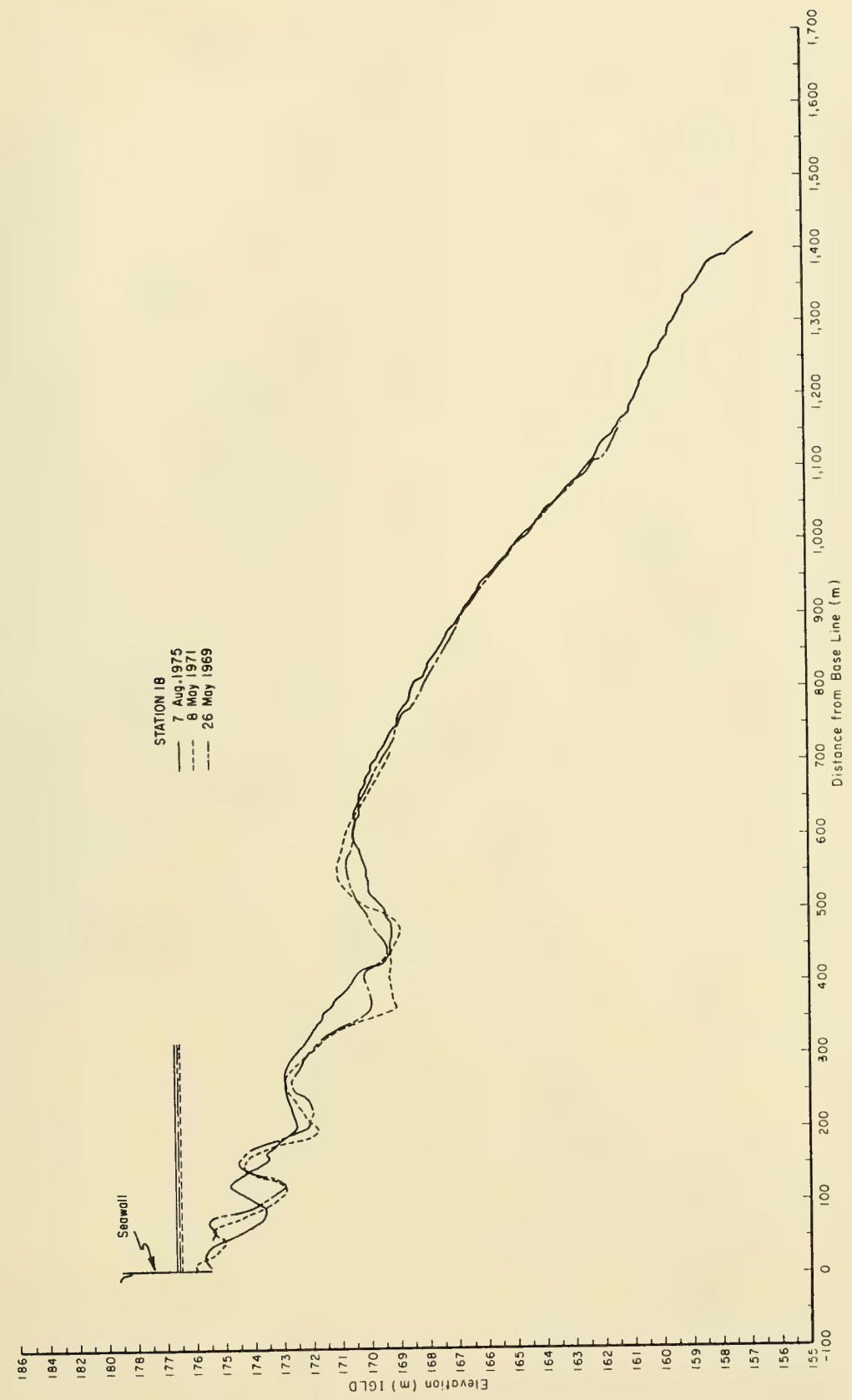




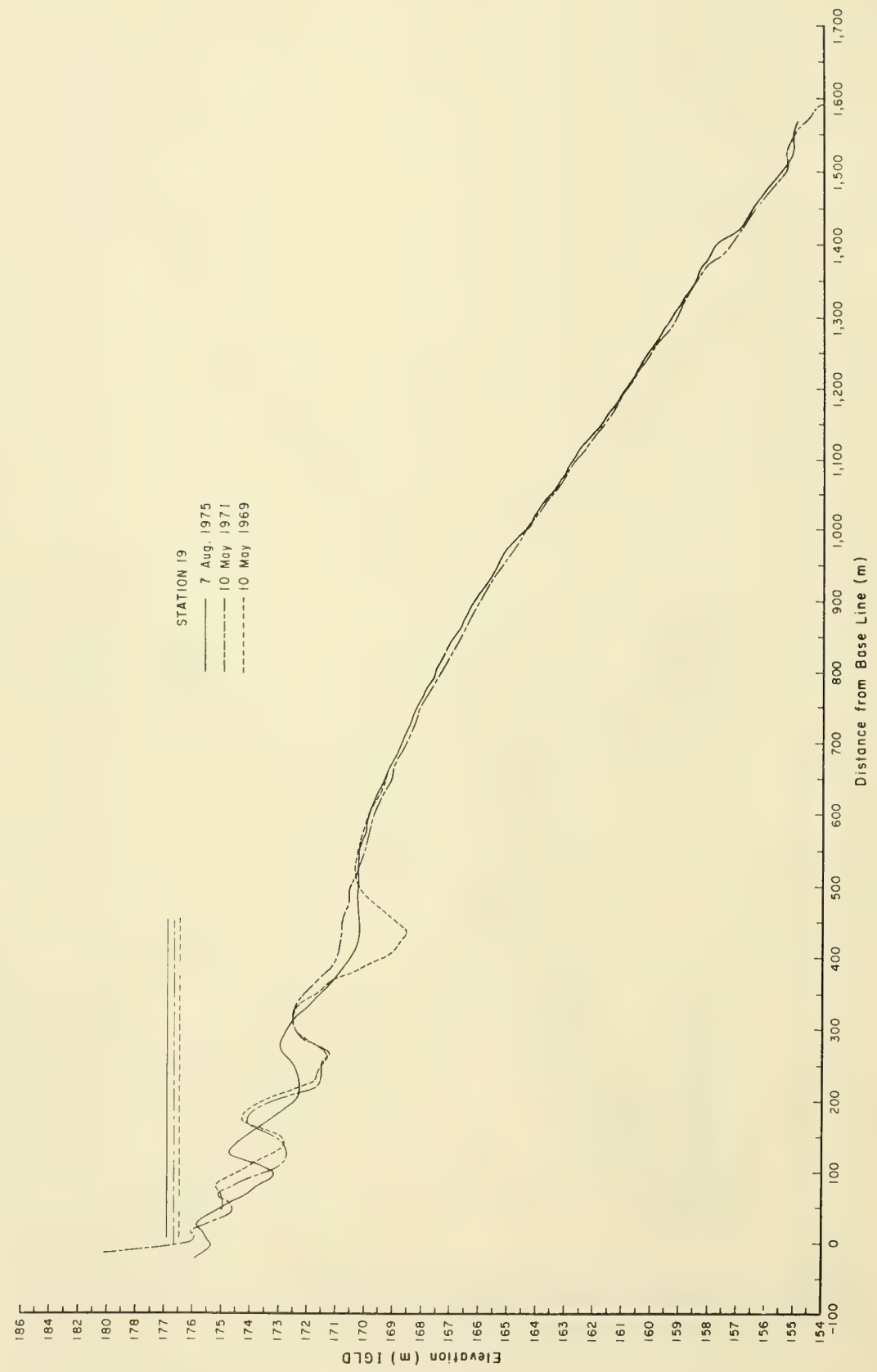




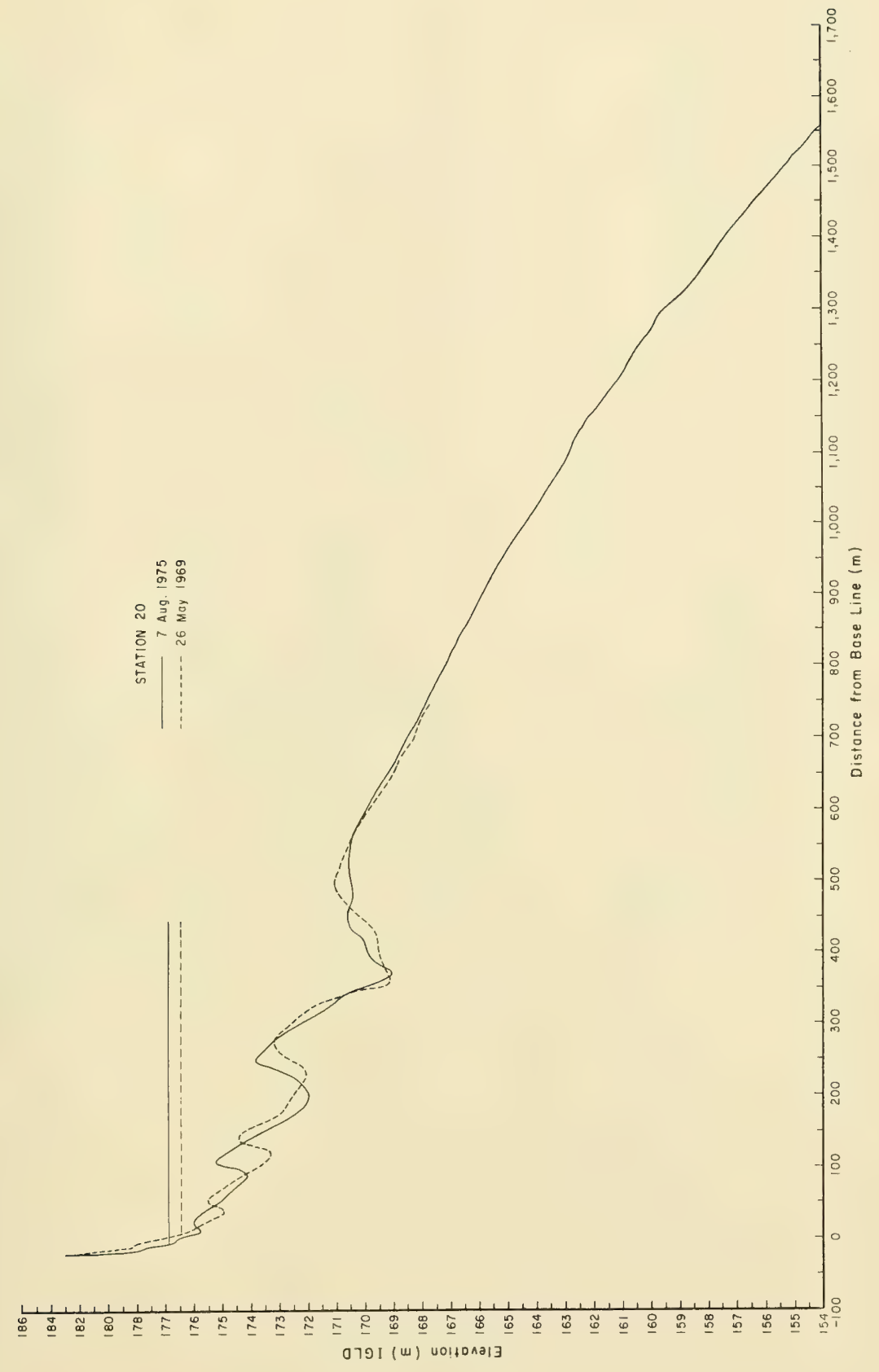




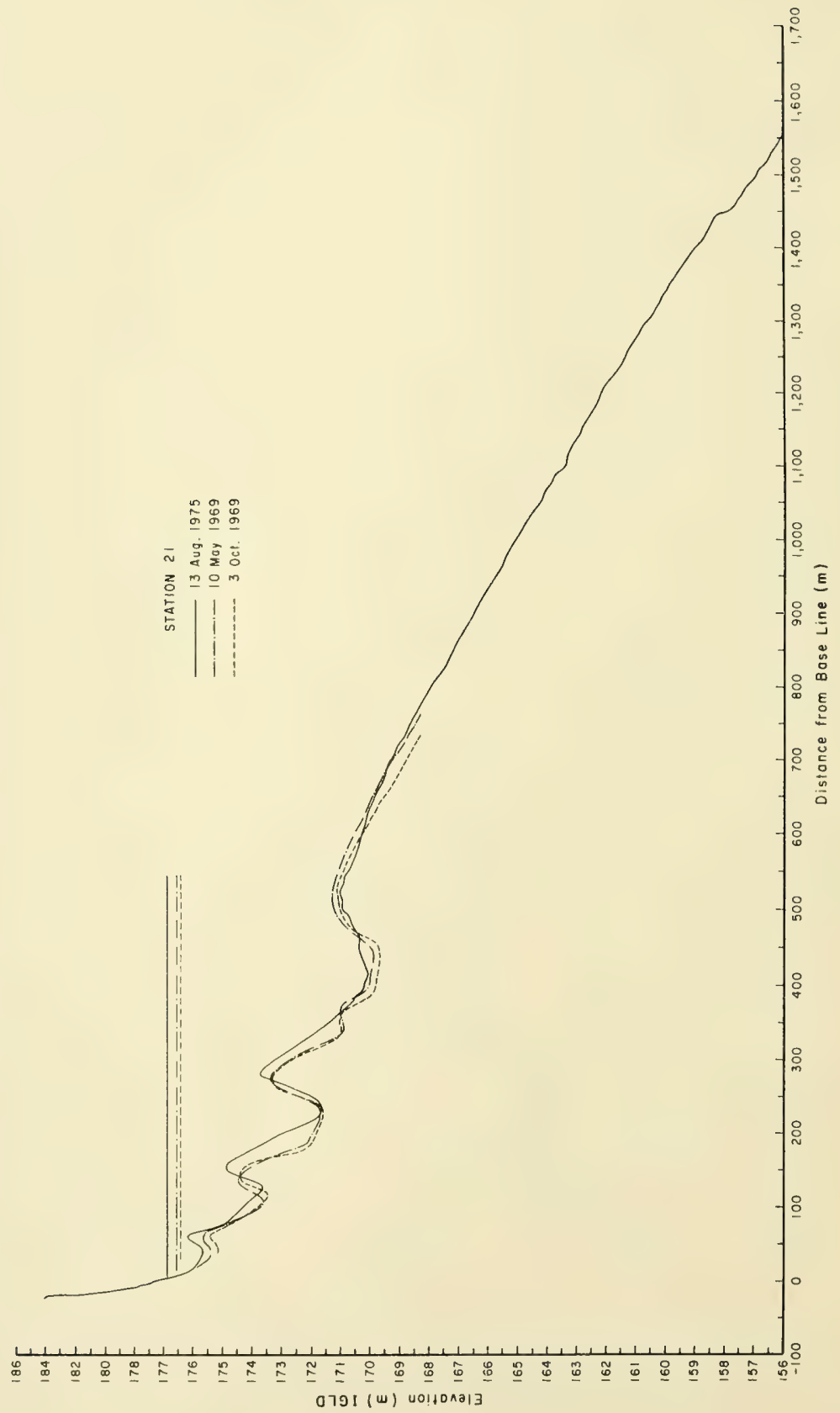




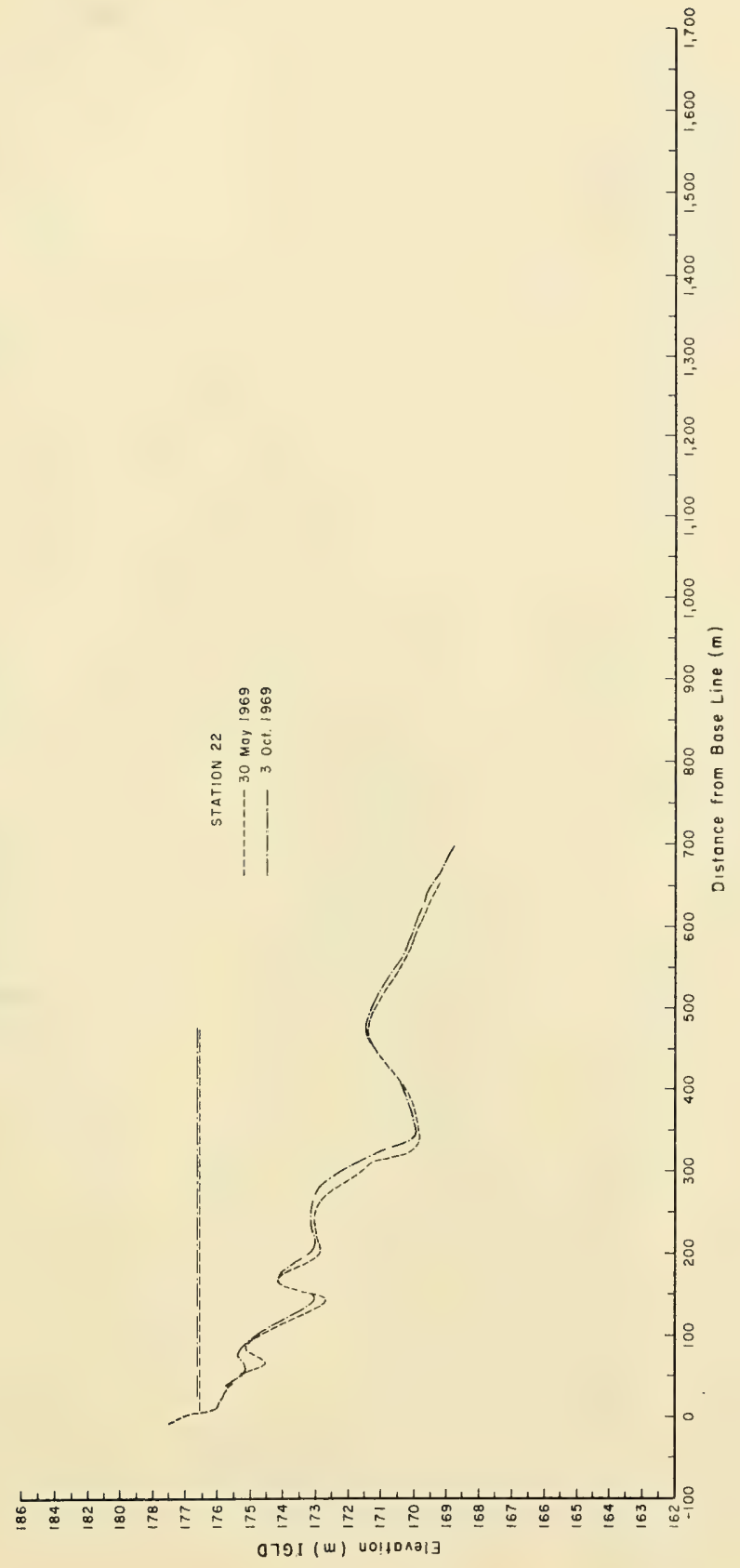




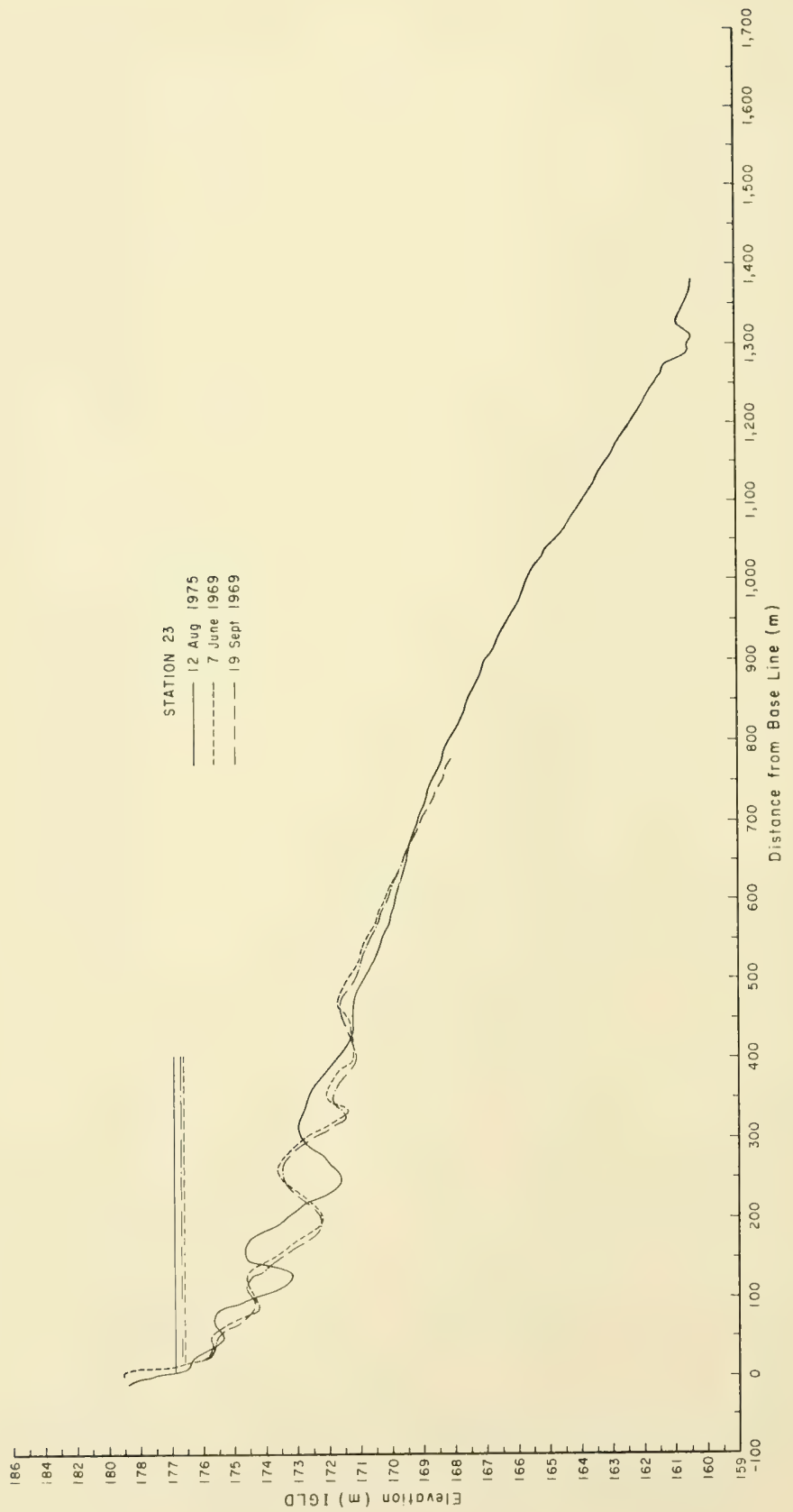




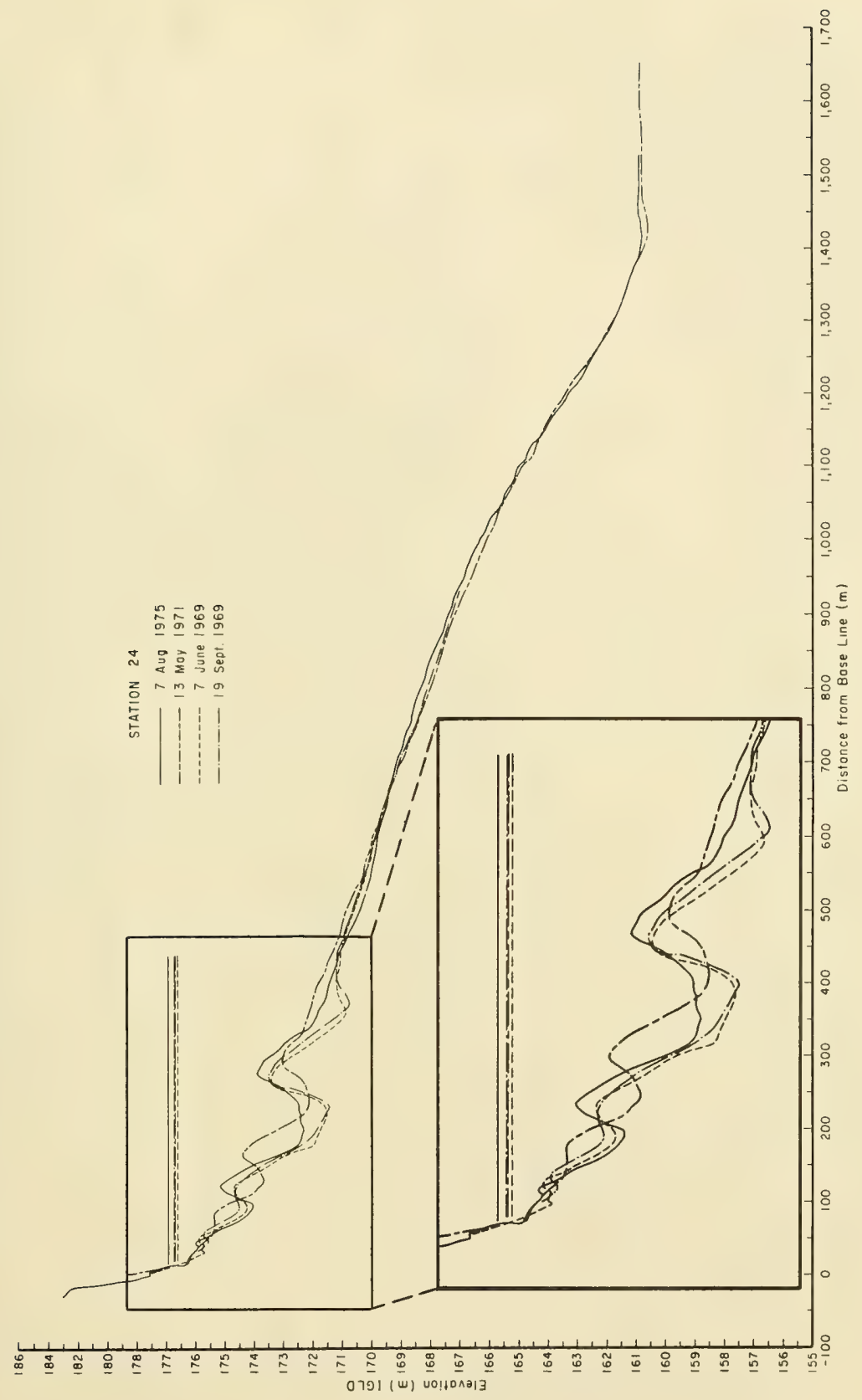




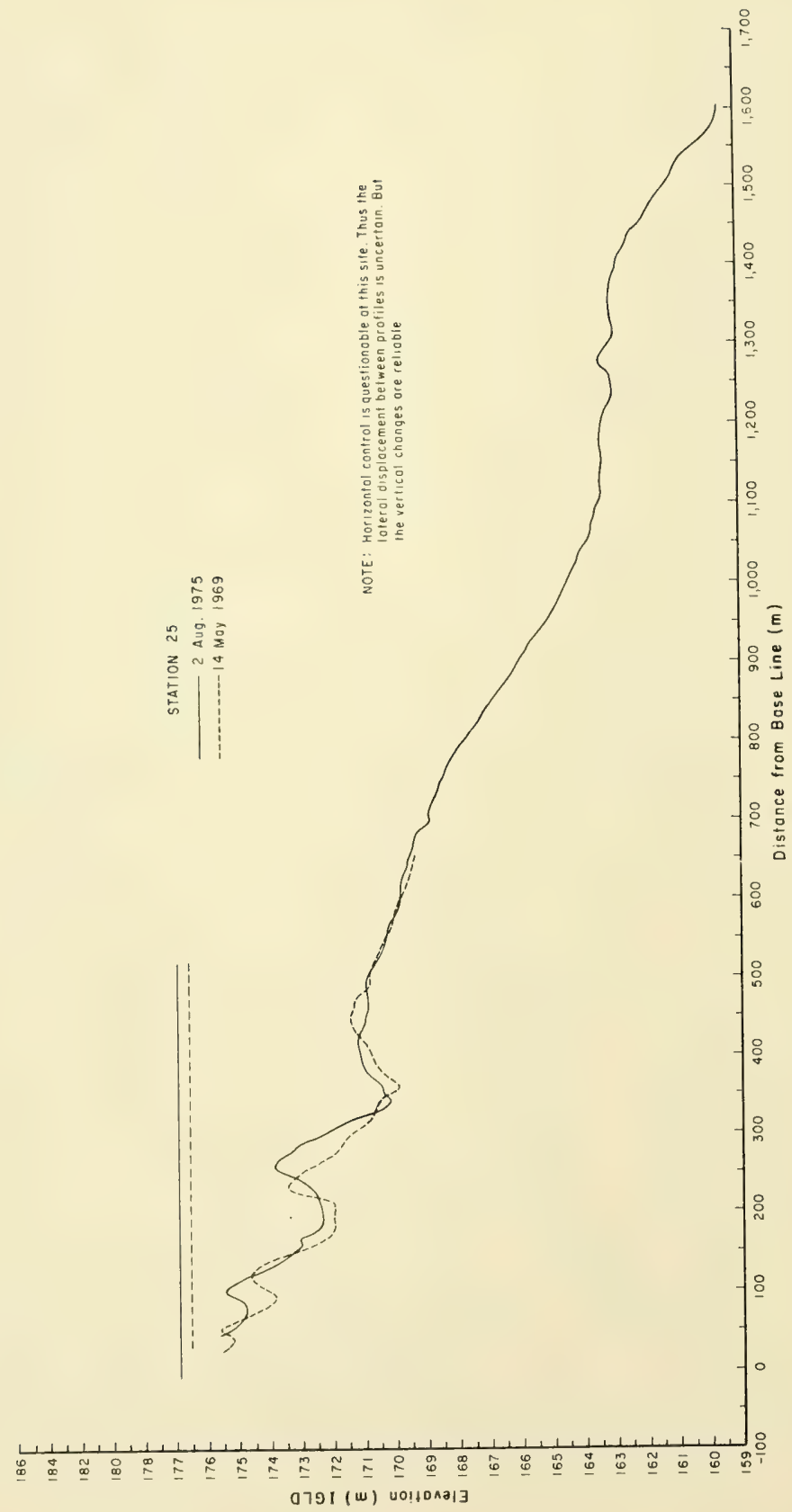




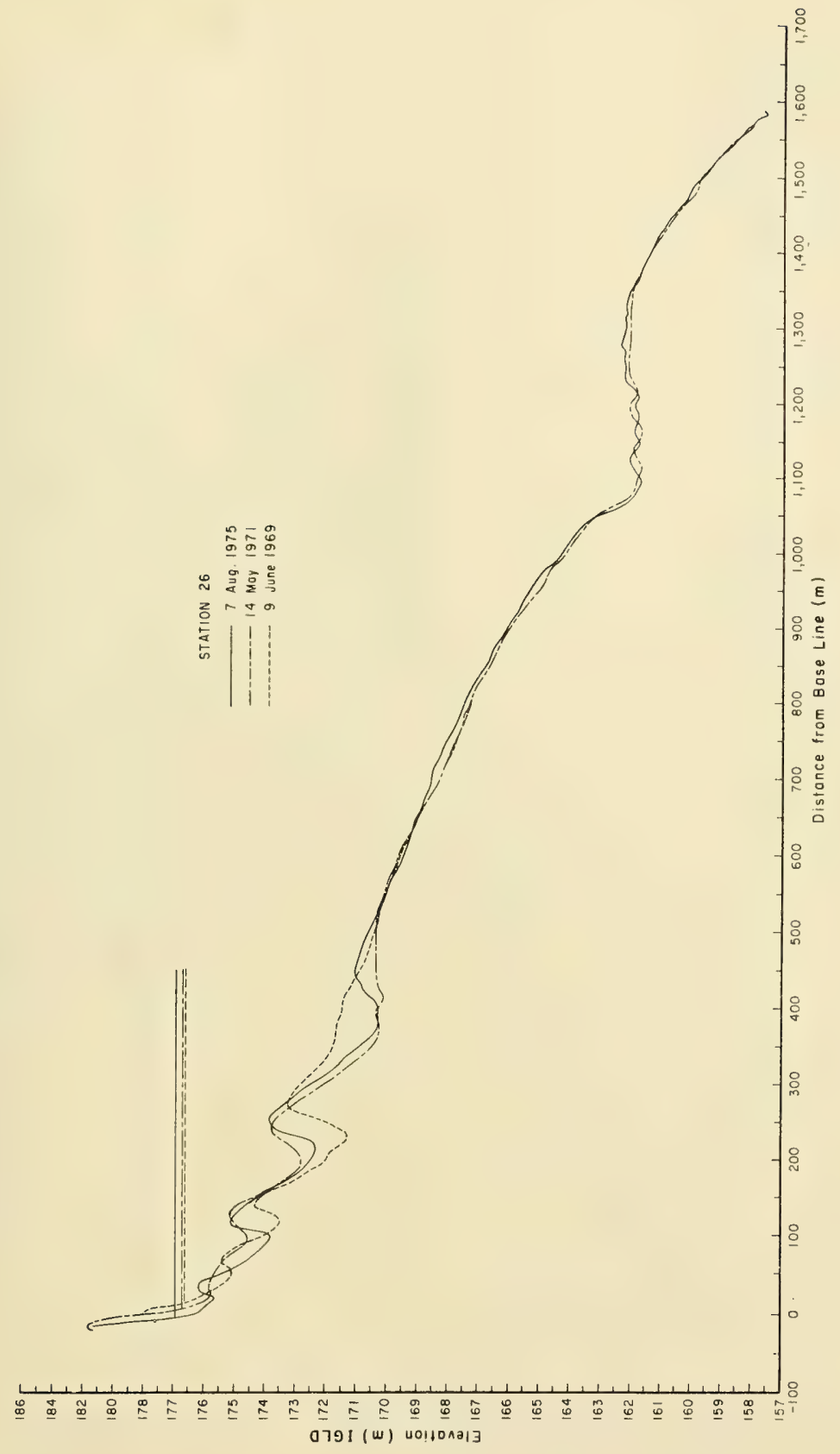




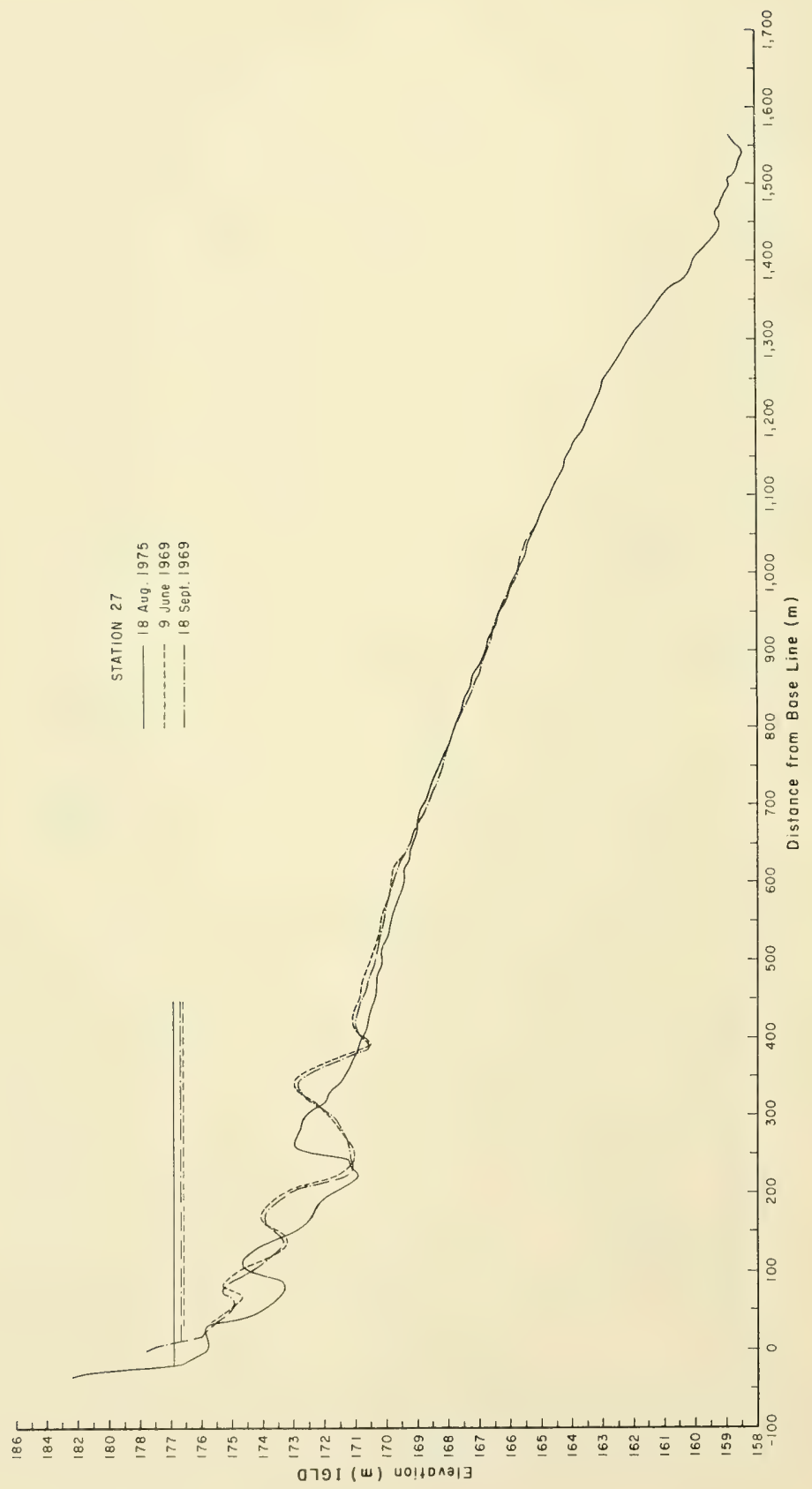




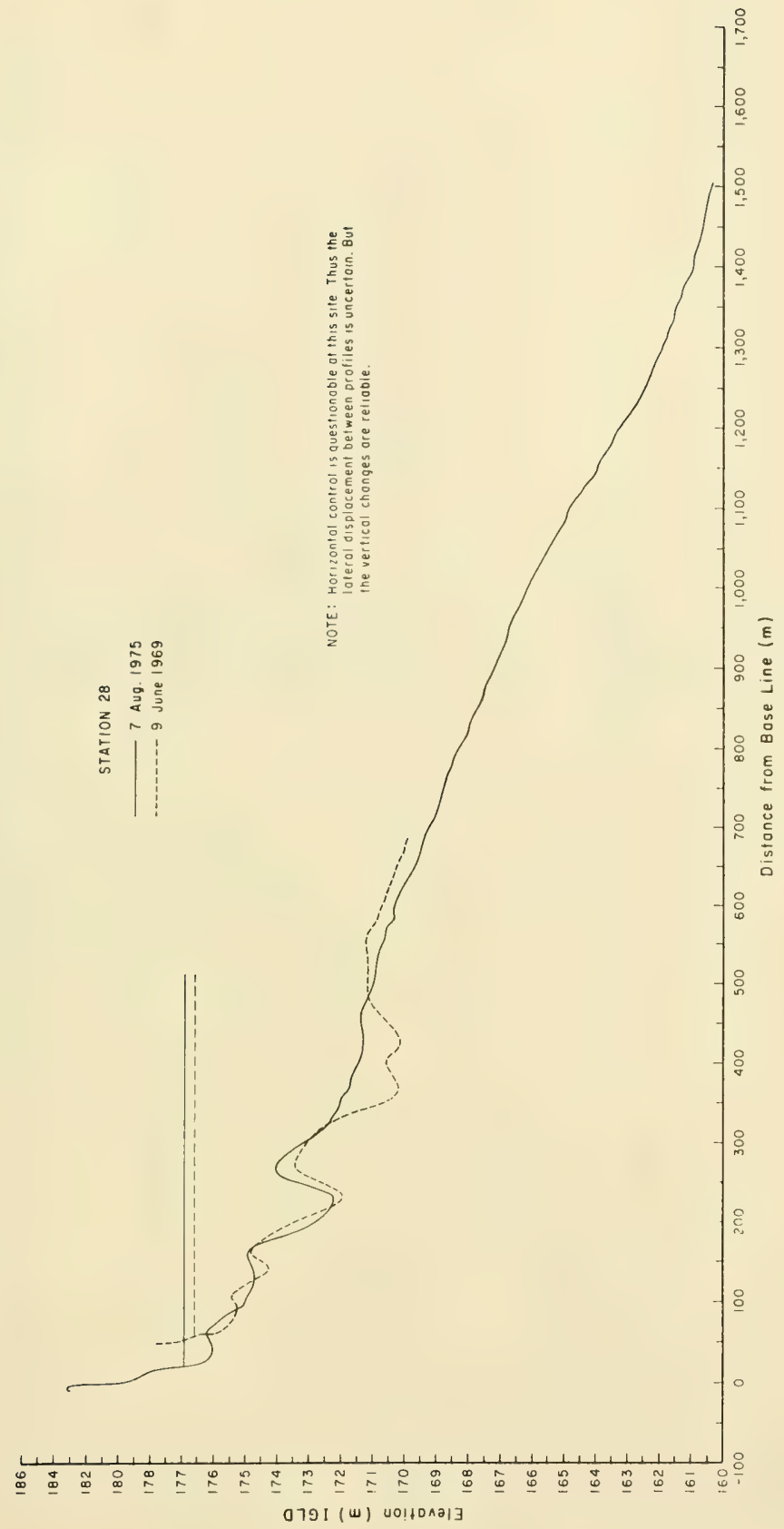




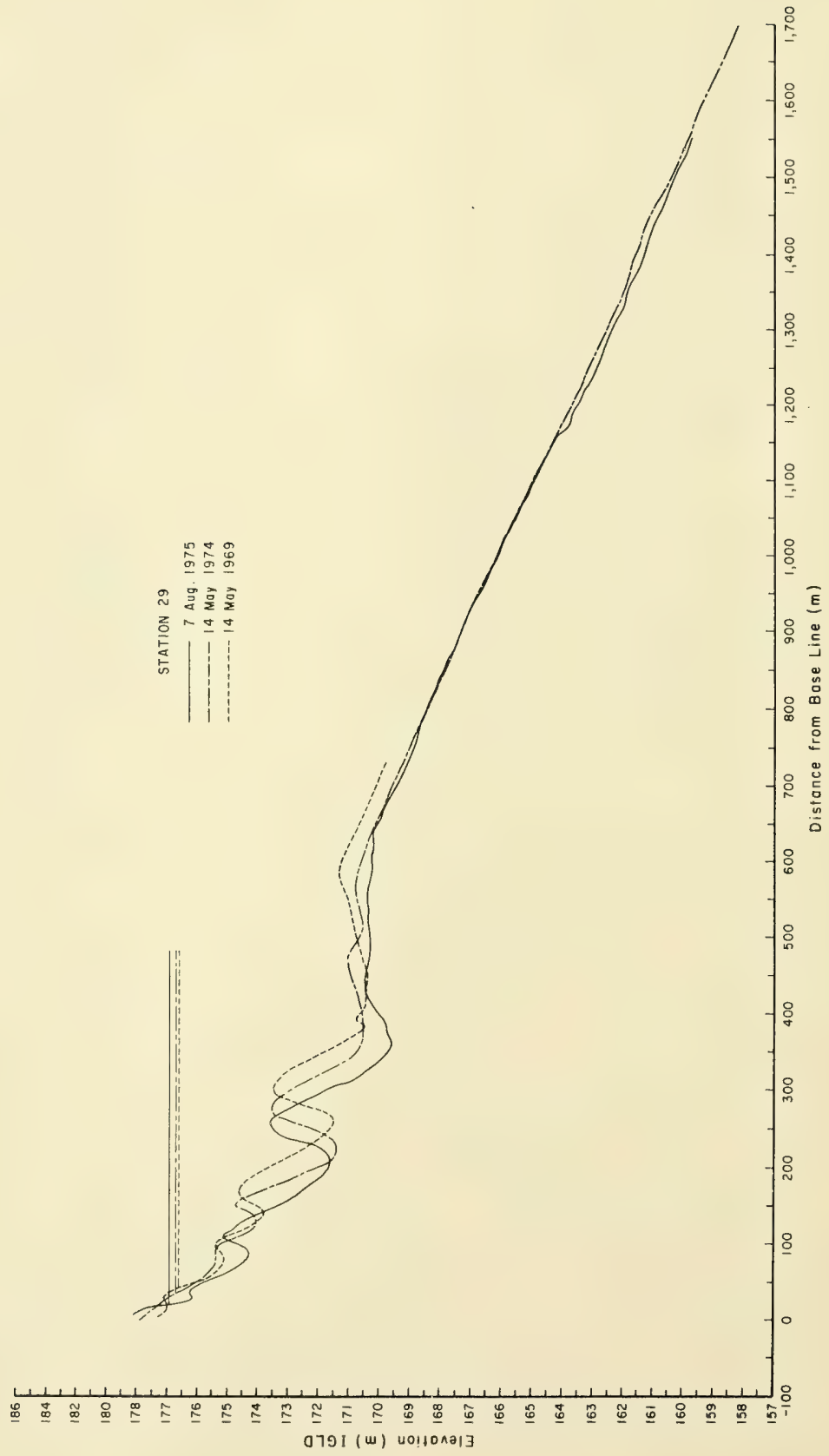




\section{APPENDIX B}

\section{VOLIIMF SALCULATIONS}

This appendix presents net profile changes, cumulative volume curves (CVC), and average thicknesses of these volumes (Th). The calculation procedures are described in Section IIL, 6, b and illustrated in Figure 12. Table $l$ in the text tabulates the rates of change in cubic meters per meter per year. 


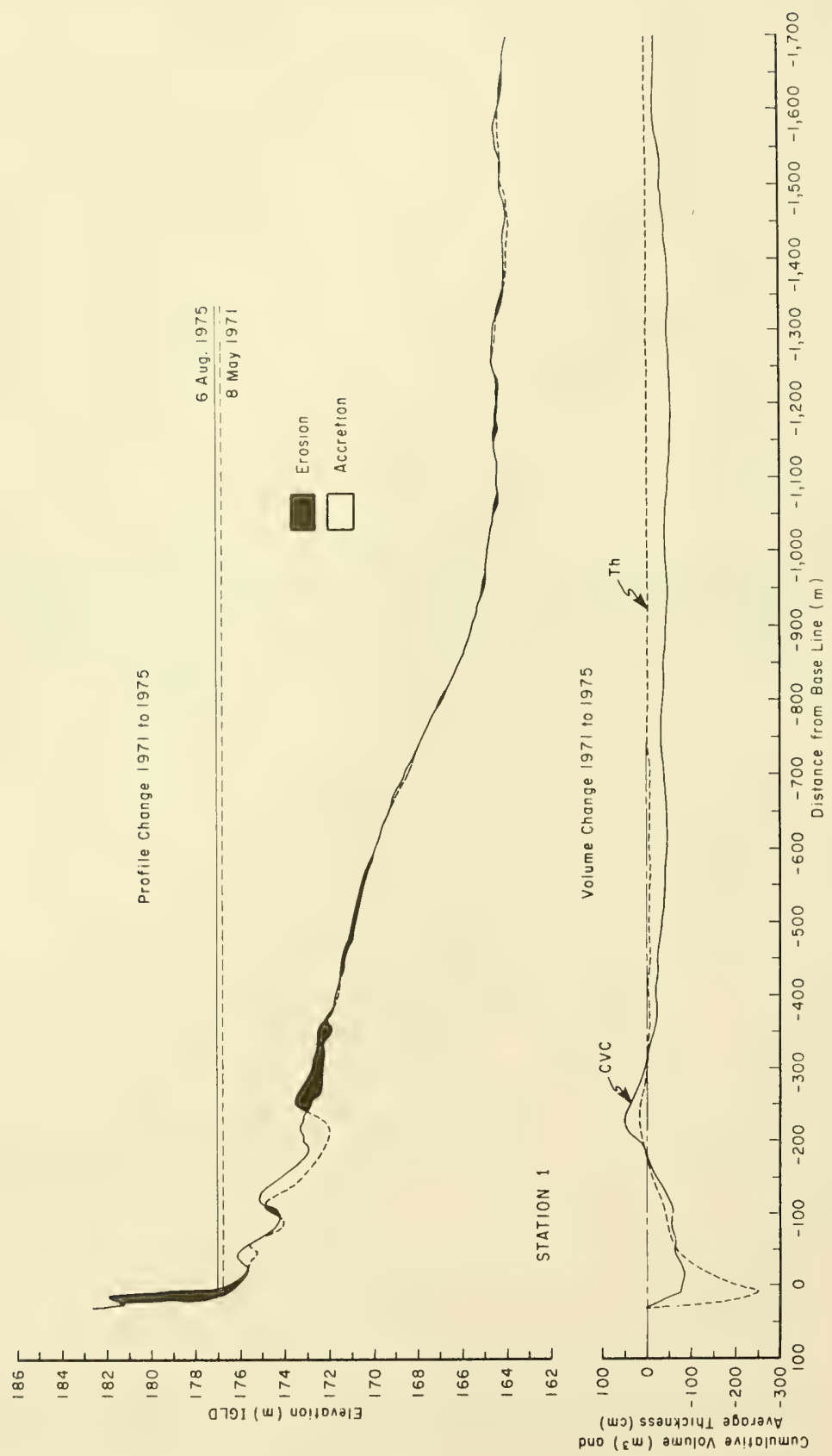




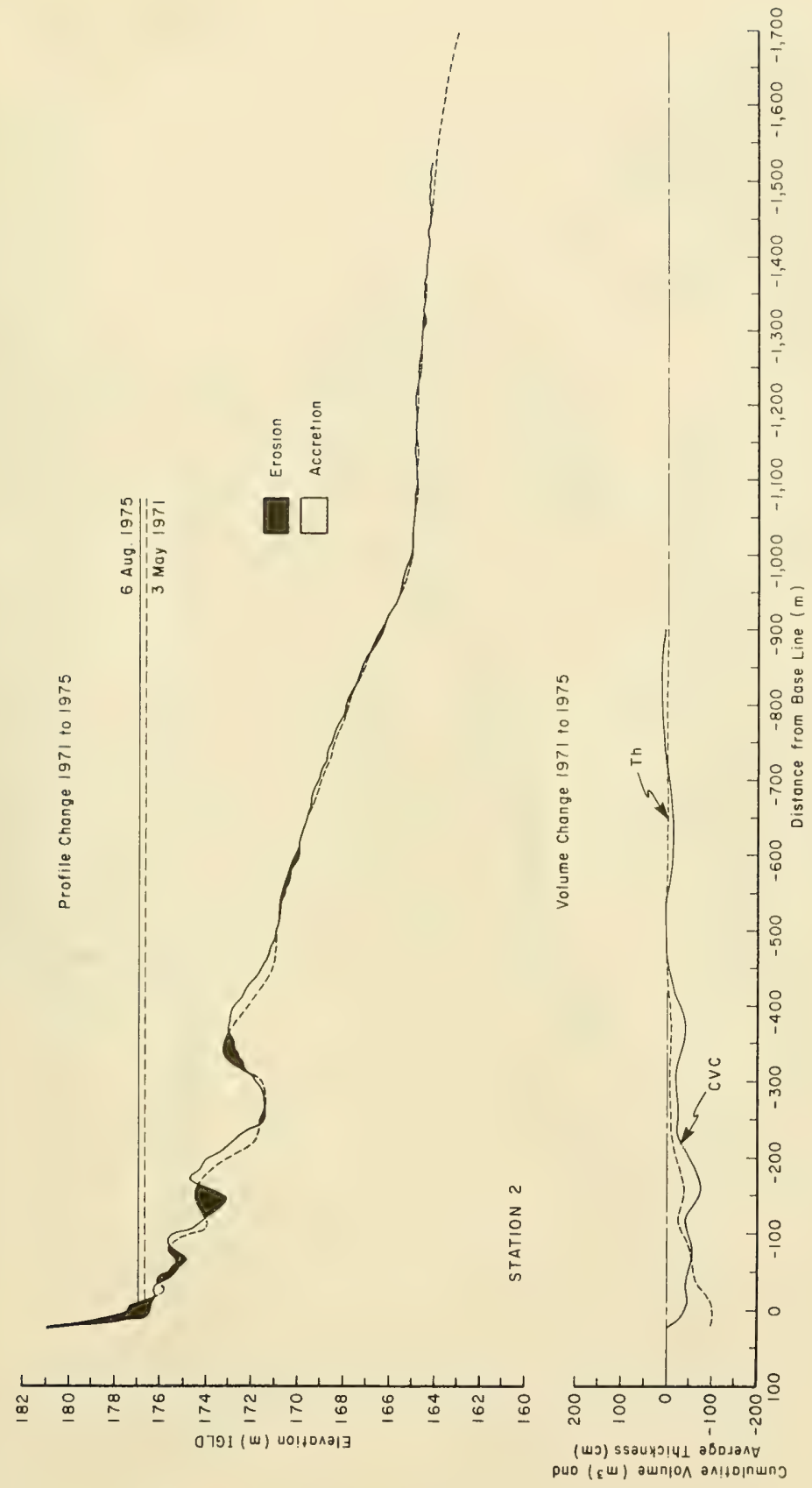




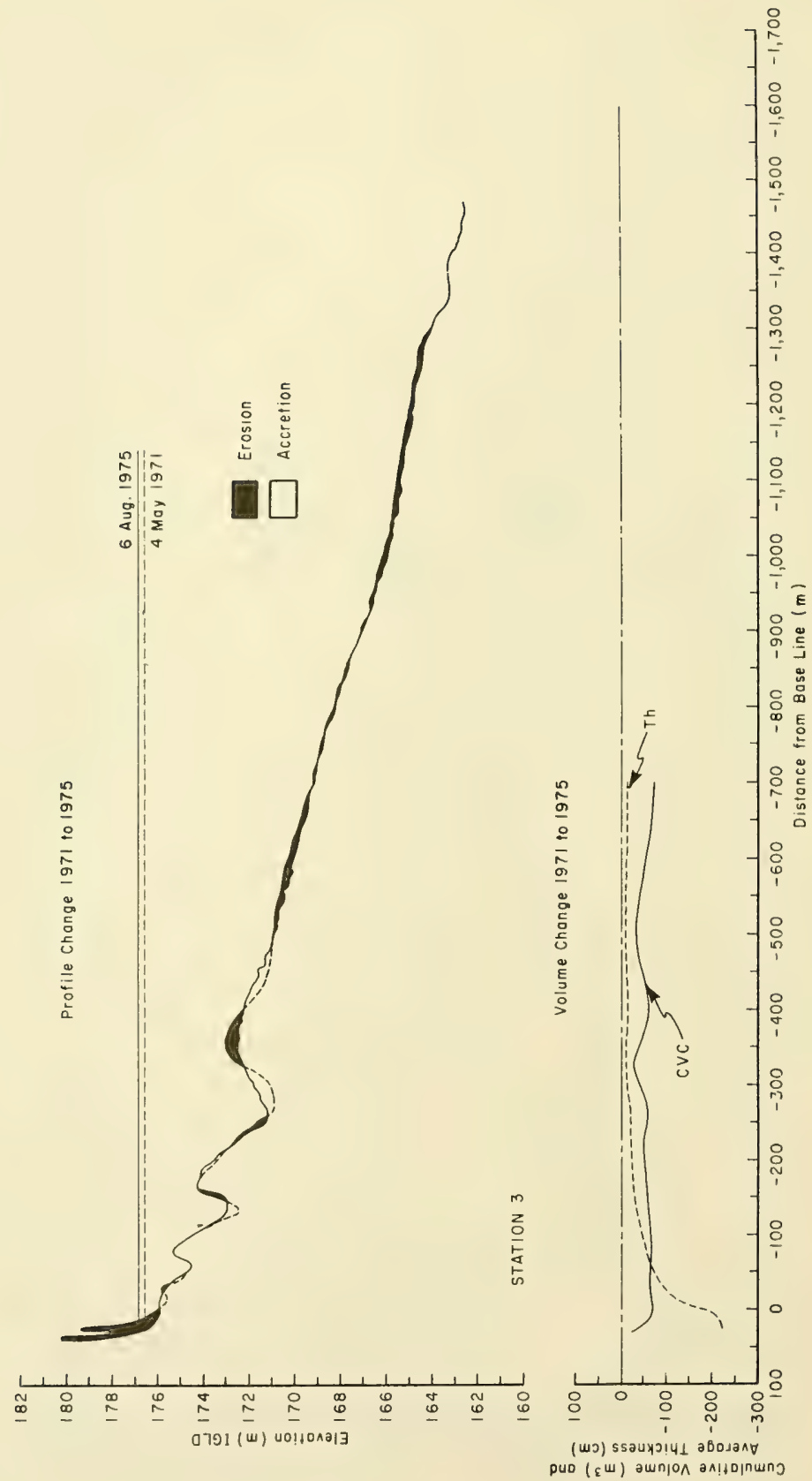




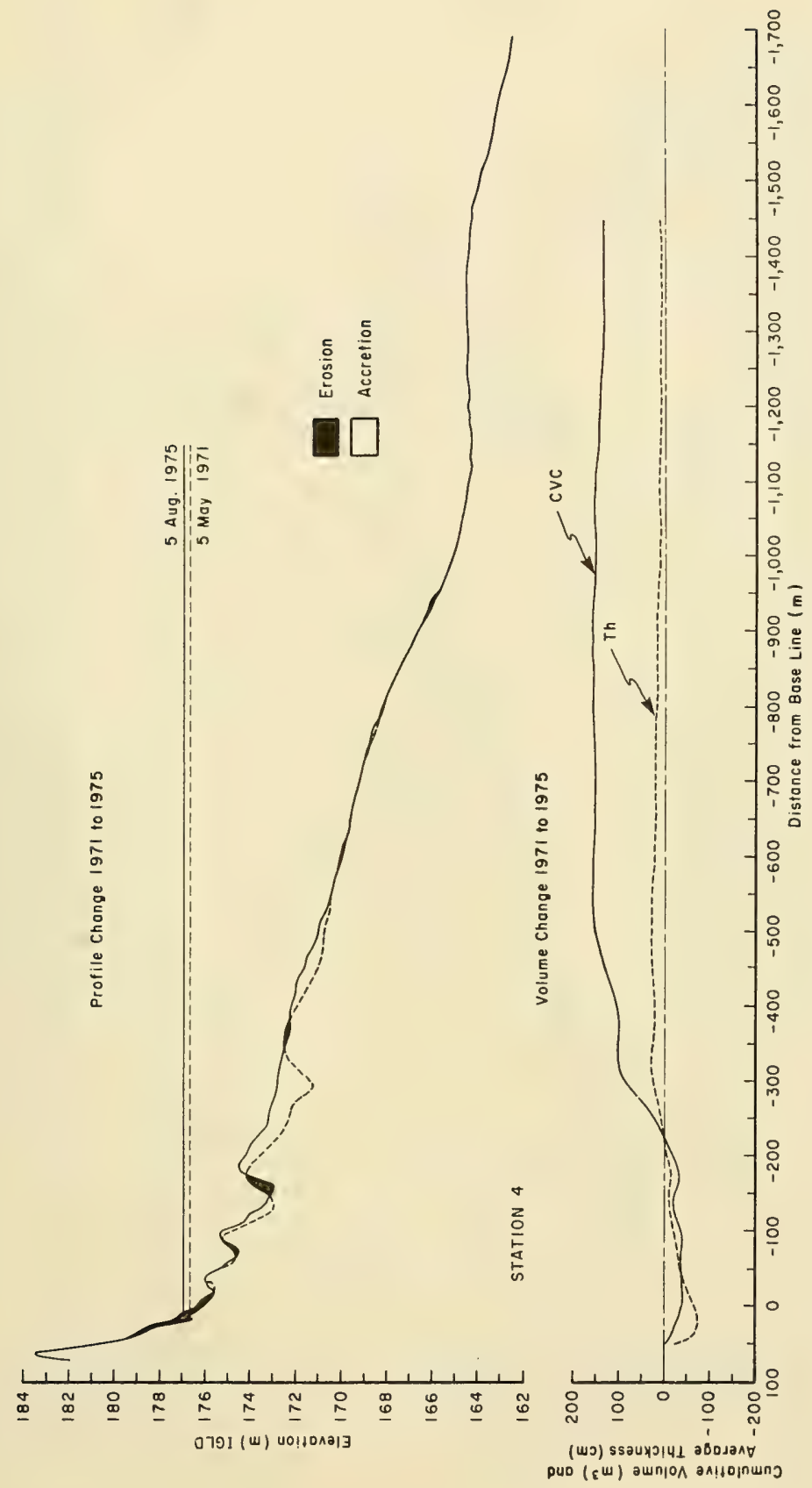




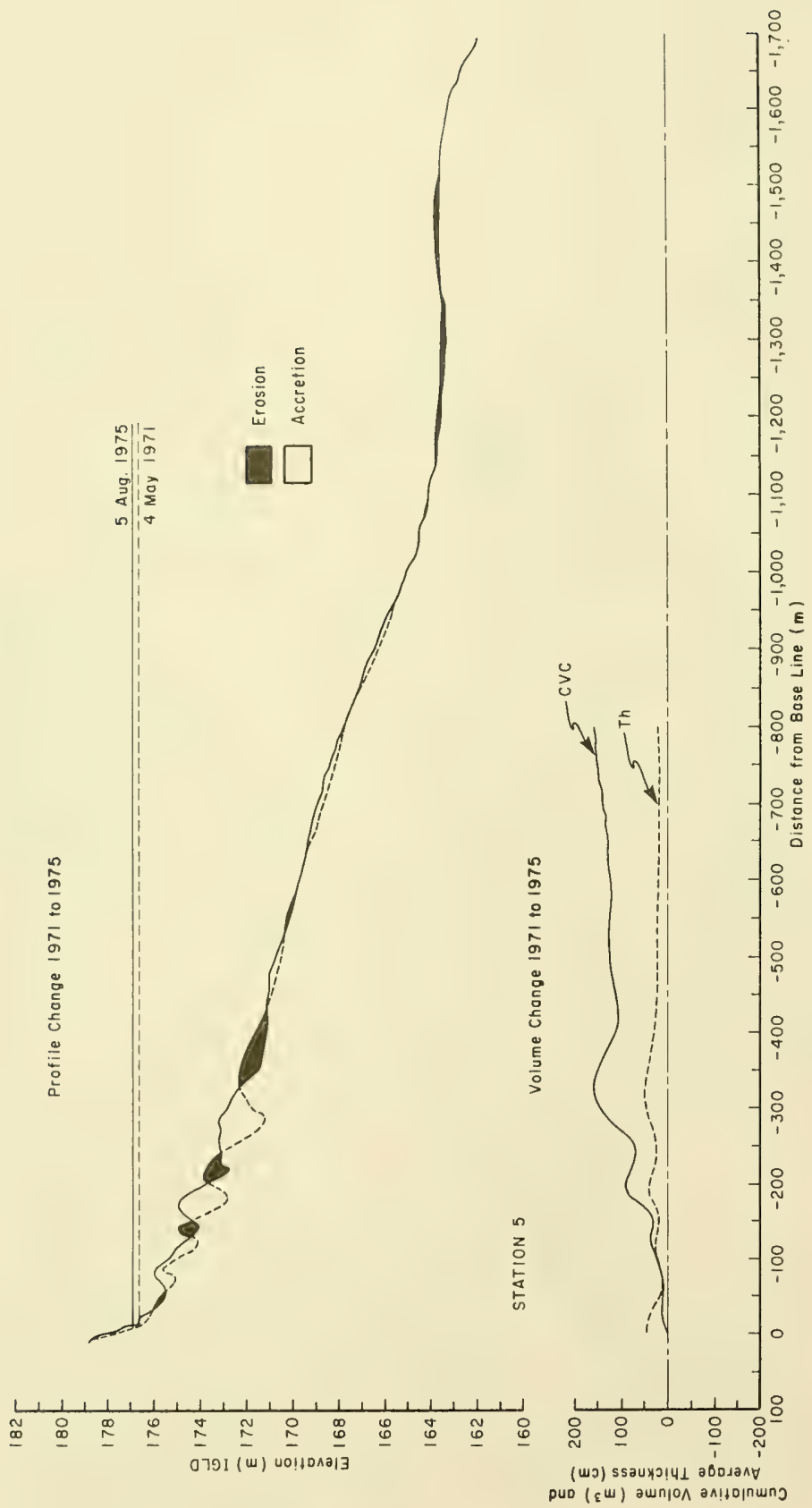




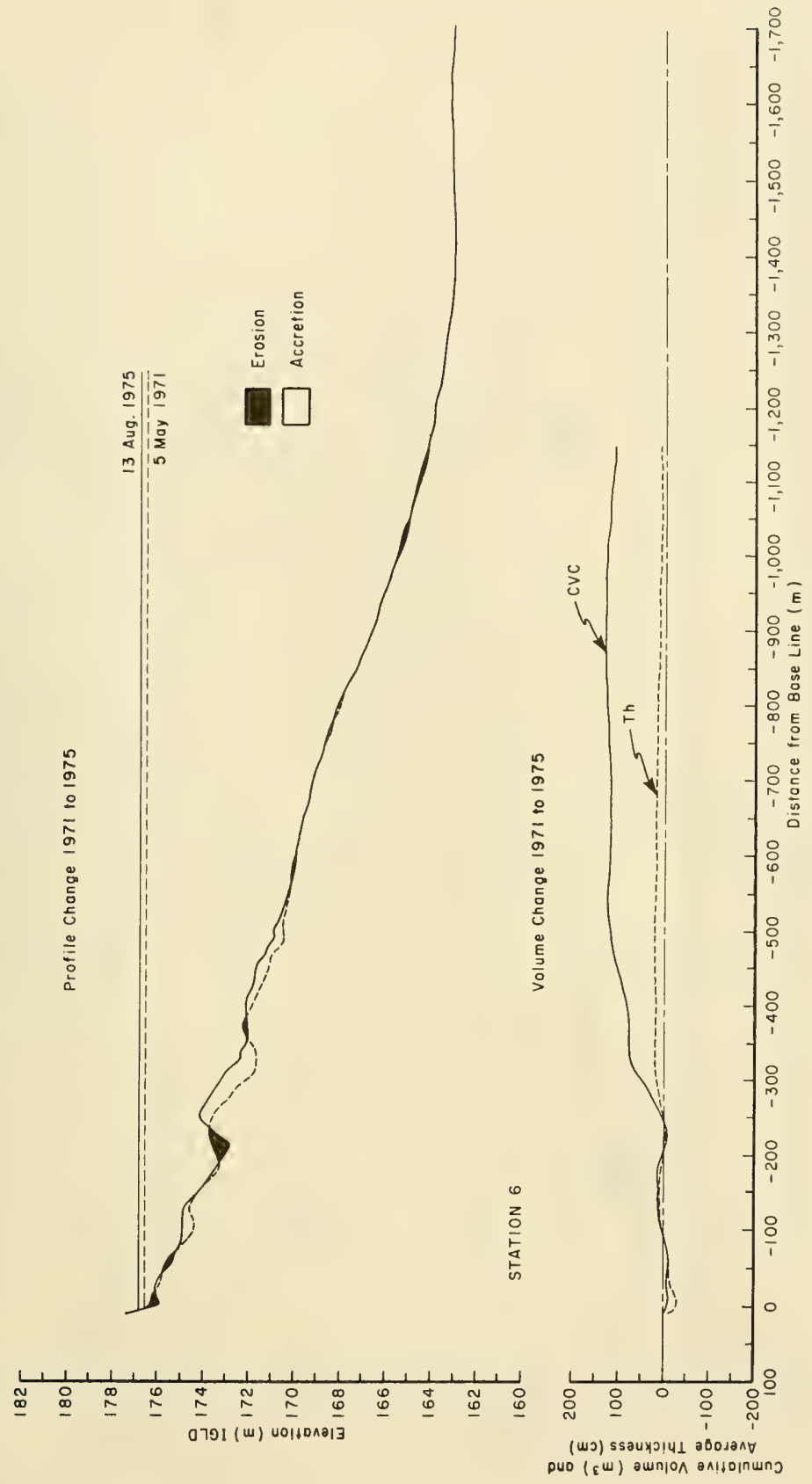




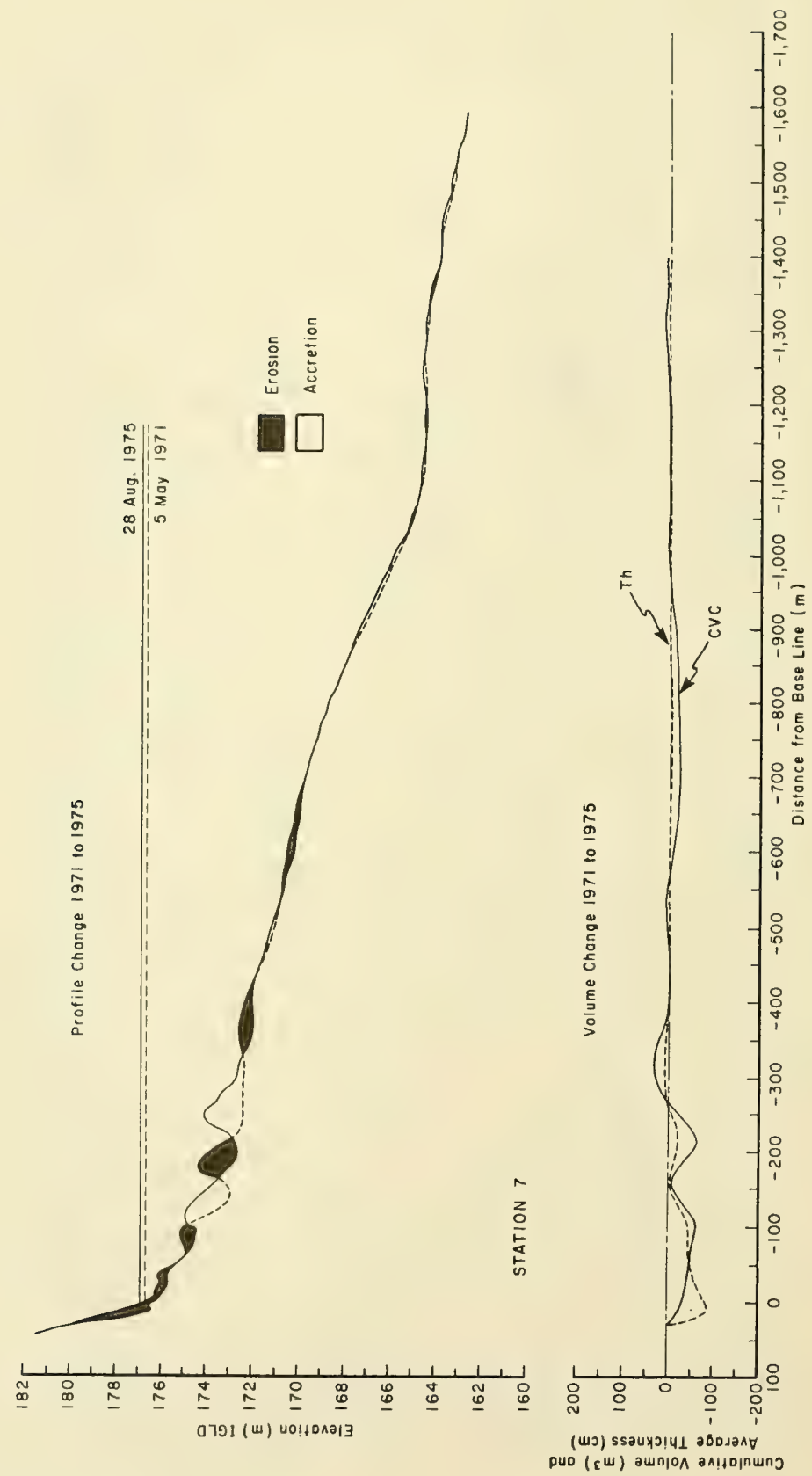




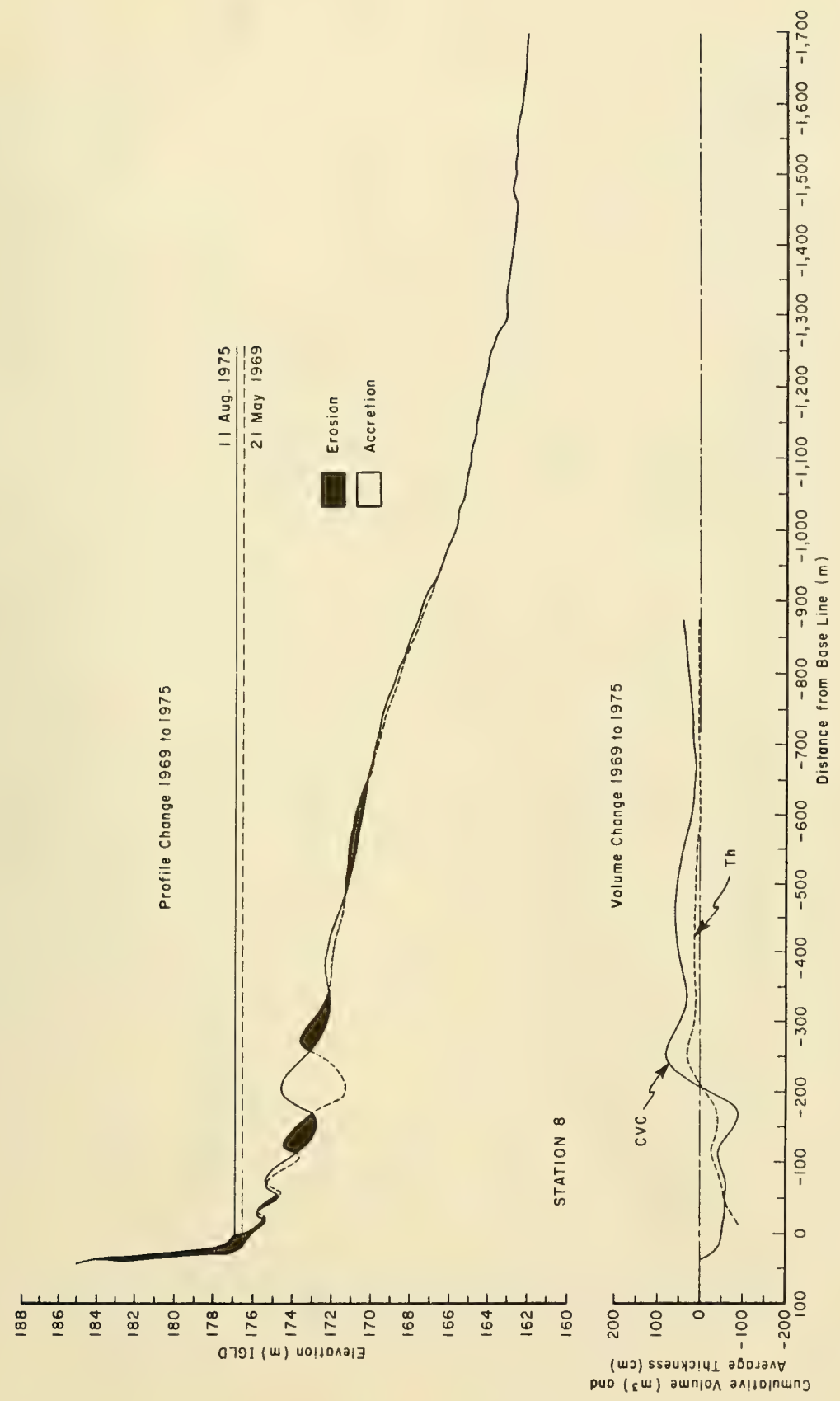




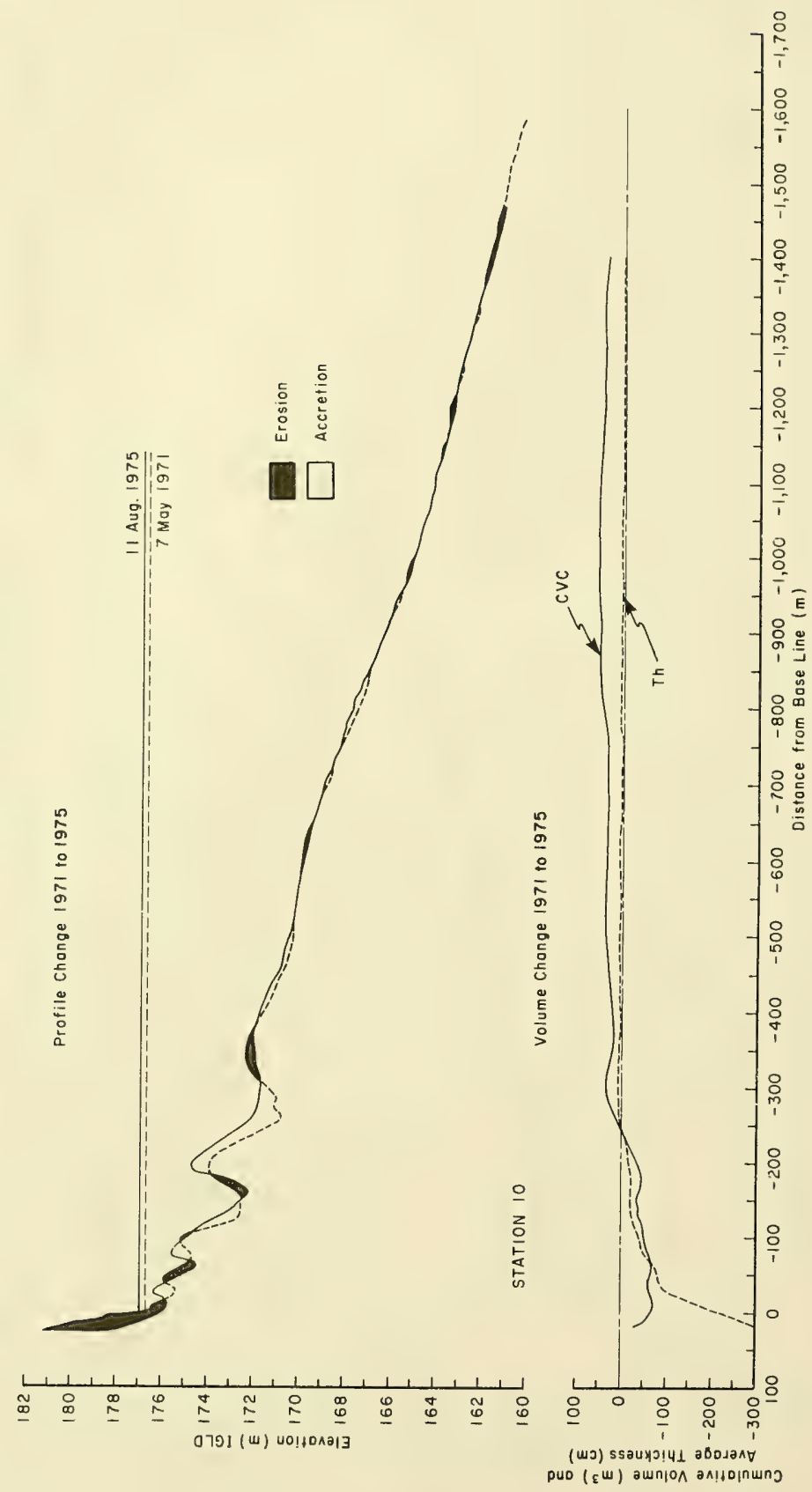




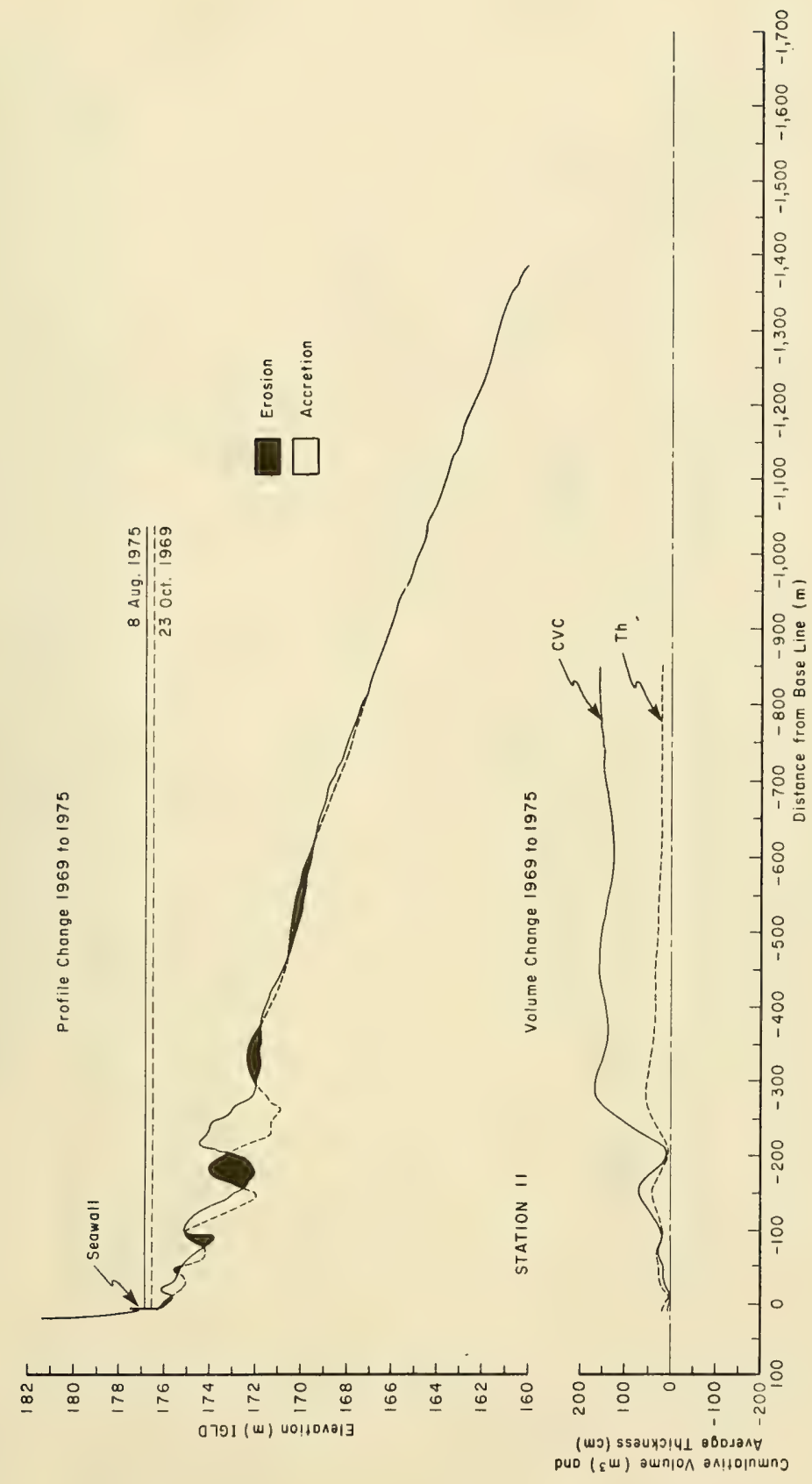




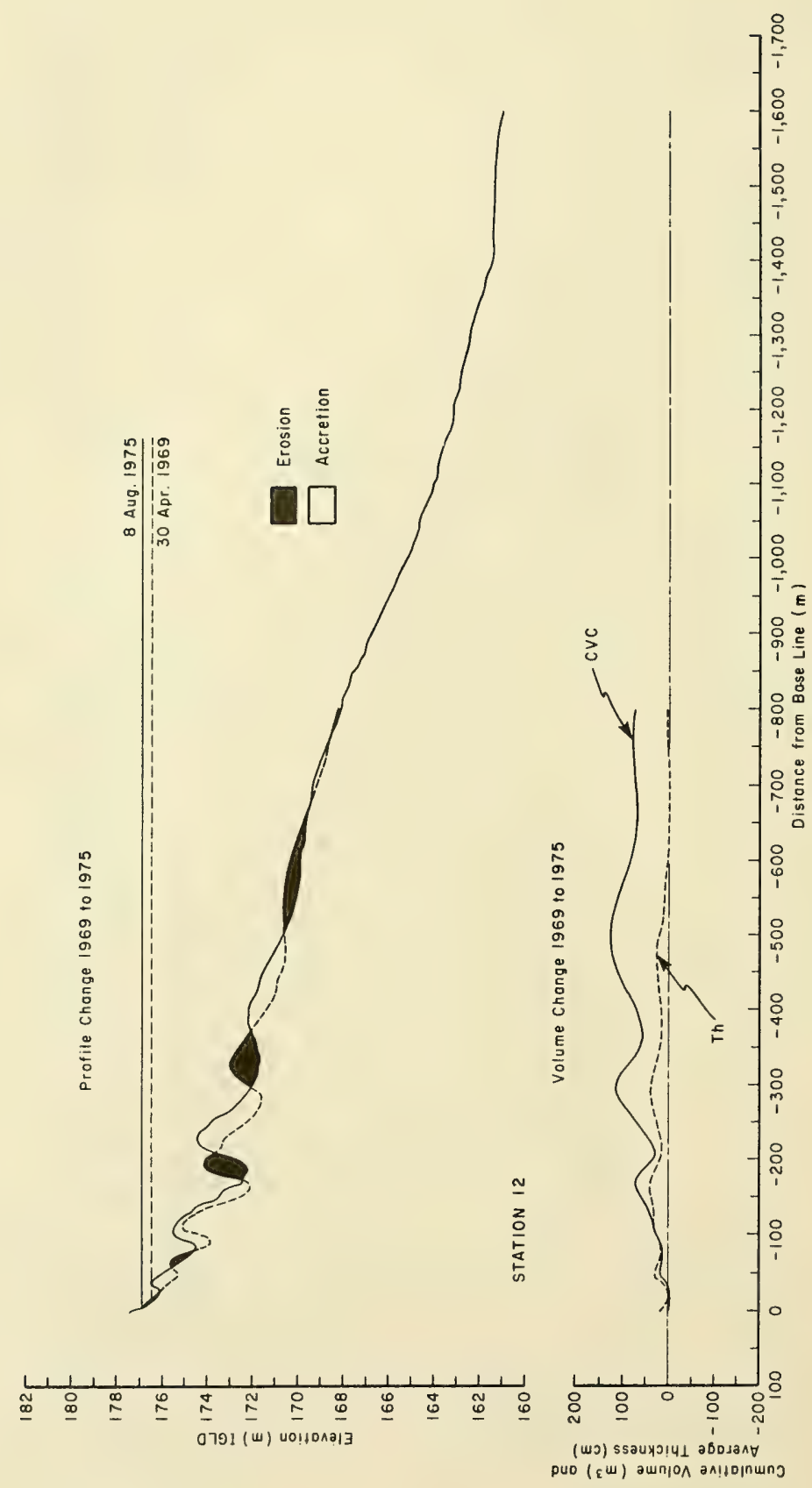




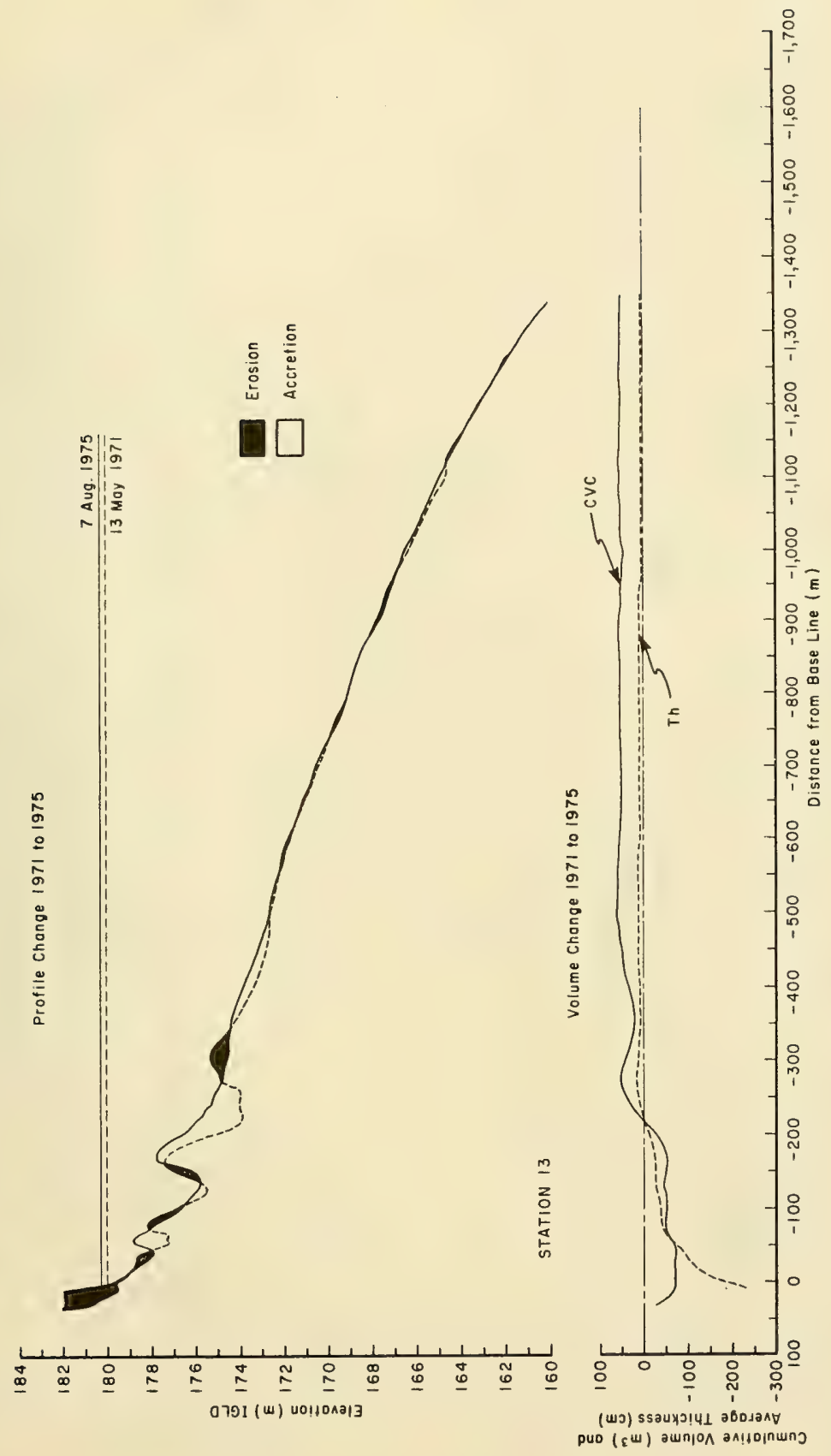




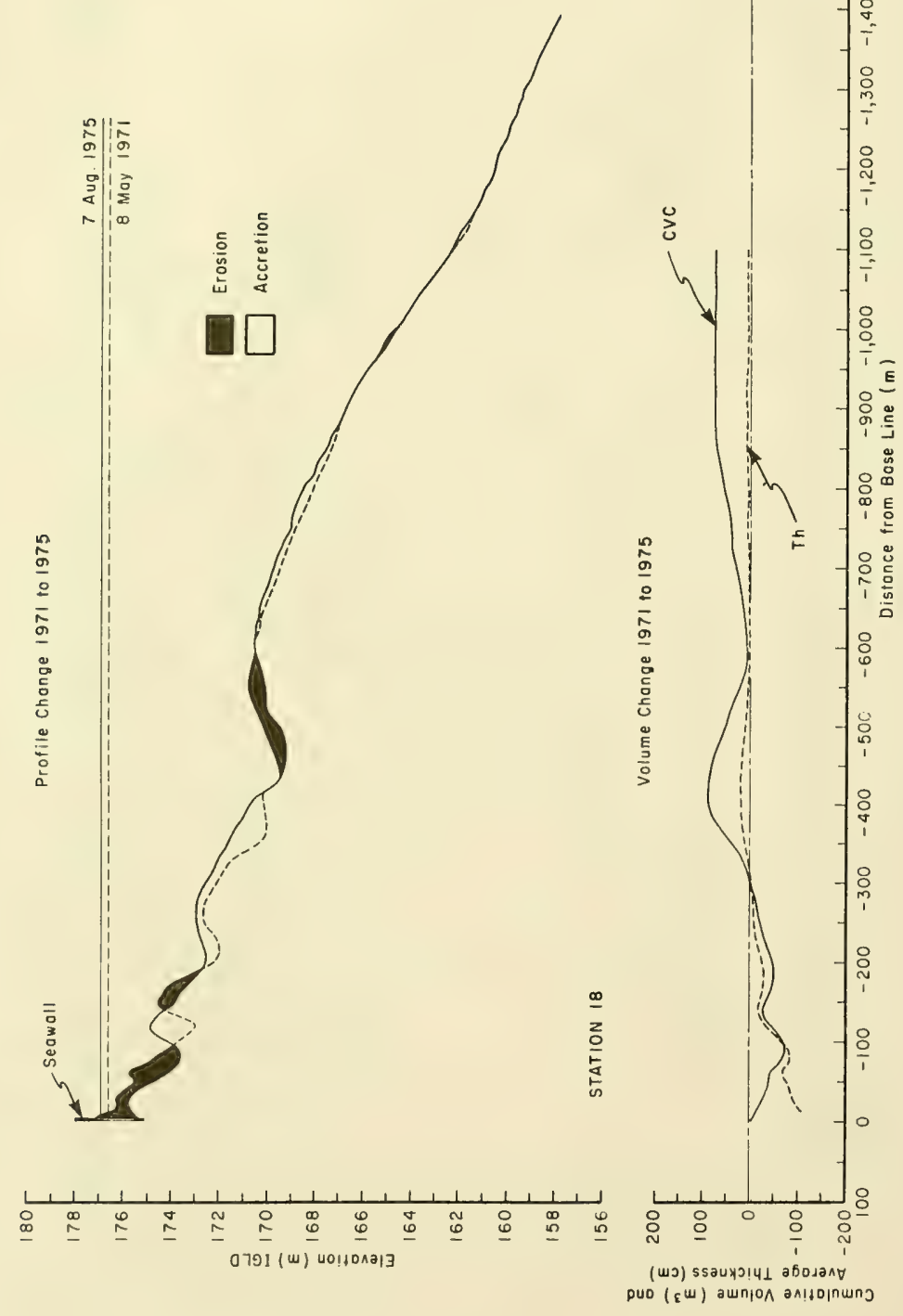




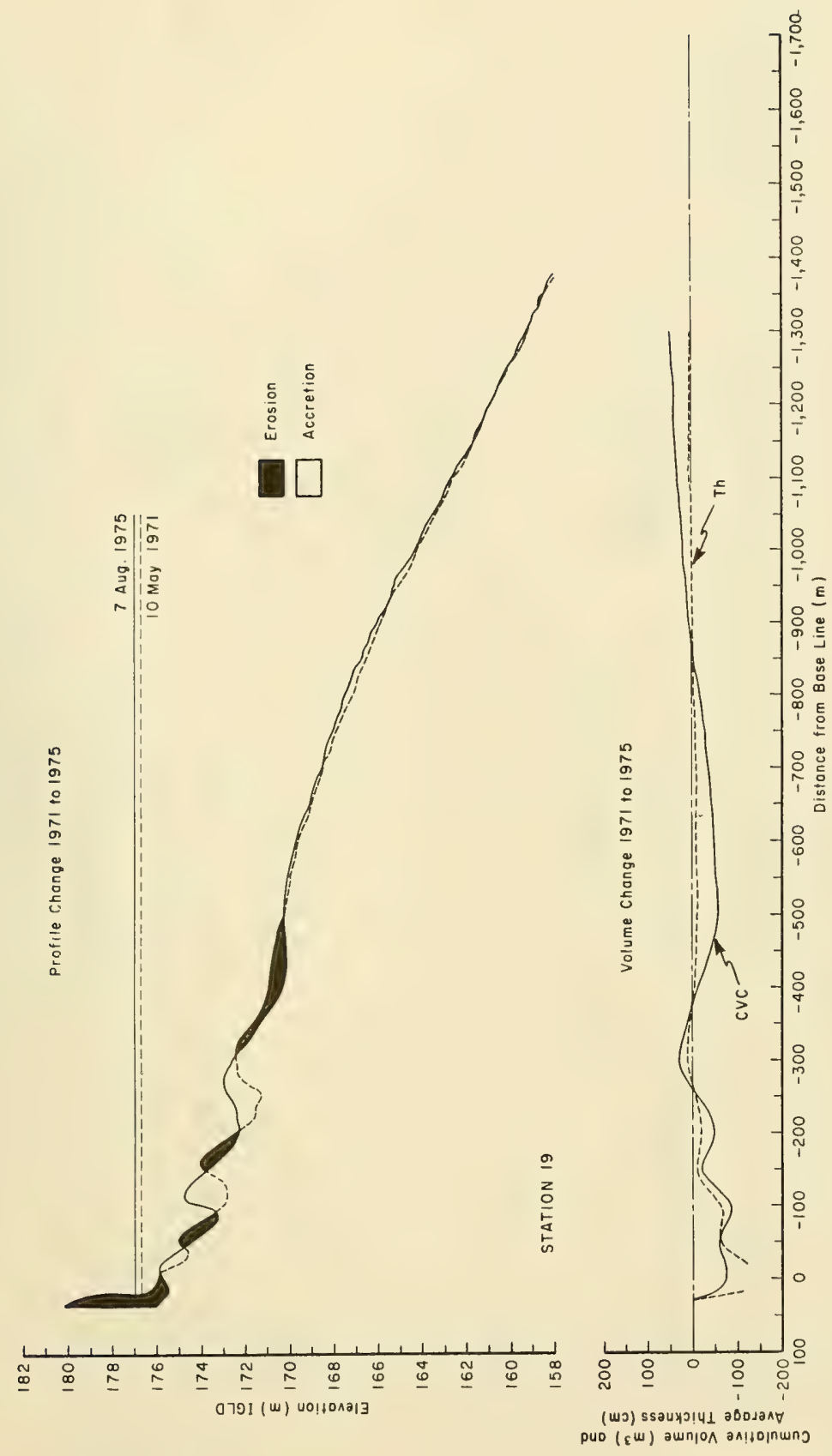




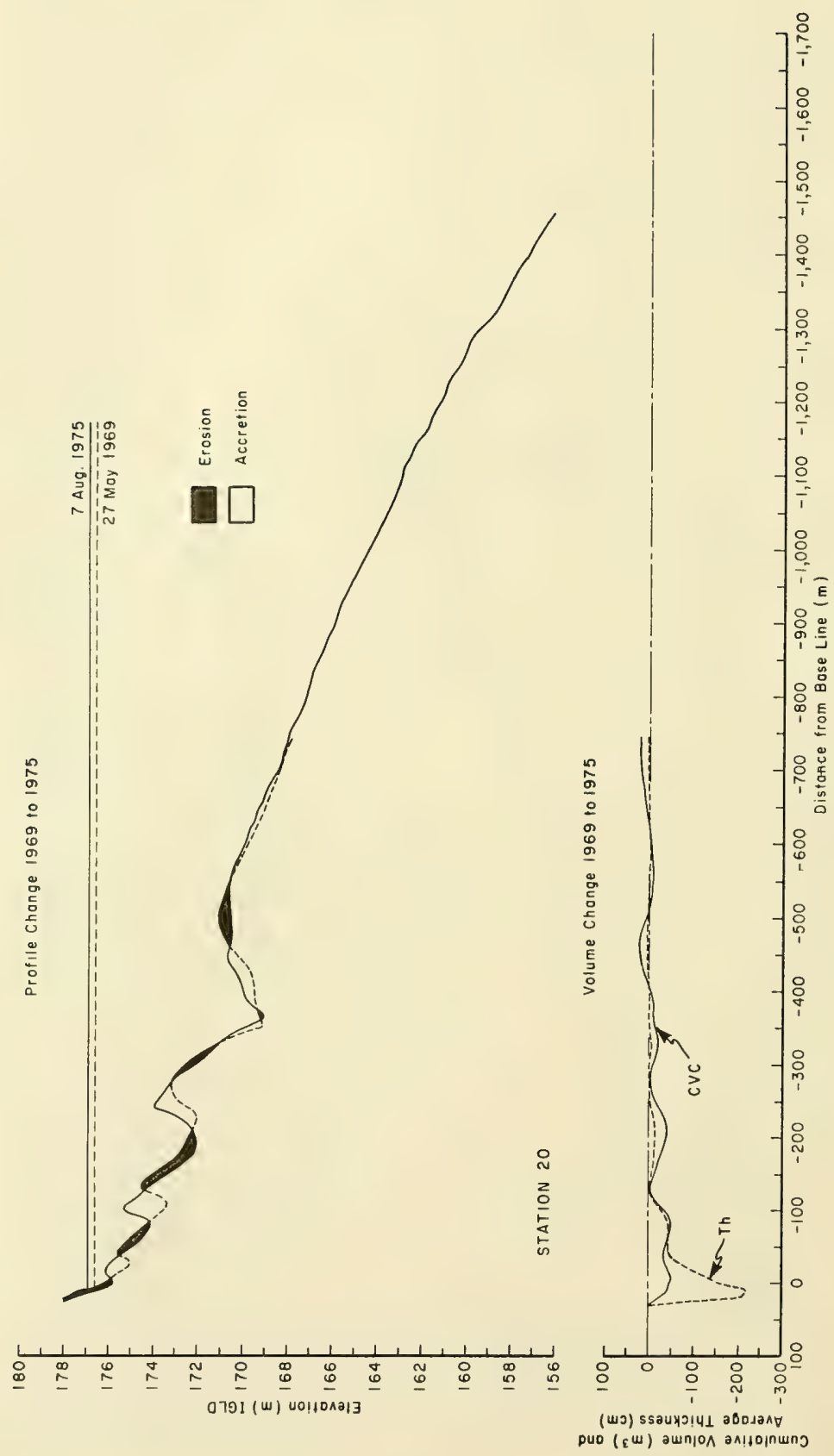




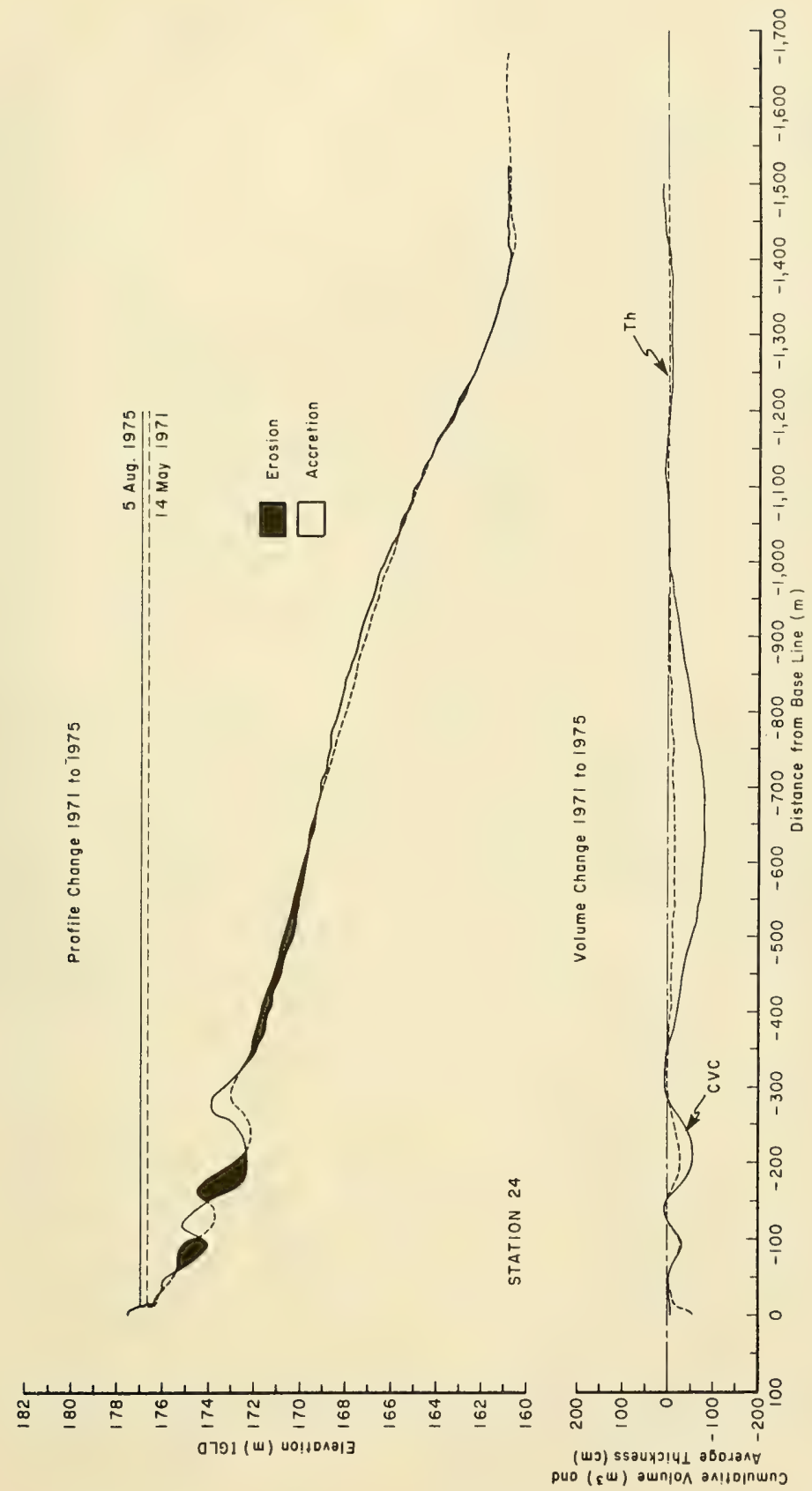




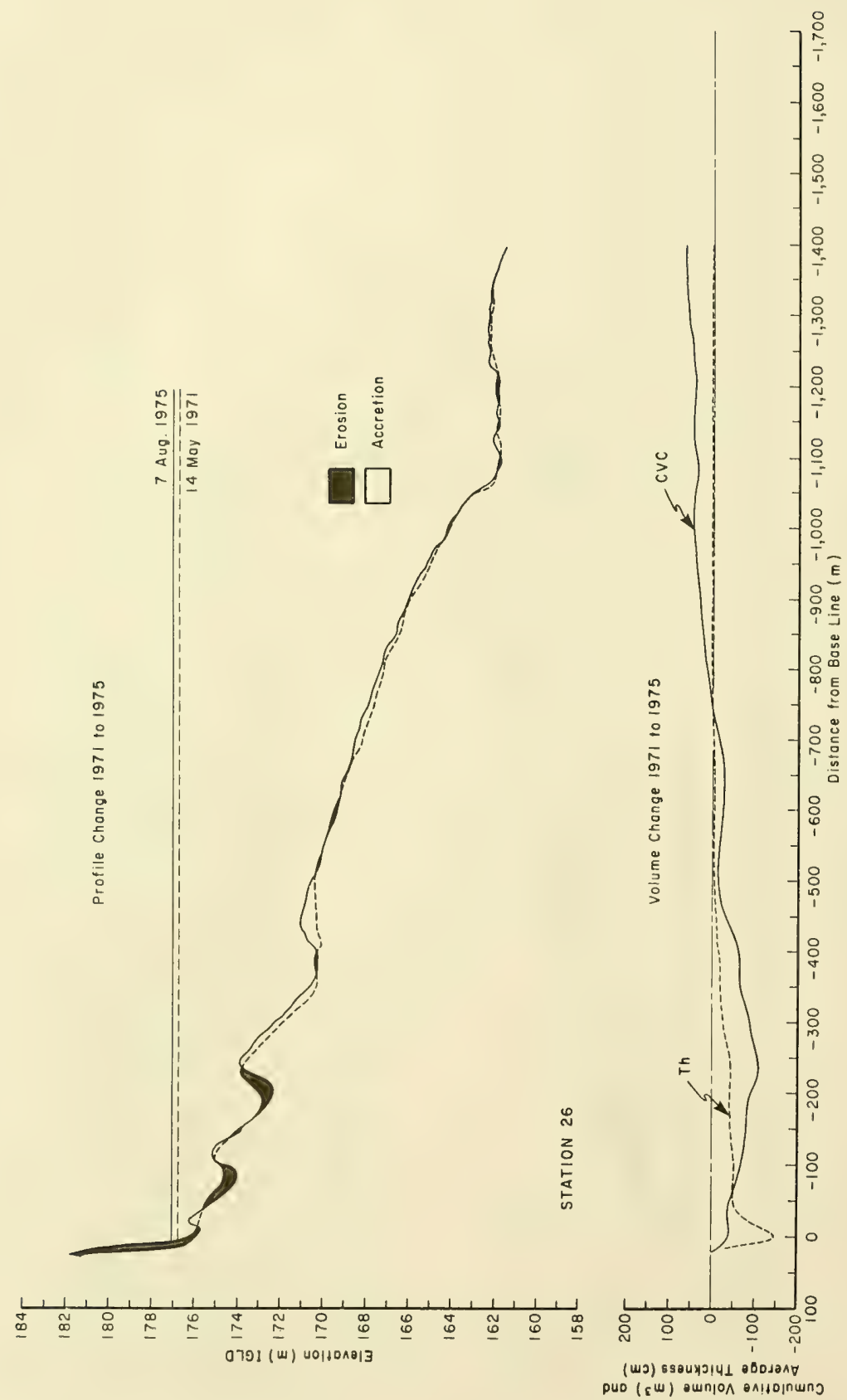




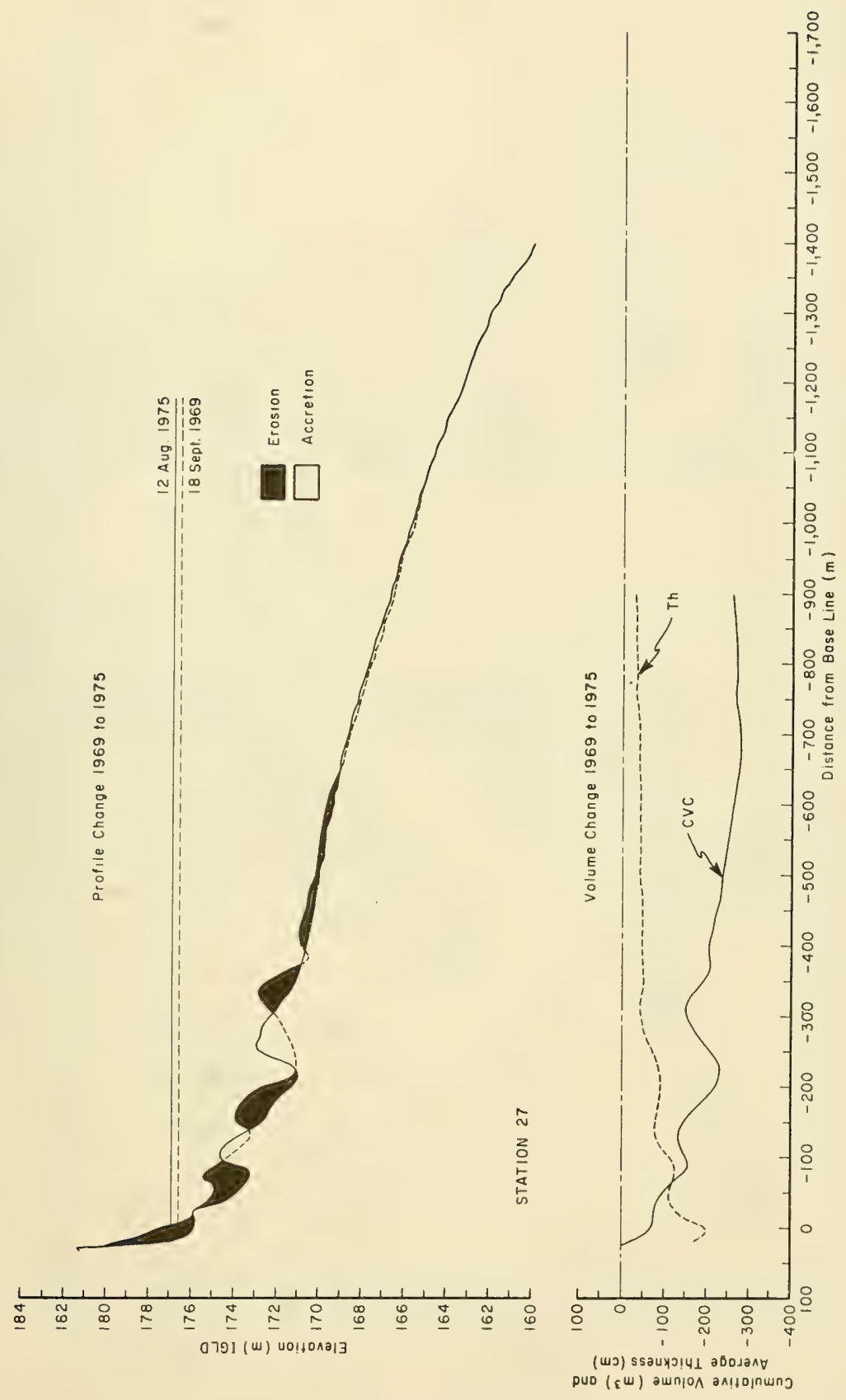




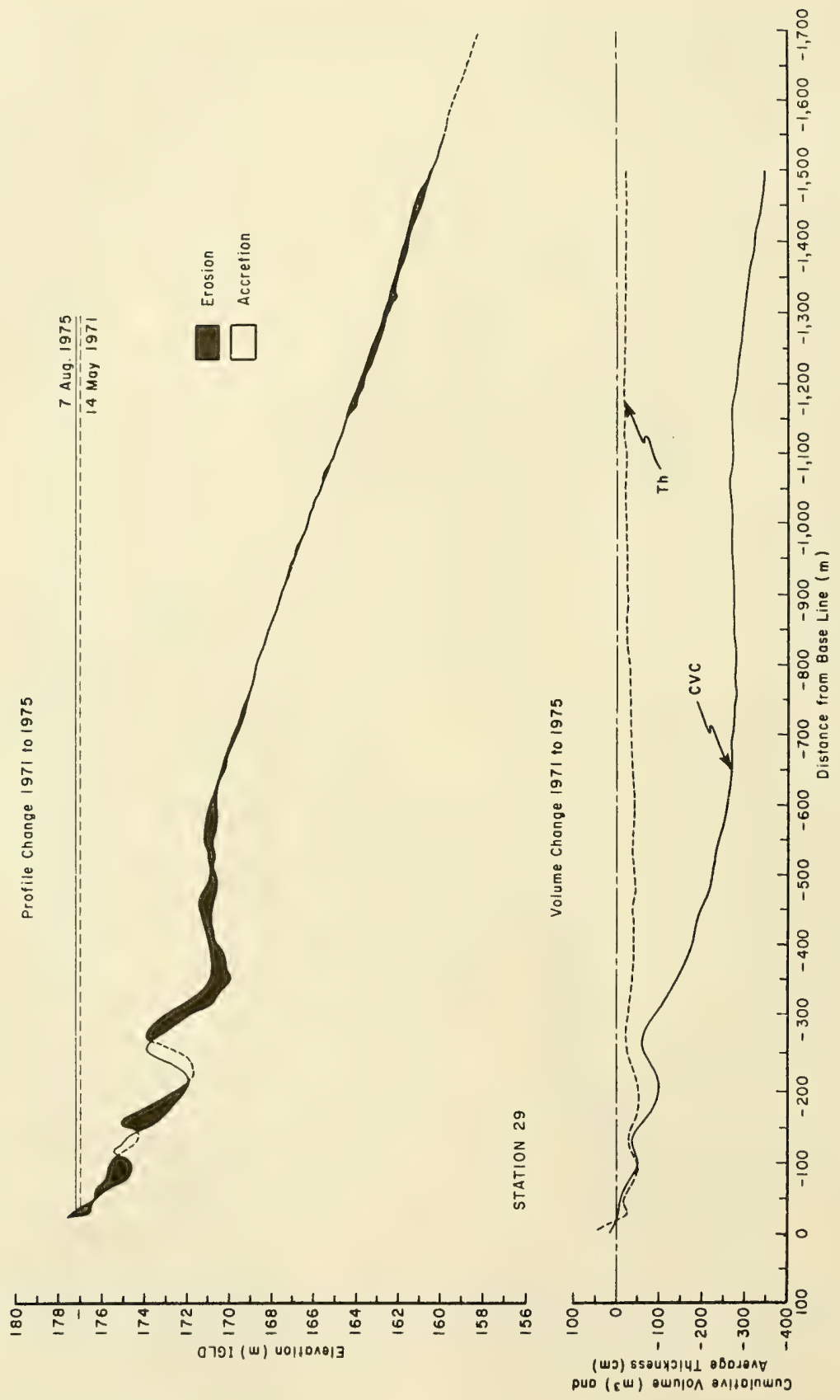




\section{APPENDIX C}

\section{VARIATIONS IN EXPOSURE TO STORM WAVES AT THE, GREAT LAKES}

This appendix presents location maps (Figs. C-1 to C-5) and wave height measurements (Tables $\mathrm{C}-1$ to $\mathrm{C}-5$ ) for the Great Lakes study sites. Heights along the fence shown below are related to the energy of storm waves obtained from a numeric hindcast model by Resio and Vincent (1976a, 1976b, 1976c, 1977, 1978).

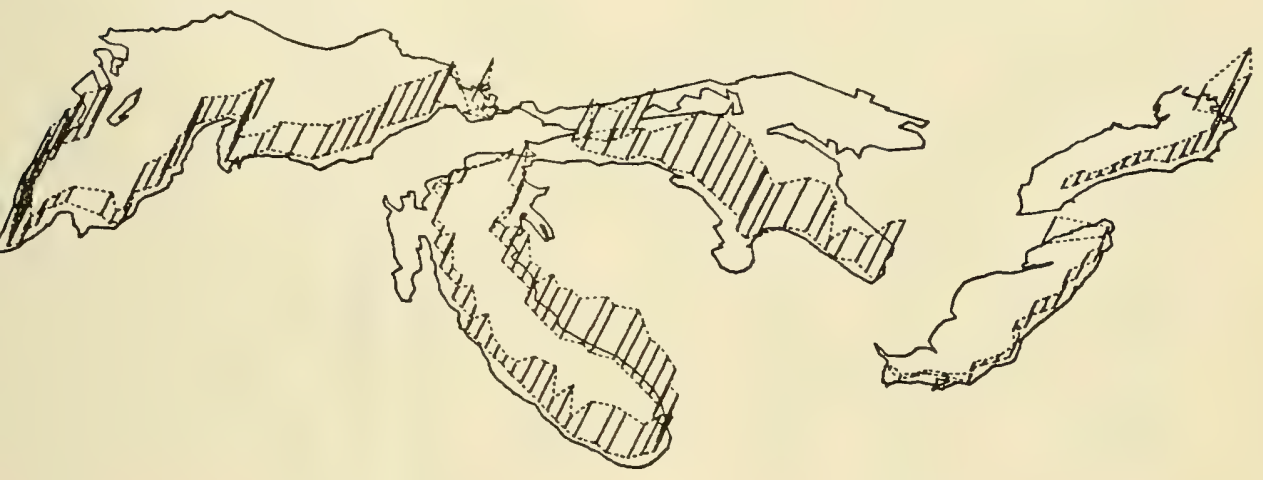




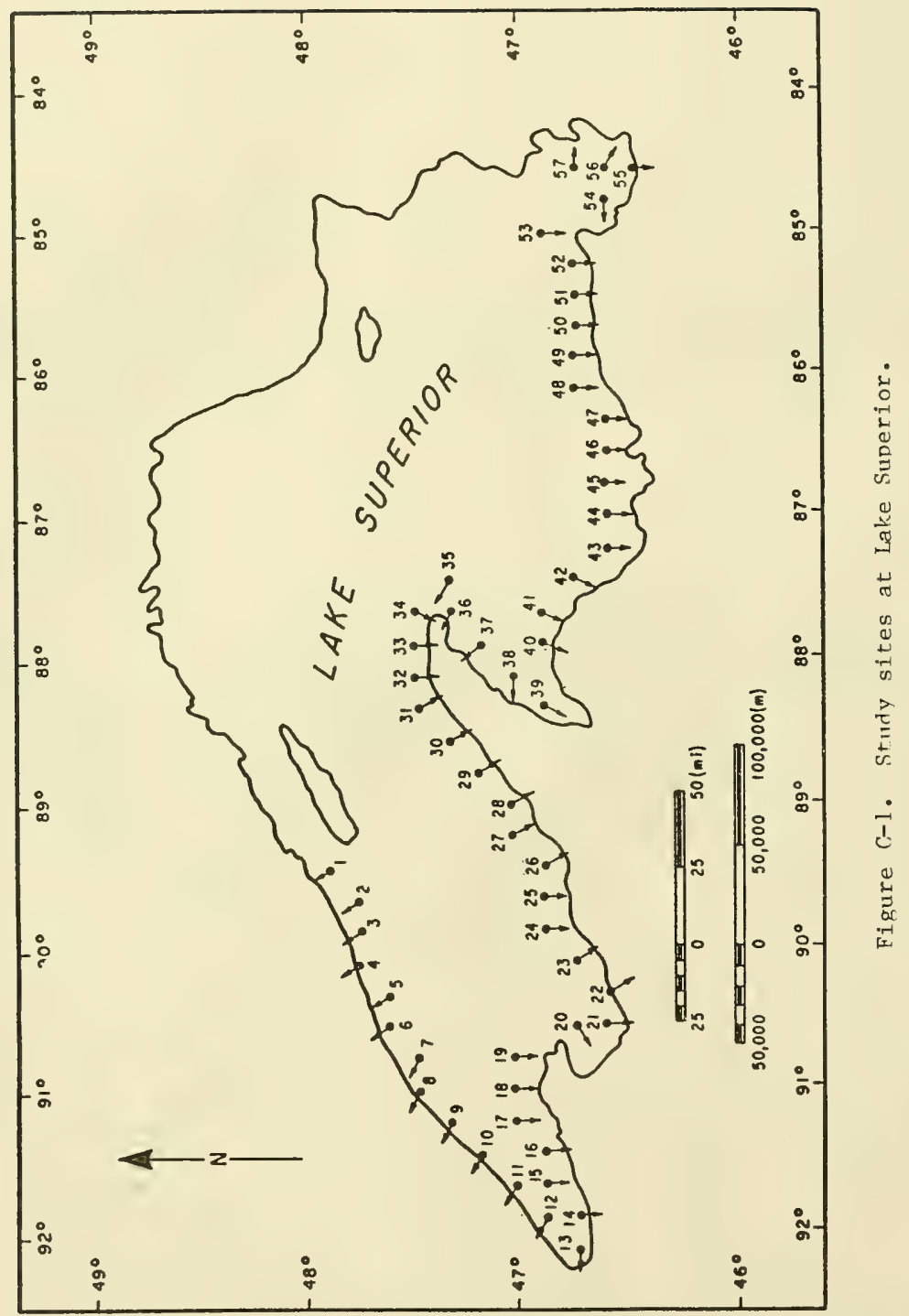


Table C-1. Wave heights (in meters) at Lake Superior study sites.

\begin{tabular}{|c|c|c|c|c|}
\hline SITE & LOCATTUN & L.ATTTUINE & L.ONG T TUIE & $\mathrm{h}_{5}$ \\
\hline 1 & PIGEON IAAY, MNA & 47.95 & 89.41 & 5.3 \\
\hline 2 & GRANII PORTAGE, MN & 47.80 & 89.63 & 5.8 \\
\hline 3 & FARQUHAR KNOIES, MEN & 47.80 & 89.83 & 5,8 \\
\hline 4 & BRULE RTVER, MN & 47.80 & 90.08 & 5.9 \\
\hline 5 & GRANII MARALS, MN & 47.66 & 90.28 & 5.9 \\
\hline 6 & POPLAR RTVER, MN & 47.66 & 90.4 .9 & 5.9 \\
\hline 7 & CARLTON PEAK, MN & 47.50 & 90.68 & 6.2 \\
\hline 8 & TACONTTE HARBOR, MAN & 47.50 & 90.91 & 6.0 \\
\hline 9 & IAAPTTSM RTVER, PSN & 47,34 & 91.11 & 6.0 \\
\hline 10 & LITTLE TWO HAREORS, MPN & 47.20 & 91,32 & 6,0 \\
\hline 11 & AGATE HAY, TIN & 47.05 & 91.52 & 5.6 \\
\hline 12 & KNTFE RTVER, MN & 46.90 & 91.72 & 5.5 \\
\hline 13 & IMLUTH, MN & 46.75 & 91.92 & 5.8 \\
\hline 14 & BRULE POTNT, WI & 46.75 & 91.72 & 4.4 \\
\hline 15 & I.RON RIVER, WT & 46.90 & 91.51 & 3.9 \\
\hline 16 & CRANBERRY RTVER, WI & 46.91 & 91.30 & 4.2 \\
\hline 17 & SJSKIWIT IAAY, W] & 47.06 & 91.09 & 3,8 \\
\hline 18 & POINT IETOUR, WI & 47.07 & 90.88 & 4.0 \\
\hline 19 & ROCKY JSLARHII, WJ. & 47.08 & 90.67 & 4.1 \\
\hline 20 & MARBLE POINT, WI & 46.78 & 90,45 & 4.6 \\
\hline 21 & SAXOR HARHOR, WJ & 46.64 & 90.45 & 3.9 \\
\hline 22 & MONTREAL RIVER, MI & $46: 64$ & 90.24 & 4.2 \\
\hline 23 & PRESQUE ISLE RIVER, MI. & 46.80 & 90.04 & 4.1 \\
\hline 24 & PORCUPINE MOUNTAINS, MI & 46.94 & 89.81 & 4.9 \\
\hline 25 & PORCUPJNE MOLITTAINS, HI & 46.94 & 89.61 & 5.0 \\
\hline 26 & ONTONAGON, ML & 46.94 & 89.40 & 5.3 \\
\hline 27 & FOURTEEN MILE POINT, MI & 47.09 & 89.19 & 5.2 \\
\hline 28 & ELM RTVER, MI & 47,11 & 88.98 & 5.4 \\
\hline 29 & REIRTGEE, MJ. & 47.24 & 88.77 & 5.3 \\
\hline 30 & CALLUMET, MI & 47.38 & 88.55 & 5.3 \\
\hline 31 & EAGILE KTVER, MI & 47.53 & 88.34 & 4.9 \\
\hline 32 & EAGLE HARBOR, MT & 47.53 & 88.14 & 4.7 \\
\hline 33 & COPPER HAREOR, MI & 47.53 & 87.91. & 4.5 \\
\hline 34 & SCHLATTER LAKE, MI & 47.53 & $87 \cdot 7-0$ & 4,3 \\
\hline 35 & MONTTOU ISL.ANI, MI & 47.38 & 87.49 & 5.4 \\
\hline 36 & KEWEENAW POTNT, MI & 47.38 & 87.70 & 5.5 \\
\hline 37 & POTNT ISABELLEE, MI & 47.24 & 87.91 & 5.4 \\
\hline 38 & TRAVERSE POINT, MI & 47.09 & 88,14 & 5.5 \\
\hline 39 & PEQUUAMTNG, MI. & 46,95 & 88.35 & 4.7 \\
\hline 40 & HURON RTVER POINT, MI & 46.95 & 87.91 & 4.4 \\
\hline 41 & FIG BAY, MI & 46.95 & 87.70 & 4.8 \\
\hline 42 & GARLIC POINT, MI & 46.81 & 87.50 & 4.9 \\
\hline 43 & MARQQUETTE, HI]. & 46.66 & 87.29 & 5.1. \\
\hline 44 & IIEERTON, MI & 46.66 & 87.08 & 5.2 \\
\hline 45 & AU TRAIN FAY, MI. & 46.66 & 86.86 & 5.1 \\
\hline 46 & GRANII ISLANI, MI & 46.66 & 86.65 & 5.3 \\
\hline 47 & GRANII PORTAL, POINT, MI & 46.65 & 86.45 & 5.4 \\
\hline 48 & AU SAELE POINT, MI & 46.79 & 86.23 & 5.5 \\
\hline 49 & GRANI MARAIS, MI & 46.78 & 86.02 & 5.5 \\
\hline 50 & SUCKER RIVER, MI & 46.78 & 85.80 & 5.5 \\
\hline 51 & IIEER PARK, MI & 46.79 & 85.60 & 5.6 \\
\hline 52 & LITTLE LAKE HARROR, MI & 46.77 & 85.39 & 5.6 \\
\hline 53 & CRISFP POINT, MI & 46.91 & 85.18 & 5.3 \\
\hline 54 & PARALIISE, MI & 46.62 & 84,97 & 3.0 \\
\hline 55 & POINT JROOUOYS, MI & 46.46 & 84.75 & 3.9 \\
\hline 56 & GROS CAP, MI & 46.61 & 84.76 & 3.0 \\
\hline 57 & GOULAIS RIVER, MI & 46.76 & 84.75 & 5.5 \\
\hline
\end{tabular}




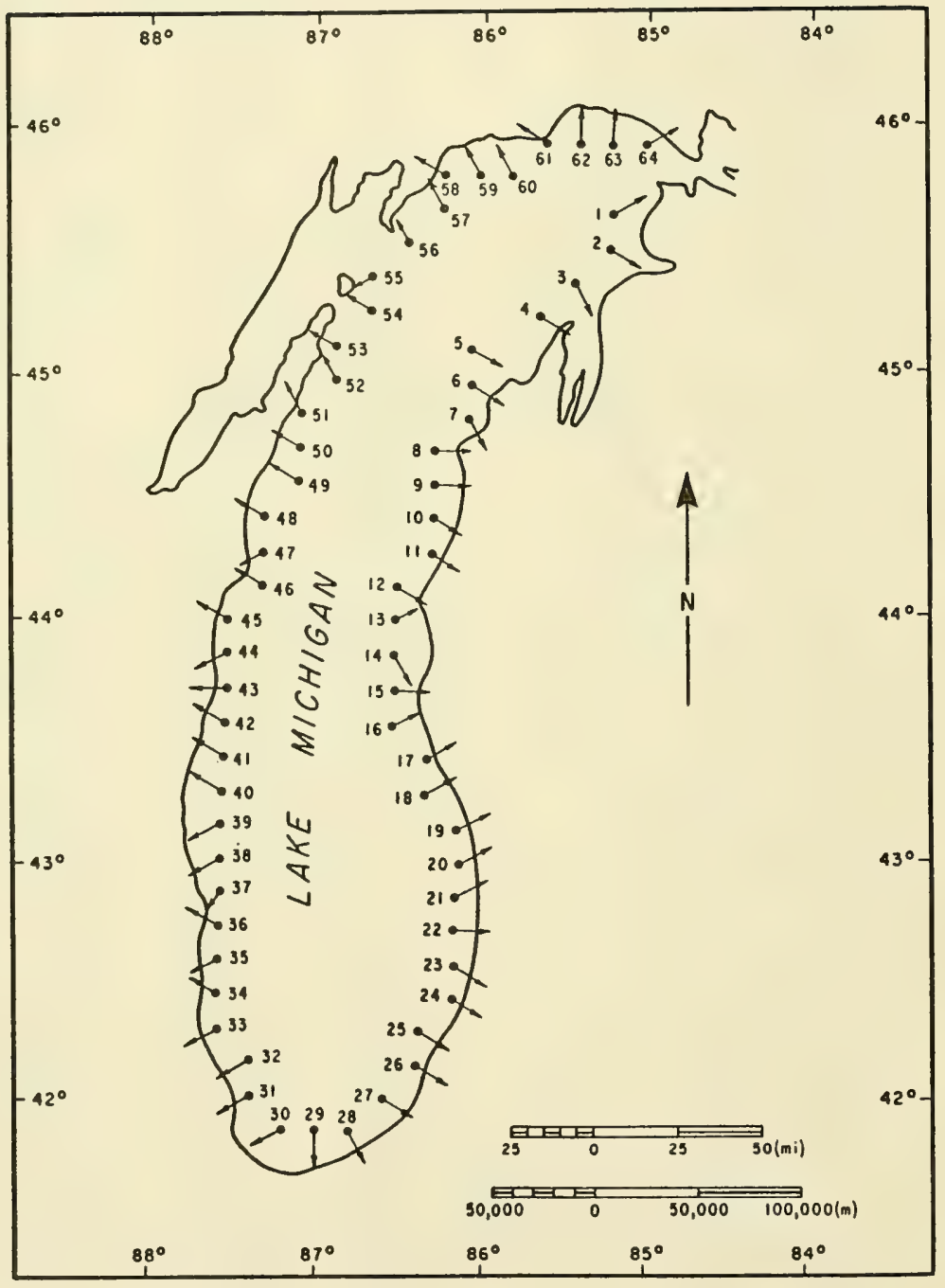

Figure C-2. Study sites at Lake Michigan. 
Table C-2. Wave heights (in meters) at Lake Michigan study sites.

\begin{tabular}{|c|c|c|c|c|}
\hline SITE & LOCATION & L.ATI I TUGE & LONG I TUIJE & $h_{5}$ \\
\hline 1 & STIIRGF CIN HAY, MJ. & 45.64 & 85.32 & 5.4 \\
\hline 2 & HARFOR SPRTNG, MI & 45.50 & 85.32 & 3.7 \\
\hline 3 & FISHERMAN TSLANH, MI & 45.37 & 85.50 & 4,3 \\
\hline 4 & TRAVERSE BAY, MI & 45.23 & 85.72 & 4.1 \\
\hline 5 & TRAVERSE CITY, HI & 45,10 & 86,15 & 3.7 \\
\hline 6 & MANCTOU, ME & 44,95 & 86.15 & 3.9 \\
\hline 7 & PLATTE I.GKE, MI & 44.80 & 86,17 & 4,6 \\
\hline 8 & FRANKFORT, iqt & 44,68 & 86.39 & 5,2 \\
\hline 9 & ARCAII]A, MT. & 44,53 & 86,40 & 5,2 \\
\hline 10 & ONEKAMA, MI & 44,38 & 86,40 & 4.3 \\
\hline 1.1 & MANISTEE, MJ & 44,24 & 86,41 & 4,5 \\
\hline 12 & BIG SAKLE POTNT, MI & 44.09 & 86.63 & 4,3 \\
\hline 13 & LUEIINGTON, MJ. & 43.94 & 86.64 & 5.3 \\
\hline 14 & PENTUATER, MI & 43.80 & 86.66 & 5.1 \\
\hline 15 & LITTLE SARLE POINT, MI & 43.65 & 86.66 & 5,4 \\
\hline 16 & FENONA, MI & 43.52 & 86.67 & 5.4 \\
\hline 17 & MONTAGUE, MI & 43,36 & 86,48 & 5.7 \\
\hline 18 & MIJSKEGON, $\mathrm{MI}$ & 43,23 & 86.50 & 5.7 \\
\hline 19 & GRANIIE HAUEN, MI & 43.06 & 86.32 & 5.8 \\
\hline 20 & GRANIE RAPLIS, MI & 42,93 & 86.33 & 5.6 \\
\hline 21 & HOLLAANI, HI & 42.78 & 86.33 & 5,3 \\
\hline 22 & IIOUGLAAS, MI & 42.64 & 86.35 & 5,4 \\
\hline 23 & SOUTH HAVEN, MJ. & 42.48 & 86.36 & 5,3 \\
\hline 24 & S SOUTH HAVEN, MI & 42,34 & 86.37 & 5.2 \\
\hline 25 & BENTON HAREOR, MI & 42.21 & 86.57 & 5,0 \\
\hline 26 & S ST, JOSEPH, MI & 42.06 & 86,58 & 5,0 \\
\hline 27 & NEW BUFFALO, M]. & 41.93 & 86.78 & 4,8 \\
\hline 28 & MICHIGAN CITY, INO & $41: 78$ & 86.99 & 5.2 \\
\hline 29 & BURNS HARHOR, INII & 41.79 & 87.18 & 5.4 \\
\hline 30 & CHICABO, TLLL & 41.80 & 87.38 & 5,1 \\
\hline 31 & CH]CAGO SHIP CANAL, ILL. & 41.95 & 87.56 & 5.4 \\
\hline 32 & EVANSTON, TLL & 42.10 & 87.56 & 5.3 \\
\hline 33 & HIGHLANI PARK, ILL. & 42,26 & 87.73 & 5,2 \\
\hline 34 & WAUKEGAN, TLL & 42.40 & 87.73 & 3.8 \\
\hline 35 & KENOSHA, WT & 42.54 & 87.73 & 5.2 \\
\hline 36 & $S$ RACINE, WI & 42.69 & 87.71 & 3.9 \\
\hline 37 & N RACINE, WI. & 42.83 & 87,70 & 5.2 \\
\hline 38 & $S$ BTILWALIKEE, WI & 42.97 & 87.69 & 5.0 \\
\hline 39 & MILWAUKEE, WY. & 43,12 & 87,68 & 4.8 \\
\hline 40 & S POIRT WASHINGTON, WI & 43.27 & 87.68 & 3.9 \\
\hline 41. & PORT WASHINGTON, WI & 43.41 & 87.67 & 3.7 \\
\hline 42 & N PORT WASHINISTON, WI & 43.55 & 87.66 & 3,8 \\
\hline 43 & S SHEBOYGAN, WI & 43.69 & 87.65 & 4.0 \\
\hline 44 & N SHEBOYGAN, WI & 43.84 & 87.65 & 4.7 \\
\hline 45 & MANITOWOC, WI & 43.98 & 87.64 & 3.8 \\
\hline 46 & TWO RIVERS, WI & 44.13 & 87,43 & 3.7 \\
\hline 47 & RAWLEY POINT, WI & 44.27 & 87.42 & 4.5 \\
\hline 48 & KEWAIJNEE, WI & 44.42 & 87,41 & 3.8 \\
\hline 49 & ALGOMA, WI & 44.56 & 87.20 & 3.6 \\
\hline 50 & STURGEON BAY CANAL, WI & 44.70 & 87.20 & 3.6 \\
\hline 51 & JACKSONPURT, WI & 44.84 & 87.18 & 4.7 \\
\hline 52 & BAILEYS HARBOR, WI & 44.98 & 86.98 & 4.5 \\
\hline 53 & N CANAL LIGHT, WI & 45,14 & 86.96 & 3.6 \\
\hline 54 & WASHINGTON ISLANII, WI & 45.27 & 86.74 & 3.4 \\
\hline 55 & FISHERMAN SHCIAL, WI & 45,41 & 86.73 & 3.2 \\
\hline 56 & ESCANAEA, MI & 45,54 & 86.52 & 4.7 \\
\hline 57 & POINT AUX KARQSUES, MI & 45.68 & 86,30 & 4.1 \\
\hline 58 & N POINT AUX BARQUJES, MI & 45,83 & 86.29 & 3.3 \\
\hline 59 & MANISTJRIJE:, MI & 45.83 & 86.08 & 3.9 \\
\hline 60 & PORT ISLANII, MI & 45.81 & 85.88 & 3.7 \\
\hline 61 & POTNT PATTERSON, MI & 45.94 & 85.66 & 2.6 \\
\hline 62 & MILLE COQUTNS REFF, MI & 45.94 & 85.45 & 2.2 \\
\hline 63 & SAULE STE MARIE, MI & 45.93 & 85,25 & 2.4 \\
\hline 64 & BREWOORT LAKE, MI & 45.92 & 85.04 & 3.7 \\
\hline
\end{tabular}




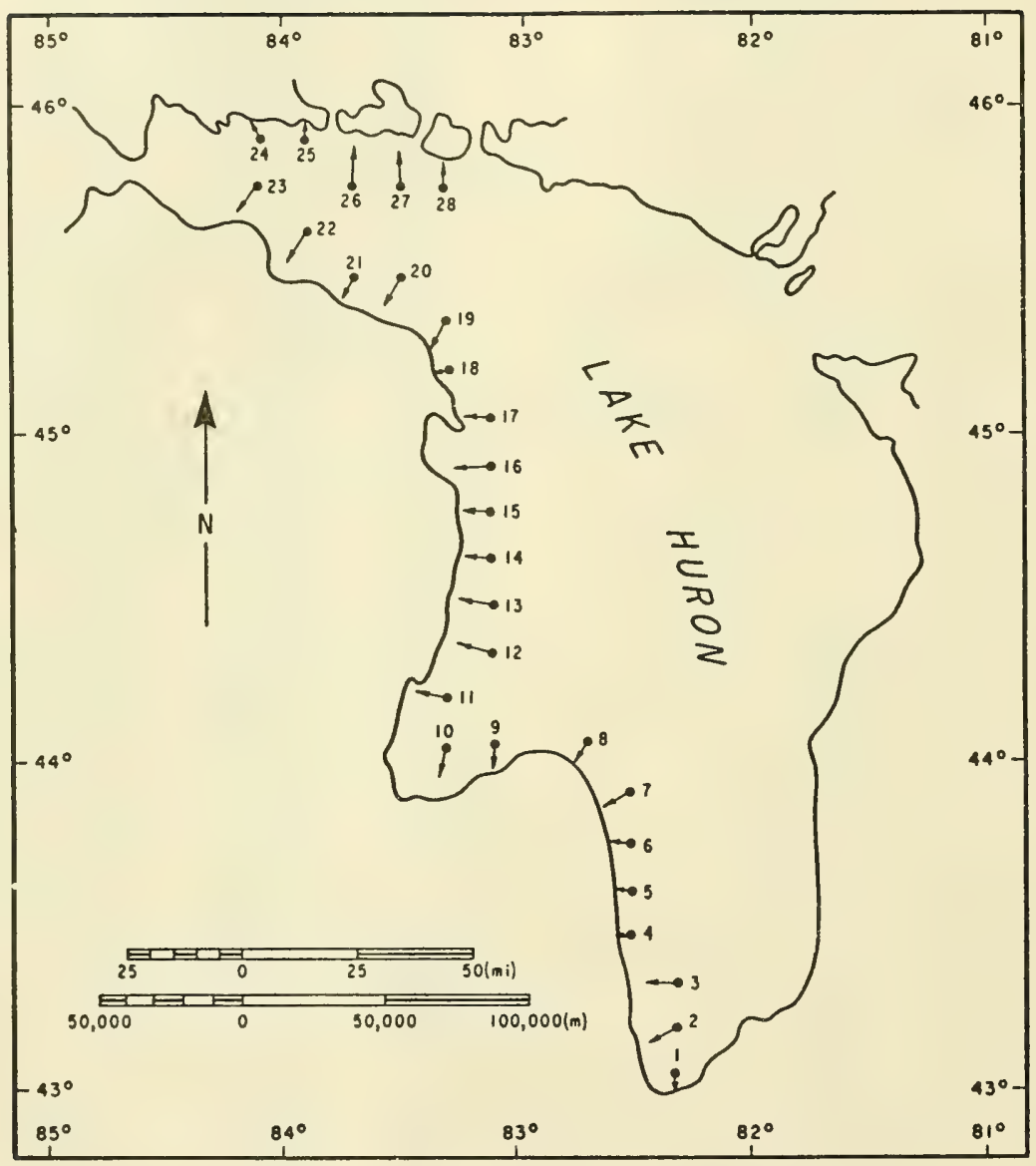

Figure C-3. Study sites at Lake Huron. 
Table C-3. Wave heights (in meters) at Lake Huron study sites.

\begin{tabular}{|c|c|c|c|c|}
\hline STTE & LOCATTON & L.ATTTUTIE & L.ONGTTUME & $h_{5}$ \\
\hline 1. & PORT HURON, MT. & 43,02 & 82.33 & 6.2 \\
\hline 2 & LAKEPORT, HT & 43,16 & $82 \cdot 33$ & 5.8 \\
\hline 3 & LEXINGTON, MI. & 43,31 & 82,33 & 4.7 \\
\hline $1+$ & PORT SANTIAC, MI & 43.45 & 82.52 & 5,0 \\
\hline 5 & FORESTUTILE, MT. & 43.59 & 82,52 & 3.7 \\
\hline 6 & HELLENA, MT & 4.3 .74 & 82.52 & 5.4 \\
\hline 7 & HARBOR BEACH, WI & 43.88 & 82.52 & 5.7 \\
\hline 8 & HURON CTTY, MT & 44,03 & 82.71 & 5.8 \\
\hline 9 & PORT CRESCENT, MT & 44,03 & 83.11 & 5,9 \\
\hline 1. 0 & ENTRANCE SAGTNAW BAY, MT & 44,03 & 83.30 & 6.0 \\
\hline 11. & TAWAS CITY, MI & 44.17 & 83,30 & 6.2 \\
\hline 1.2 & OSCORA AU SABLE, MT & 44.31 & 83.11 & 5.9 \\
\hline 13 & GREENBUSH, MT. & 44,46 & 83,11 & 5.9 \\
\hline 14. & HARRTSVILLE, MT & 44.60 & $8.3,1.1$ & 6.2 \\
\hline ]. 5 & BLACK RLVER, MJ. & 44.74 & 83.11 & 6.1 \\
\hline 1.6 & OSSTNEKE, MI & 44.89 & 83,11 & 6.1 \\
\hline 17 & NORTH POTNT, MT & 45.04 & 83,11 & 6.1 \\
\hline 18 & ROCKPORT, MI & 45,18 & 83.30 & 6.0 \\
\hline 19 & STONE PORT, MT & $45 ;, 32$ & 83.30 & 5.2 \\
\hline 20 & AlHAS POINT, MI & 45,46 & 83.50 & 4.6 \\
\hline 21. & ROGERS UTTY, MI & 45,46 & 83,70 & 5,0 \\
\hline 22 & HAMMONO BAY, MI & 45.61 & 83.90 & 4.7 \\
\hline 23 & CORTHOOM POTNT, औT & 45,75 & 84.09 & 4,2 \\
\hline 24 & POINT OOIDMTTE, NI. & 45.89 & 84.09 & 5.4 \\
\hline 25 & IIETOUR REEF", M] & 45.89 & 83.90 & 5.0 \\
\hline 26 & W ENI TRUMAONO ISLANM, HT & 45,75 & 83.70 & 4.9 \\
\hline 27 & FALSE METOUIR CHANNEL, MT & 45,75 & 83.50 & 5.4 \\
\hline 28 & COCKBURN ISLAMO, MI & $1.5,75$ & 83.30 & 5.6 \\
\hline
\end{tabular}




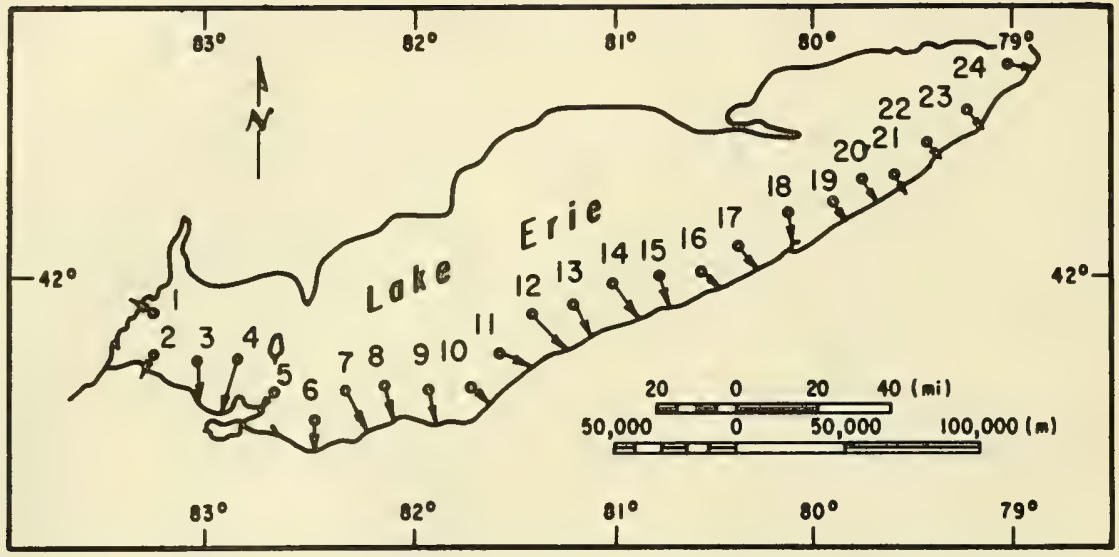

F1gure C-4. Study sites at Lake Erle.

Table C-4. Wave helghts (in meters) at Lake Erie study sites.

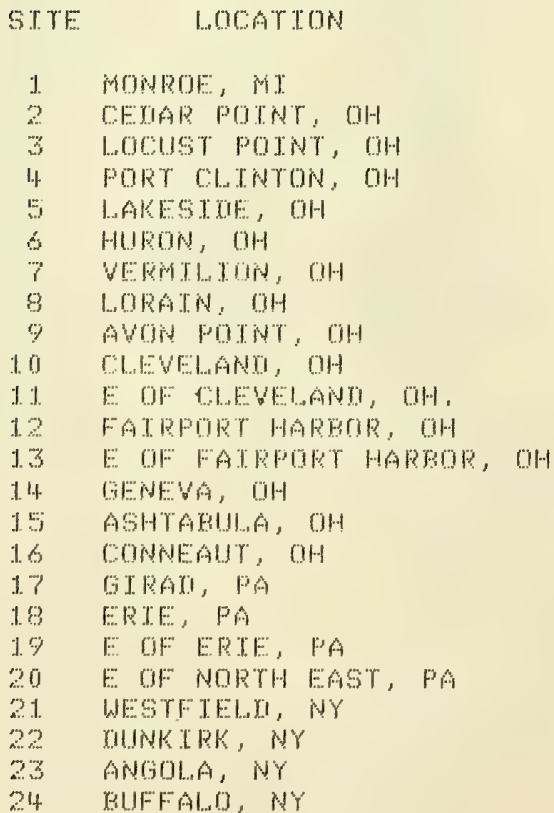

LATTRUE LONGTTUE $\quad h_{5}$

\begin{tabular}{|c|c|c|}
\hline 41.87 & 83.27 & 3.2 \\
\hline 41,72 & 83.27 & 3,1 \\
\hline 4.70 & 03,07 & 2.9 \\
\hline 41.69 & 02.50 & 3.0 \\
\hline 41,57 & 82.70 & 2 \\
\hline 4.1 .42 & 82.50 & 3.5 \\
\hline 41,67 & 82.30 & 3.1 \\
\hline 41,57 & 82,12 & 3 \\
\hline 41,56 & 91.93 & 3. \\
\hline 41.56 & 81.73 & 3.5 \\
\hline 41,68 & 81.53 & 3.7 \\
\hline 41.90 & 81,35 & 3 \\
\hline 41,97 & 81,17 & 3.5 \\
\hline $1+1,52$ & 00.90 & 4. \\
\hline $4 \%, 61$ & 80.78 & 4.1 \\
\hline 41,50 & 80.60 & 4. \\
\hline 42,12 & 80.38 & 4. \\
\hline 42,27 & 00.17 & 3.5 \\
\hline 42.27 & 79.98 & 4.0 \\
\hline 42,41 & 79,75 & 4,0 \\
\hline $42,+1$ & 79.57 & 4.1 \\
\hline 42,56 & 79.35 & 3,4 \\
\hline 42.68 & 79.15 & 3 \\
\hline 42,83 & 79.94 & 4. \\
\hline
\end{tabular}




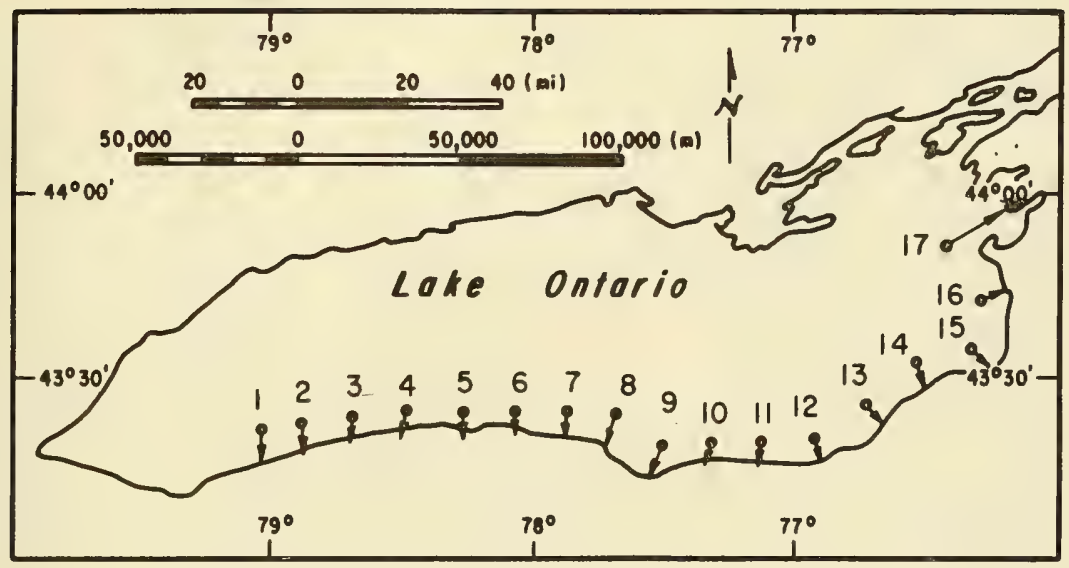

Figure C-5. Study sites at Lake Ontario.

Table C-5. Wave heights (in meters) at Lake Ontario study sites.

\section{STTE LOCATTON}

1. FORT NTAGARA, NY

2 WIISON, NY

3 APPLETON, NY

4. THIRTY MILE POTIT, HY

5 L..AKETSE: PARK, NY

6 KENTALLL, AY

7 DOWTH HAMl, TU, MY

3 WEST ROCHESTER, NY

9 EAST POCHESTEF, NY

LO PUILTNEYUTLE, NY

1. Sorius, NY

12 WOHOOTr, NY

1. FATRHAVEN, NY

1. OSUFOO, NY

1.: I.ACINA, NY

16 EFILEVILLE, NY

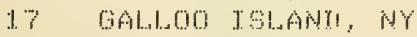

\section{L.ATTTULE LONGTTUEF $\mathbf{h}_{5}$}

\begin{tabular}{|c|c|c|}
\hline $4.3,43$ & 79.03 & 3.0 \\
\hline $4.5,43$ & 73.83 & 4,1 \\
\hline 43.45 & 78.63 & 3.4 \\
\hline 43,45 & 78.46 & 3.4 \\
\hline 43,45 & 78.250 & 3. \\
\hline $4.3,47$ & 79.07 & 3,7 \\
\hline 43,47 & 77.87 & 3 \\
\hline 43.48 & 77.65 & 3. \\
\hline 43,37 & 77,47 & 4. \\
\hline 43,37 & 77.25 & 小， \\
\hline $1.3,38$ & 77.07 & 4. \\
\hline 43,38 & 76.87 & 4. \\
\hline $1+3.48$ & 76.69 & 5 \\
\hline 43.63 & 76,50 & 5. \\
\hline $4.3,63$ & 76.28 & 5. \\
\hline $4 \%, 77$ & 76.28 & 6,1 \\
\hline 4.3 .91 & 76.50 & \\
\hline
\end{tabular}





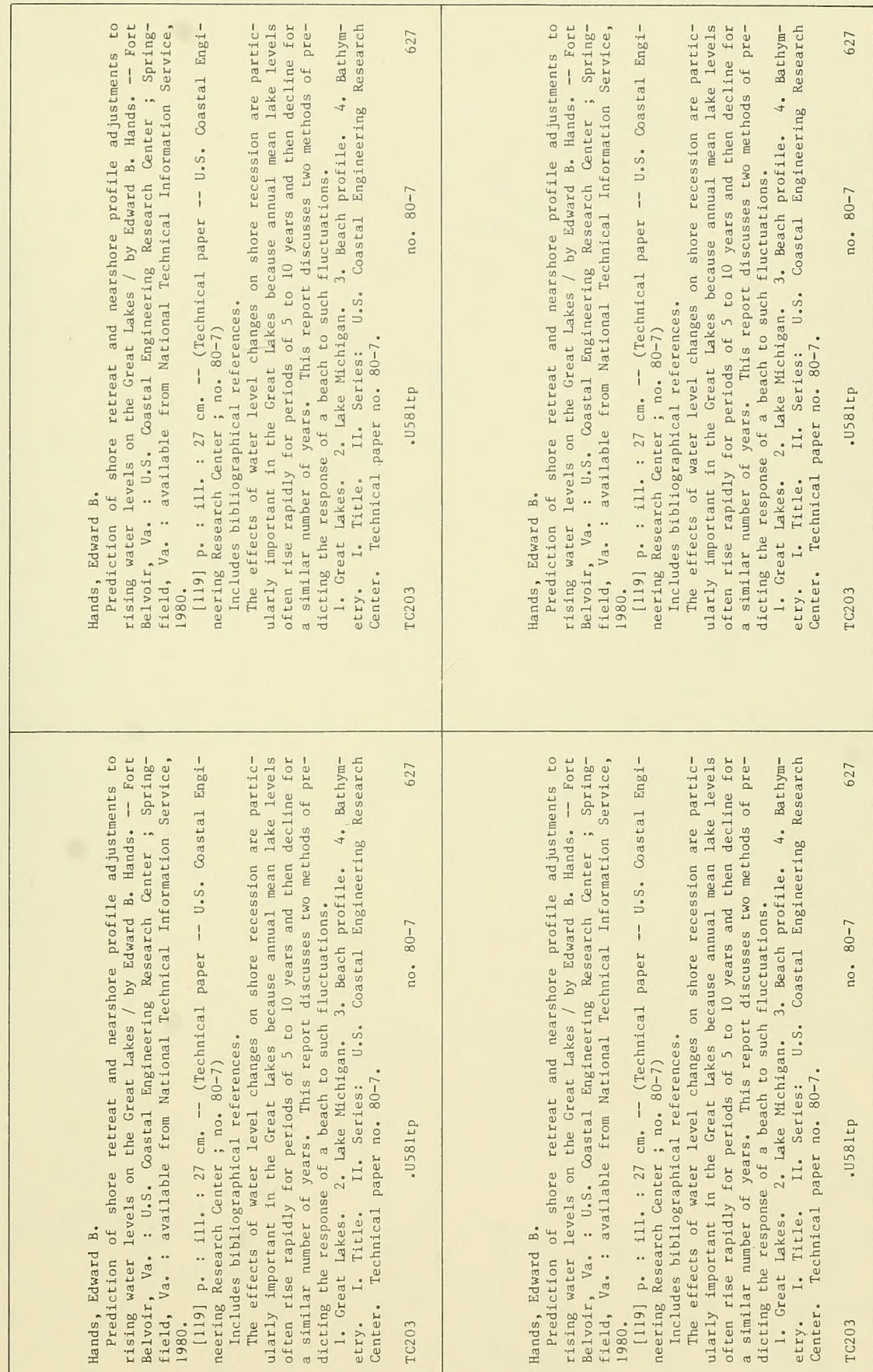



